Metals and Ceramics Division

IRIDIUM-ALLOY PROCESSING EXPERIENCE IN FY 1989

E. K. Ohriner

Date Published: November 1990

Prepared for

Office of Space and Defense Power Systems

Office of Special Applications

AF 7010200

Prepared by the

OAK RIDGE NATIONAL LABORATORY

Oak Ridge, Tennessee 37831-6285

MARTIN MARIETTA ENERGY SYSTEMS, INC.

for the

U.S. DEPARTMENT OF ENERGY

under Contract DE-AC05-81.OR21400 
TABLE OF CONTENTS

Page

LIST OF TABLES $\ldots \ldots \ldots \ldots \ldots \ldots \ldots \ldots \ldots \ldots \ldots \ldots \ldots \ldots \ldots \ldots \ldots, v$

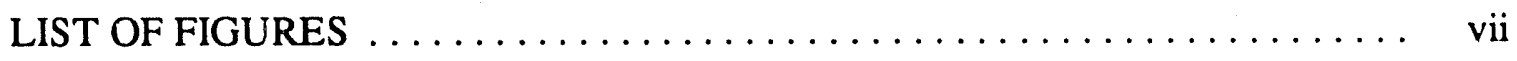

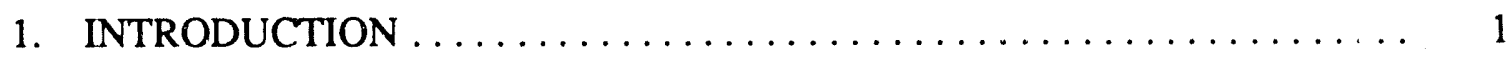

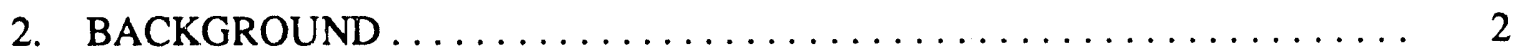

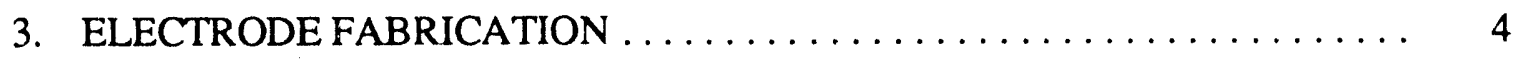

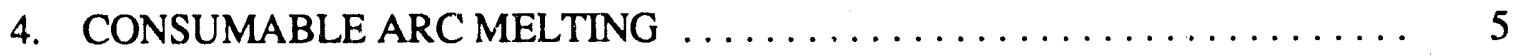

4.1 ARC MELTING OF CR2 INGOT $\ldots \ldots \ldots \ldots \ldots \ldots \ldots \ldots \ldots \ldots \ldots \ldots$

4.2 ARC MELTING OF BF7 INGOT .................... 8

4.3 ARC MELTING OF RS4 INGOT ...................... 9

4.4 ARC MELTING OF CR3 INGOT $\ldots \ldots \ldots \ldots \ldots \ldots \ldots \ldots \ldots \ldots \ldots \ldots \ldots$

4.5 ULTRASONIC INSPECTION OF GROUND INGOTS . . . . . . . 13

4.6 ARC MELTING EQUIPMENT $\ldots \ldots \ldots \ldots \ldots \ldots \ldots \ldots \ldots \ldots \ldots$

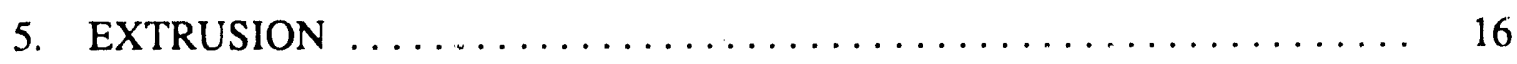

5.1 EXTRUSION OF RS3, E1, AND CR2 INGOTS ............ 17

5.2 EXTRUSION PROCESS IMPROVEMENTS $\ldots \ldots \ldots \ldots \ldots \ldots \ldots, 21$

5.2.1 Reactions of Molybdenum with Iridium Alloy............ 22

5.2.2 Chemical Removal of Intermetallic Compounds .......... 28

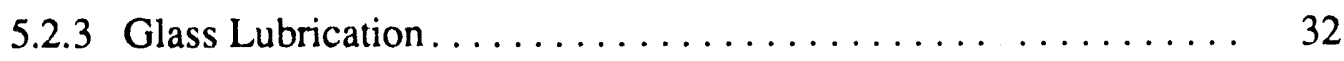

5.2 .4 Tooling Improvements $\ldots \ldots \ldots \ldots \ldots \ldots \ldots \ldots \ldots \ldots \ldots \ldots$

5.2 .5 Billet Preheat Analysis ........................ 34

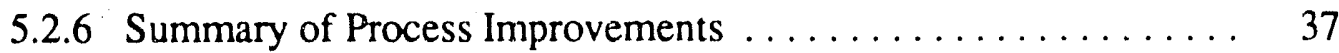

5.3 EXTRUSIONS USING IMPROVED PROCESS . . . . . . . . . . 37

5.4 EXTRUSION MICROSTRUCTURES . . . . . . . . . . . . . . . 40

5.5 ULTRASONIC EXAMINATION OF AN EXTRUSION .......... 45

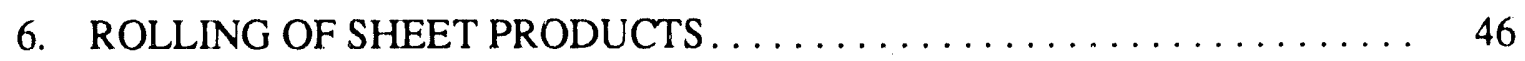

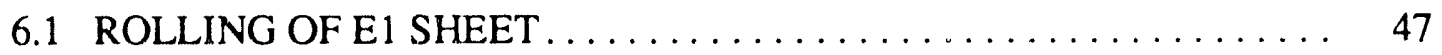

6.2 REVISION OF ROLLING PROCEDURE $\ldots \ldots \ldots \ldots \ldots \ldots \ldots \ldots, 48$

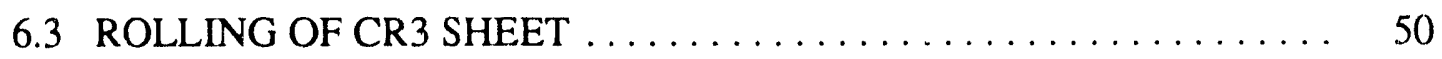

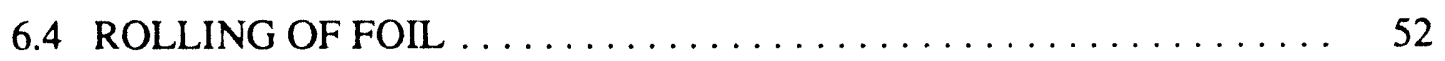


7. INSPECTIONS AND QUALIFICATION $\ldots \ldots \ldots \ldots \ldots \ldots \ldots \ldots \ldots \ldots \ldots \ldots \ldots$

7.1 NONDESTRUCTIVE TESTING OF E1 BLANKS ........... 52

7.2 CHEMICAL ANALYSES OF E1 SHEETS $\ldots \ldots \ldots \ldots \ldots \ldots \ldots$

7.3 NONDESTRUCTIVE TESTING OF CR3 BLANKS ........... 55

7.4 TENSILE-IMPACT TESTING OF D1 SHEETS $\ldots \ldots \ldots \ldots \ldots \ldots .57$

7.5 TENSILE-IMPACT TESTING OF E1 SHEETS $\ldots \ldots \ldots \ldots \ldots \ldots \quad 58$

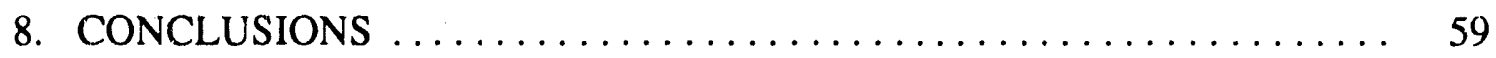

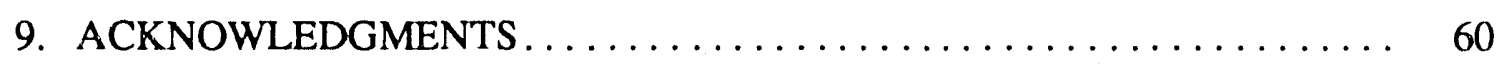

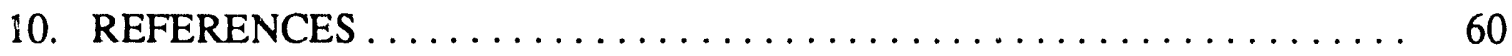




\section{LIST OF TABLES}

Table

Page

1 Summary of yields for blanks produced from FY 1984 through FY $1988 \ldots$. . 3

2 Cleaning treatments for samples from $\mathrm{D} 1$ extrusion $\ldots \ldots \ldots \ldots \ldots \ldots$

3 Characterizing data for electrolytic $\mathrm{KCN}$-cleaning tests on refinable

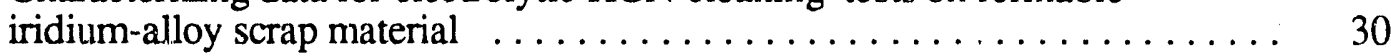

4 Results of exurusion of molybdenum billets at $1450^{\circ} \mathrm{C}$ in $88-\mathrm{mm}$ diam under various conditions of glass lubrications $\ldots \ldots \ldots \ldots \ldots \ldots \ldots$

5 Transfer times and billet length for three extrusions $\ldots \ldots \ldots \ldots \ldots \ldots$

6 Iridium-alloy sheet rolling schedules for blank production . . . . . . . . 47

7 Results from ultrasonic inspection of E1 blanks $\ldots \ldots \ldots \ldots \ldots \ldots$

8 Results from chemical analyses of E1 sheets............... 56

9 Results from ultrasonic inspection of CR3 blanks (6 of 14 sheets only) ... . 57

10 Tensile impact test results of samples cast from D1 blanks . . . . . . . 58

11 Results from tensile impact tests of E1-sheet specimens . . . . . . . . 58 


\section{LIST OF FIGURES}

Figure

Page

1 Plot of arc-melting parameters obtained for the CR2 ingot showing

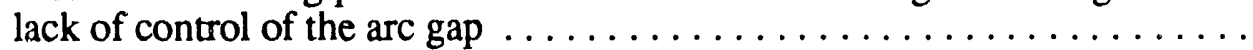

2 The CR2 ingot showing evidence of unremelted splatter at the bottom associated with an overly long arc as well as a relatively large skull height

3 Plot of arc-melting parameters obtaine 1 for the BF7 ingot showing uniform electrode feed and numerous short circuits indicative of a short arc length. . . . . . . . . . . . . . . . . . . . . . . .

4 The BF7 ingot showing uniformly smooth surface appearance and relative short skull height at the top of the ingot

5 The plot of arc-melting parameters for the RS4 ingot showing nonuriform electrode feed and a lack of arc-length control

6 Arc-melting parameters for the CR3 ingot showing uniform feed of the electrode and several short circuits indicative of a short arc length . . . . . . . . . . . . . . . . . . . . . . .

7 The arc-melted CR3 ingot exhibiting a smooth surface with no

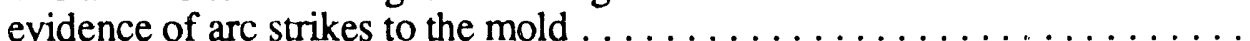

8 The surface ground CR3 ingot showing several dye-penetrant indications associated with subsurface pores as well as linear indications corresponding to regions of lack of fusion not removed by grinding

9 Portion of the ultrasonic chart of the CR2 ingot. White areas show ingot orientations for which the ultrasonic pulse reflected from the back surface is detected

10 A sketch of the grain structure in the CR2 ingot showing a columnar structure extending from the bottom surface to nearly half the height of the ingot

11 Partial extrusion of CR2 ingot showing tensile-type fracture

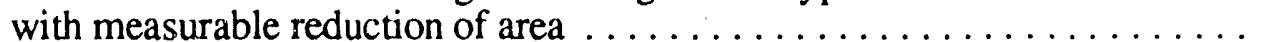

12 Extrusion loads for E1 ingot exceeding the press capacity $\ldots \ldots \ldots \ldots \ldots$

13 Extrusion loads for RS3 ingot approaching press capacity as seen at the extreme right of the curve $\ldots \ldots \ldots \ldots \ldots \ldots \ldots \ldots \ldots$ 
14 Metallographic section of iridium-molybdenum diffusion couple with about $10 \mu \mathrm{m}$ of intermetallic compounds formed

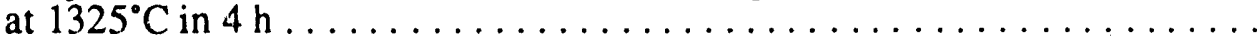

15 Metallographic section of iridium-molybdenum diffusion couple with about $15 \mu \mathrm{m}$ of intermetallic compounds formed

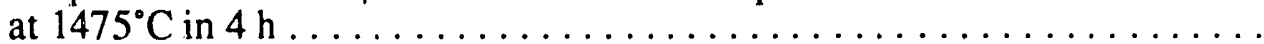

16 The Arrhenius plot of natural log of intermetallic layer thickness formed in iridium-molybdenum diffusion couples heated for $4 \mathrm{~h}$ increases with reciprocal temperature showing no appreciable effect of preoxidation of the molybdenum at temperatures in the range 1325 to $1475^{\circ} \mathrm{C}$

17 Electron microprobe backscattered electron image of an iridium-molybdenum diffusion couple heated $4 \mathrm{~h}$ at $1475^{\circ} \mathrm{C}$ showing intermetallic layers and grain structure of the intermetallic compound on the surface of the iridium base metal $\ldots \ldots \ldots \ldots \ldots$

18 Electron microprobe Mo $\mathrm{L}_{\alpha} \mathrm{X}$-ray map of an iridium-molybdenum diffusion couple heated $4 \mathrm{~h}$ at $1475^{\circ} \mathrm{C}$ showing two intermetallic layers, IrMo closest to the top surface and $\mathrm{Ir}_{3}$ Mo underneath

19 Metallographic section of D1 extrusion showing intermetallic compounds of molybdenum with iridium on the surface $\ldots \ldots \ldots \ldots \ldots$

20 Metallographic section of D1 extrusion following electrolytic cleaning in $\mathrm{KCN}$ showing removal of intermetallic layers on

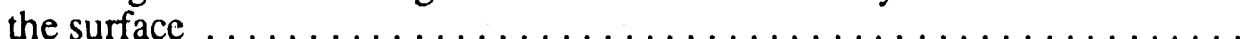

21 The calculated heating of a molybdenum-canned iridium ingot showing the center of the ingot to be at temperature within $1 \mathrm{~h}$

22 The calculated cooling of a molybdenum-canned iridium ingot showing that temperatures below $1300^{\circ} \mathrm{C}$ may be at times

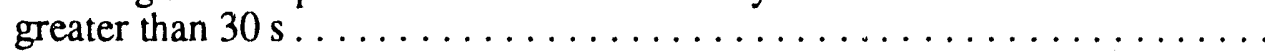

23 The load curves for RS4, CR3, and BF7 ingots, extruded using the improved process, showing maximum load significantly below the press capacity . . . . . . . . . . . . . . . . . . . .

24 Microstructure of the E1 extrusion showing partial recrystallization of both the $(a)$ nose region and $(b)$ tail region $\ldots \ldots \ldots \ldots \ldots$

25 Microstructure of the RS4 extrusion showing (a) about $10 \%$ recrystallization in the nose region and $(b)$ about $90 \%$ recrystallization in the tail region 
26 Microstructure of the CR3 extrusion showing (a) the nose region with approximately $50 \%$ recrystallization and $(b)$ the tail region with essentially no recrystallization

27 Microstructure of the BF7 extrusion showing (a) complete recrystallization in the nose region and $(b) 50 \%$ recrystallization in the tail region

28 Ultrasonic map of the nose from the RS4 extrusion showing a 1.5 -mm-diam reference hole and a residual pore from just below the top surface of the original ingot $\ldots \ldots \ldots \ldots \ldots \ldots \ldots$

29 Ultrasonic map of the nose from the RS4 extrusion showing the extruded structure.

30 Microstructure of sheet E1-6 showing recrystallization in excess of $5 \% \ldots$

31 Microstructure, of sheet E1-7 showing no evidence of recrystallization . . . .

32 Microstructure of CR3 sheet following breakdown rolling with $1200^{\circ} \mathrm{C}$ preheat temperature showing substantial recrystallization structure.

33 Microstructure of CR3 sheet following recrystallization at $1300^{\circ} \mathrm{C}$ showing evidence of original grain boundaries in the arc-melted ingot 


\title{
IRIDIUM-ALLOY PROCESSING EXPERIENCE IN FY 1989*
}

\author{
E. K. Ohriner
}

\begin{abstract}
Iridium-alloy blanks and foil are produced at the Oak Ridge National Laboratory for use as fuel cladding material in radioisotope thermoelectric generators for space power sources. Until 1984, the material was produced from small 500-g drop castings. A new process has been developed in which consumable electrodes of about $10 \mathrm{~kg}$ are arc melted, extruded, and then rolled to produce the sheet products. The work performed during FY 1989 included the arc melting of three electrodes and the extruding and rolling to sheet of three billets. Significant improvements have been made in the extruding and arc-melting processes. Preliminary results show that these improvements have had an important effect in increasing the rate of blank acceptance in nondestructive evaluations.
\end{abstract}

\section{INTRODUCTION}

The DOP-26 iridium alloy (Ir-0.3\% W- $0.006 \% \mathrm{Th}-0.005 \% \mathrm{Al}$ ) was developed by the Oak Ridge National Laboratory (ORNL) for use as fuel cladding in radioisotope thermoelectric generators (RTGs) used for space power. ${ }^{1}$ Iridium-alloy sheet products have been produced at ORNL for about 20 years in the form of DOP-26 alloy blanks and DOP-4 (Ir-0.3\%, $\mathrm{V}-0.003 \% \mathrm{Th}-0.005 \% \mathrm{Al})$ foil. These flight-quality products were used in manufacturing multihundred watt and general purpose heat-source flight hardware. These iridium-alloy sheet products were produced from small 500-g drop-cast ingots. In 1984, development of a new iridium-alloy sheet and foil-manufacturing process, the consumable-electrode arc melting and extrusion of large 10-kg ingots, was begun. ${ }^{2}$ Since

*Research sponsored by Office of Space and Defense Power Systerns, Office of Special Applications, U.S. Department of Energy, under contract DE-ACO5-84OR21400 with Martin Marietta Energy Systems, Inc. 
that time, a total of eight developmental and production ingots have been processed to blanks. This report summarizes the iridium-alloy process development activities in the areas of consumable arc melting and extrusion experience during FY 1989. In addition, those process improvernents implemented during the year are described, and the technical justifications are discussed.

The procissing of the materials described in this report was done under full configuration control. Approved procedural revisions were obtained whenever necessary for all processing of these production materials. The only exceptions to this are the materials labelled as RS3 and RS4 which consisted entirely of solid scrap, and was therefore not suitable for recycling for flighi-quality products.

\section{BACKGROUND}

Demonstration of the new arc-melting and extruding process for iridium-alloy sheet and foil was initiated in FY 1984. A DOP-26 consumable arc-cast ailoy ingot (designated AC) was made, cut into two $19-\times 19-\times 54-\mathrm{mm}$ ingots, and rolled into sheet per existing

production procedures for similar-size drop-cast ingots. Blanks cut from these sheets were found to be free of both ultrasonic- and penetrant-detected defects. In FY 1985, new process development was continued by arc melting two consumable electrodes (B 1 and B2), extruding to rectangular bar, cutting into billets, and rolling into sheets using a procedure modified for extruded material. Blanks cut from the B1 and B2 sheets were also found to be free of ultrasonic- and penetrant-detected defects, giving a yield of greater than 95\% acceptance. A third ingot, produced from recycled material and designated BR3, was later found to be contaminated with molybdenum. Changes were implemented in the recycling practice to avoid using contaminated material. During FY 1986, an additional ingot (B4) was processed to blanks. Inspection results showed rejection of 15 of 
43 blanks for ultrasonic-detected defects. During FY 1987, another ingot (B5) was processed, resulting in rejection of 11 of 42 machined blanks, and sheet material equivalent to an additional 7 blanks was found defective by ultrasonic inspection. ${ }^{3}$

During FY 1988, inspection of 57 blanks processed from the $\mathrm{C} 1$ ingot during FY 1987 resulted in the rejection of 39 blanks. The rejections were associated with visible blisters on the rolled sheets following recrystallization; the blisters were believed to be the result of gas-filled pores in the casting. The D1 ingot was processed to blanks during FY $198 \%$, resulting in the rejection of 11 of the 48 blanks for ultrasonic indication. (During FY 1989, an additional four D1 blanks failed penetrant inspection and were reworked.) he yields of blanks at nondestructive examination for these new process ingots and for the most recent standard process ingots ( $X R$ and $Z R$ ) are summarized in Table 1.

Table 1. Summary of yields for blanks produced from FY 1984 through FY 1988

\begin{tabular}{|c|c|c|c|c|c|c|c|}
\hline \multirow{2}{*}{$\begin{array}{l}\text { Ingot } \\
\text { identity }\end{array}$} & \multirow{2}{*}{$\begin{array}{c}\text { No. } \\
\text { of } \\
\text { ingots }\end{array}$} & \multirow{2}{*}{$\begin{array}{l}\text { Potential } \\
\text { blanks }\end{array}$} & \multirow{2}{*}{$\begin{array}{l}\text { Defective } \\
\text { sheet } \\
\text { equivalent } \\
\text { blanks } a\end{array}$} & \multirow{2}{*}{$\begin{array}{c}\text { Machined } \\
\text { blanks }\end{array}$} & \multirow{2}{*}{$\begin{array}{c}\text { No. of } \\
\text { deliverable } \\
\text { blanks }\end{array}$} & \multicolumn{2}{|c|}{ Yield (\%) } \\
\hline & & & & & & $\begin{array}{l}\text { From } \\
\text { sheet }\end{array}$ & $\begin{array}{l}\text { From } \\
\text { blanks }\end{array}$ \\
\hline $\mathrm{XR}$ & $18^{b}$ & 108 & 25 & 83 & 68 & 63 & 82 \\
\hline $\mathrm{ZR}$ & $12^{b}$ & 72 & 14 & 58 & 39 & 54 & 67 \\
\hline $\mathrm{B} 1$ & $1^{c}$ & 46 & & $42^{d}$ & 42 & 100 & 100 \\
\hline $\mathrm{B} 2$ & $1 c$ & 46 & & $39 e$ & 39 & 100 & 100 \\
\hline B4 & $1 c$ & 50 & 7 & 43 & 28 & 56 & 65 \\
\hline B5 & $1^{c}$ & 54 & 12 & 42 & 31 & 57 & 74 \\
\hline BR6 & $1 c$ & 75 & 12 & 63 & 42 & 56 & 67 \\
\hline $\mathrm{C} 1$ & ${ }_{1} c$ & 57 & & 57 & 18 & 32 & 32 \\
\hline D1 & $1^{c}$ & 48 & & 48 & 35 & 73 & 73 \\
\hline
\end{tabular}

$a_{\text {From ultrasonic inspection of sheets. }}$

$b_{\text {Drop-cast ingots. }}$

$c_{\text {Consumable arc-melted ingot. }}$

$d$ Sheet material equivalent to four blanks was used for tensile test specimens.

eSheet material equivalent to seven blanks was ised for mechanical test specimens. 
The inability to consistently achieve a high blank yield via the new process was attributed largely to poor ingot/extrusion billet quality and inadequacies in the extrusion process. Development efforts during FY 1989 were focused on these two problem areas.

\section{ELECTRODE FABRICATION}

A total of six electrodes were fabricated in FY 1989: two from virgin material, two from recycle material, and two from refinable scrap material for experimental use only. One virgin-material electrode, $\mathrm{BF} 7$, was fabricated for use in foil production. A total of six drop castings of 25.4-mm diam were prepared with a nominal thorium content of $30 \mathrm{ppm}$ and a nominal aluminum content at $50 \mathrm{ppm}$. Each drop casting contained $73 \%$ material from B-batch powder and $27 \%$ material from C-batch powder. The drop castings with a total weight of $8 \mathrm{~kg}$ were welded together with an electron-beam (EB) welder to produce a consumable electrode $760 \mathrm{~mm}$ long.

Currently, an E2 electrode is being fabricated from $100 \%$ virgin E-batch powder. A total of nine segments of $27-\mathrm{mm}$ diam have been drop cast to produce a total of $13,550 \mathrm{~g}$ of DOP-26 alloy. This is the planned aim weight of electrodes for future ingots, and a $1.6-\mathrm{mm}$ increase in diameter is required to obtain this weight and meet the practical limitations of length. The powder compacts of Ir- $0.3 \% \mathrm{~W}$ alloy, which were used in the fabrication of E2, were produced from unwashed E-batch powder. Powder washing had been previously omitted for the butions used to fabricate the $\mathrm{E} 1$ ingot with no effect on the impurity content or impact properties of the finished sheet. Powder washing had been introduced in the early days of the iridium-alloy processing to help remove salts and other impurities in the powder. This washing is no longer necessary because the iridium powder now used contains much lower quantities of these impurities. 
The first recycled-material electrode, CR2, was fabricated from "heads" and "skulls". from drop-casting operations and blanked sheets or "skeletons." The recycle material was composed of $3.9 \mathrm{~kg}$ from Z-batch, $6.4 \mathrm{~kg}$ from B-batch, and $3.4 \mathrm{~kg}$ from C-batch powders. A total of ten drop-cast segments of DOP-26 alloy each $25.4 \mathrm{~mm}$ were produced. Nine of these segments with a total weight of $12.6 \mathrm{~kg}$ were welded together to produce the CR2 electrode.

The second recycle electrode, CR3, was produced from recycled CR2 material in the form of a partial extrusion, heads, skulls, and a segment. The partial extrusion, which provided most of the material for the electrode, was broken into small pieces and cleaned using normal procedures for extruded recycle material. Chemical analysis by spark-source mass spectrograph (SSMS) of samples from skulls of six of 12 arc-melted buttons showed all impurity levels to be within acceptable limits. A total of $10.9 \mathrm{~kg}$ of 25.4 -mm-diam electrode segments were welded to produce the CR3 electrode.

The electrodes, RS4 and RS5, were produced from slightly out-of-specification DOP-26 alloy and used in arc-melting and extruding developmental activities. Chemical analysis by SSMS shows the molybdenum content to be about $100 \mathrm{ppm}$ as compared to a specified 50-ppm maximum. The RS4 electrode was produced from 25.4-mm-diam electrode segments weighing a total of $7.9 \mathrm{~kg}$. The RS5 electrode was produced from $27-\mathrm{mm}$-diam segments weighing a total of $7.6 \mathrm{~kg}$.

\section{CONSUMABLE ARC MELTING}

The consumable arc melting of iridium-alloy electrodes is considered to be one of the most critical steps in the production of sheet products. It is the final melting step ar.d should produce a defect-free ingot for subsequent metalworking steps. Efforts to improve the quality of the arc-melted ingot in FY 1988 led to an increase in the ingot 
diameter from 51 to $63 \mathrm{~mm}$, an increase in the electrode-to-mold clearance, and a reduction of the incidence of arcing to the mold wall. ${ }^{4}$ The RS3 scrap-material ingot and the E1 virgin-material ingot made during 1988 were the first o1 63-mm diameter. ${ }^{4}$ An additional four ingots of this size were made during FY 1989. The fabrication of the electrodes for the $\mathrm{BF} 7$ foil ingot, the CR2 and CR3 recycled-material ingots, and the RS4 scrap-material ingot is described in Sect. 3.

\subsection{ARC MELTING OF CR2 INGOT}

The CR2 electrode was placed in the consumable arc-melting furnace and sentered with respect to the mold flange to within $\pm 3 \mathrm{~mm}$ corresponding to a range for the electrodeto-mold clearance of 16 to $22 \mathrm{~mm}$. The minimum clearance of $16 \mathrm{~mm}$ was found to be adequate to prevent arc strikes to the mold wall during previous melts. A new mold of $63-\mathrm{mm}$ diam by $13-\mathrm{mm}$ wall thickness was used. The chamber was pumped to a vacuum of $1.5 \mathrm{mPa}$ prior to melting.

The arc current, voltage, and position of the electrode in the mold are shown graphically in Fig. 1. The initial arc current of $3600 \mathrm{~A}$ was decreased to $3200 \mathrm{~A}$ over the first $30 \mathrm{~s}$. At $70 \mathrm{~s}$ into the melt, the electrode was manually lowered $180 \mathrm{~mm}$ when it became evident that the arc length was excessive. The electrode was then returned to automatic advance under voltage control with a constant arc current of $3600 \mathrm{~A}$. At approximately $160 \mathrm{~s}$ into the melt, the electrode feed rate was decreased when the arc length appeared unusually small. The total melt time was $210 \mathrm{~s}$, and the weight of the melted alloy was $11.4 \mathrm{~kg}$.

The appearance of the melted ingot can be seen in Fig. 2. In comparison to ingots melted recently in the 50-mm-diam mold, the surface appearance is excellent. The rougher surtace appearance seen at the bottom of the ingot is due to excessive arc length, but the 


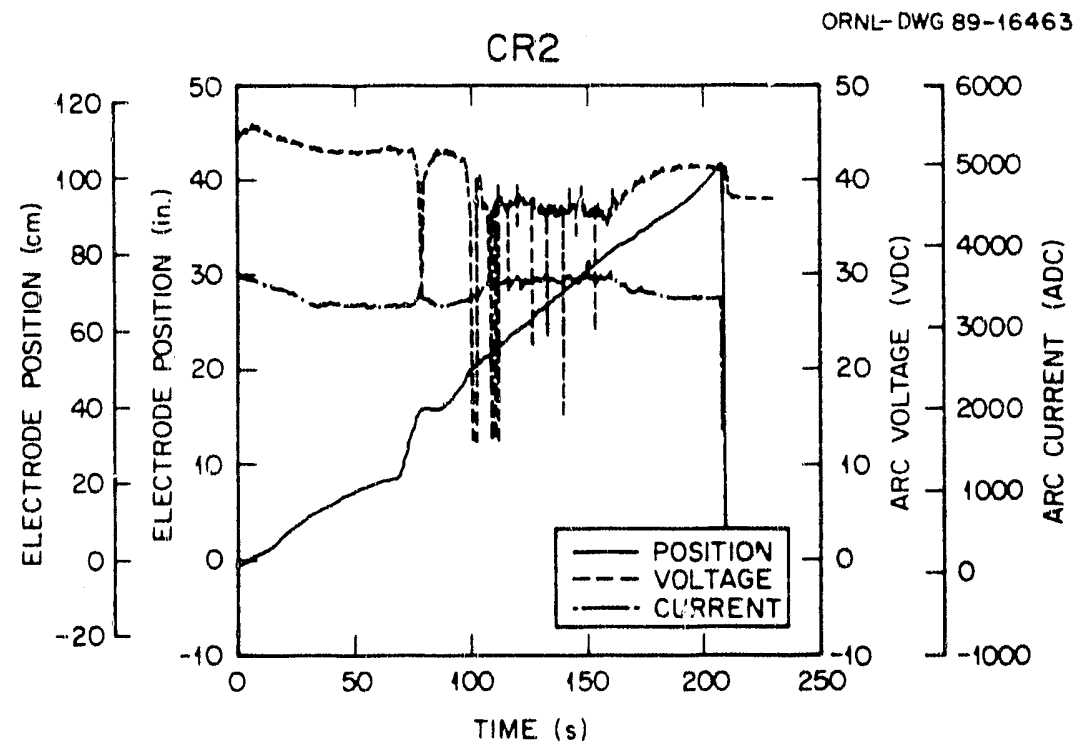

Fig. 1. Plot of arc-melting parameters obtained for the CR2 ingot showing lack of control of the arc gap.

Y P 7081

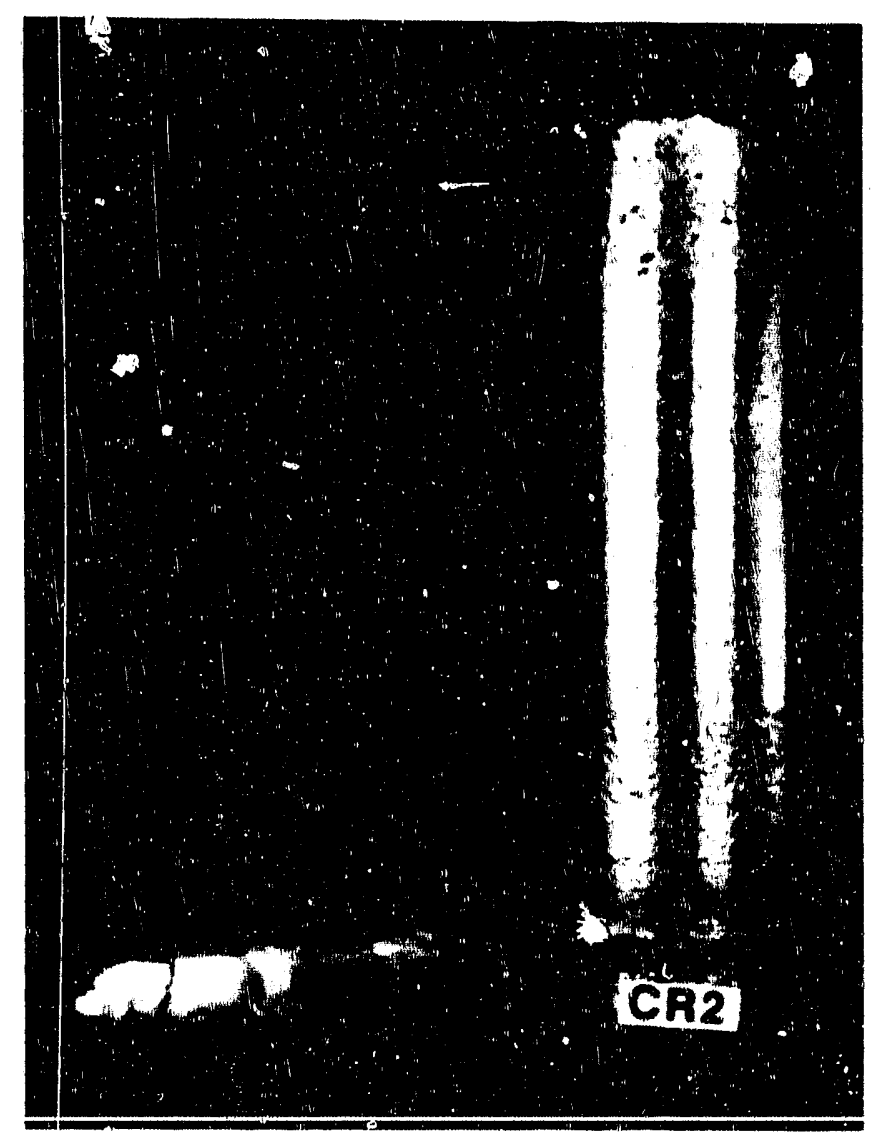

Fig. 2. The CR2 ingot showing evidence of unremelted splatter at the bottom associated with an overly long arc as well as a relatively large skull height. 
surface roughness is not expected to have any affect on subsequent processing. The thin skull extending about $50 \mathrm{~mm}$ above the solid surface of the ingot can also be associated with a long arc. Th.re is only one region of adherent copper on the ingot. This is believed to be the result of an arc strike to the mold wall. The location of the expected minimum electrode-to-mold clearance, based on alignment measurements prior to melting, is in a similar rotational position but about 25 to $55 \mathrm{~mm}$ below the location of the strike. The copper mold exhibited an iridium-alloy coating over its entire surface except in the one region corresponding to the strike. The ingot diameter varied from $62.2 \mathrm{~mm}$ at the bottom to $63.0 \mathrm{~min}$ at the top because of the mold taper. The ingot was cut to a $158-\mathrm{mm}$ length and ground to a $61.5-\mathrm{mm}$ diam.

\subsection{ARC-MELTING OF BF7 INGOT}

The BF7 electrode was placed in the furnace and centered to within about $\pm 2.5 \mathrm{~mm}$ with respect to the flange for the mold. The 63-mm-diam copper mold was the same as was used previously to melt the $\mathrm{CR} 2$ electrode. The mold had a heavy iridium-alloy coating on the entire inner surface except for one small damaged region. The vacuum chamber was evacuated to a pressure of $1.9 \mathrm{mPa}$ before the ingot was melted.

The electrode was melted at an average arc current of about $3200 \mathrm{~A}$ and an average arc voltage of about $36 \mathrm{~V}$. The arc current, arc voltage, and position of the electrode with elapsed time are shown graphically in Fig. 3. The numerous voltage drops are an indication of short circuits caused by molten metal droplets closing a short arc gap. At approximately $90 \mathrm{~s}$ into the melt, the weldamatic controller was adjusted to give a slightly larger arc gap. The effect of this is seen in the reduced frequency of arc shorts, but there is no evidence of either an increase in baseline arc voltage or in the rate of the advance of the 


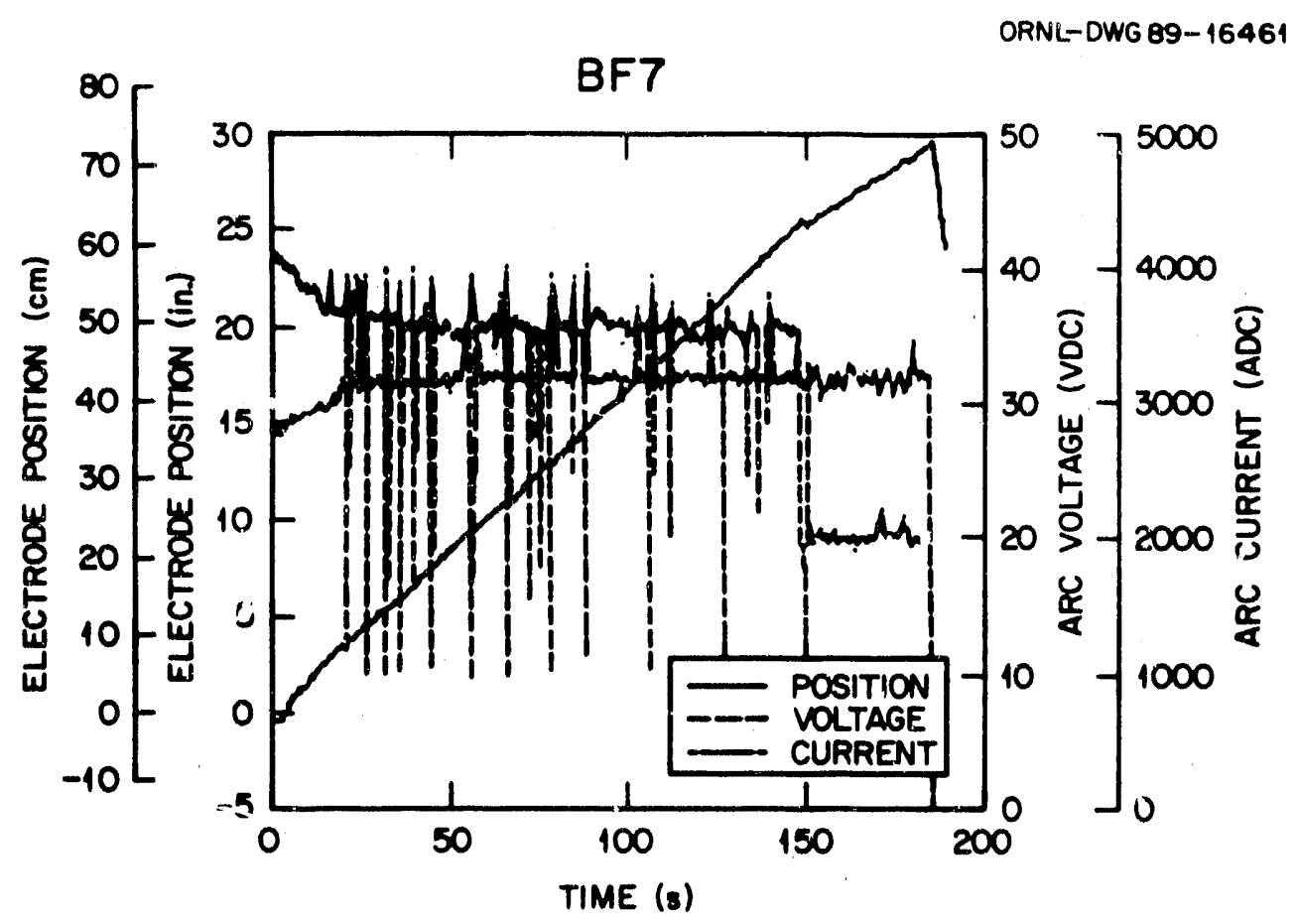

Fig. 3. Plot of arc-melting parameters obtained for the BF7 ingot showing uniform electrode feed and numerous short circuits indicative of a short arc length.

electrode. The electrode was hot-topped for the final $35 \mathrm{~s}$ at a reduced arc current of 2000 A to minimize the size of the shrinkage cavity at the top of the ingot.

The BF7 ingot, shown in Fig. 4, has a smooth surface and exhibits no evidence of adherent copper from the mold. The region with the roughest surface corresponds to the small damaged region of the used copper mold. No additional mold damage was observed. The BF7 ingot was cylindrically ground to a $61-\mathrm{mm}$ diam, which resulted in the removal of 0.9 to $1.4 \mathrm{~mm}$ from the diameter of casting.

\subsection{ARC MELTING OF RS4 INGOT}

The arc melting of the RS4 scrap-material electrode was performed to provide an ingot for extruding experiments and to determine the effect of a recent replacement of the 


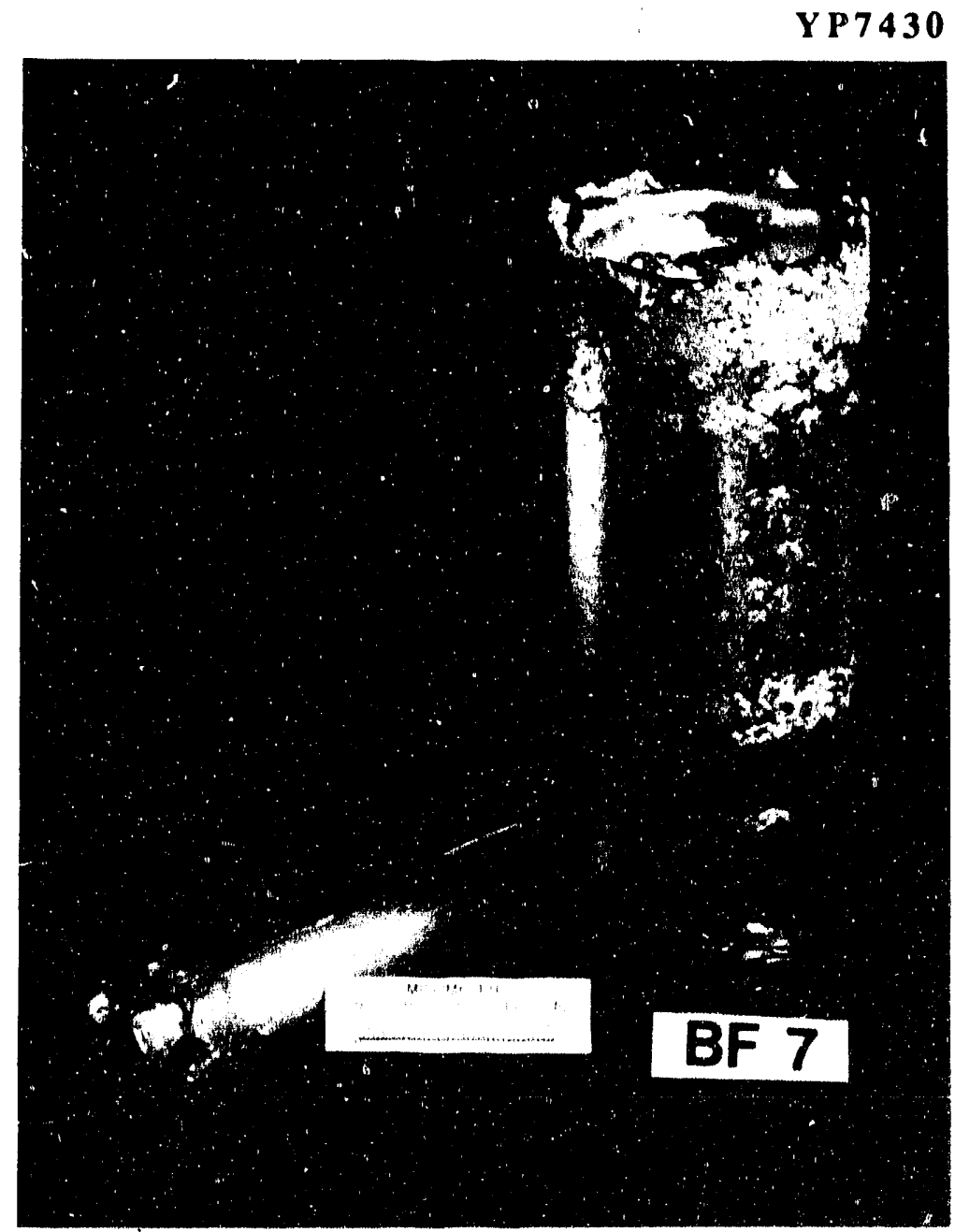

Fig. 4. The BF7 ingot showing uniformly smooth surface appearance and relative short skull height at the top of the ingot.

furnace's electrode electrical cables on the melting characteristics of the iridium alloy. The melt was made at a current of $3000 \mathrm{~A}$, and a voltage of $36 \mathrm{~V}$ was used to control the arc gap. The plot of current, voltage, and position during the melt is shown in Fig. 5. The results indicated that a much longer arc was now associated with the current and voltage, which previously produced a controlled short arc for the BF7 ingot. It can be concluded that the old cables produced a significant voltage drop over their length, resulting in a lower actual arc voltage than was recorded. Use of the new cables requires a significant reduction in the voltage used to control the arc length. 


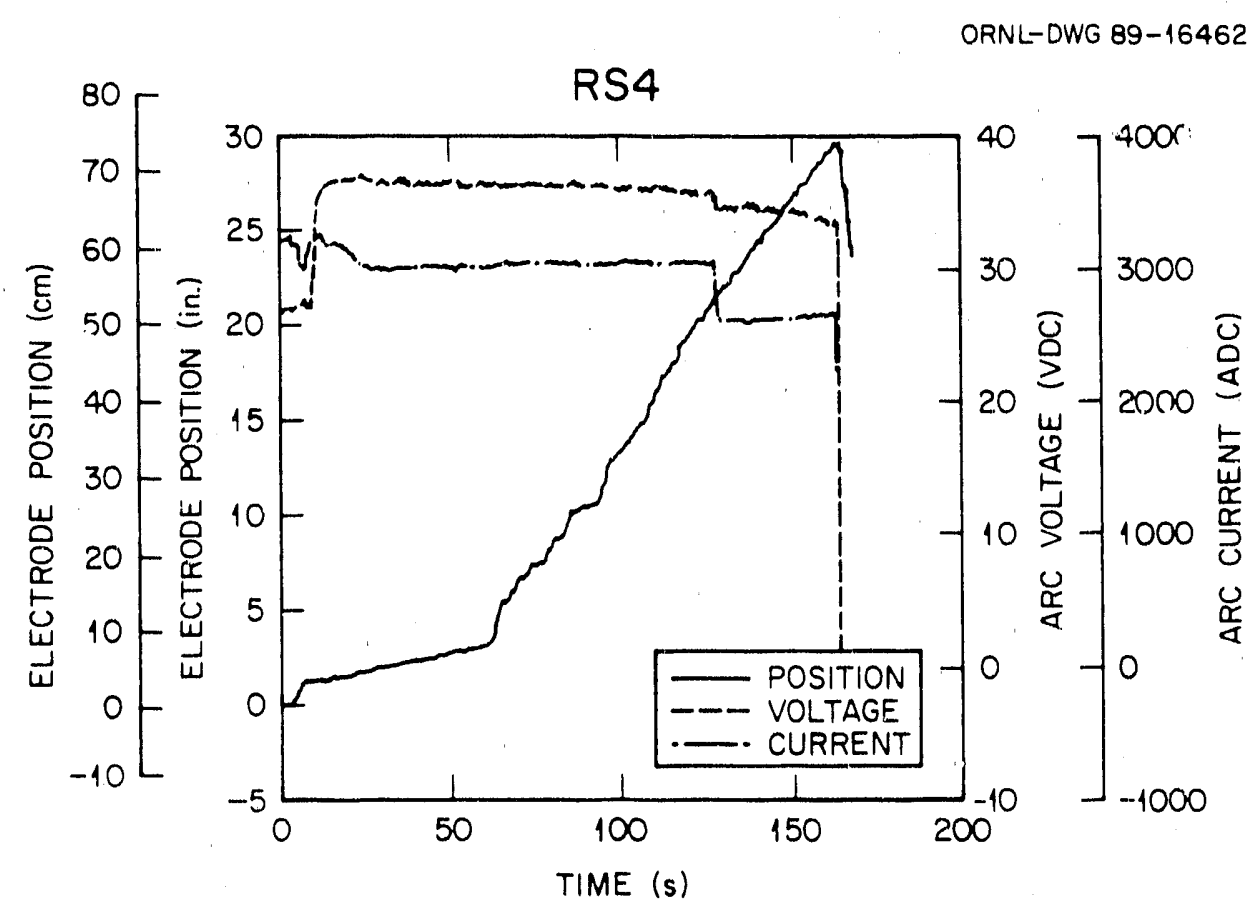

Fig. 5. The plot of arc-melting parameters for the RS4 ingot showing nonuniform electrode feed and a lack of arc-length control.

\subsection{ARC MELTING OF CR3 INGOT}

The CR3 electrode was melted in the iridium alloy-coated mold previously used to melt $\mathrm{CR} 2$ and BF7 ingots. The current of $3100 \mathrm{~A}$ and the voltage of 30 to $32 \mathrm{~V}$ were maintained to give a relatively short arc (estimated at $15 \mathrm{~mm}$ or less). The electrode-tomold clearance was maintained at $19 \pm 4 \mathrm{~mm}$. The initial chamber pressure was $1.6 \mathrm{mPa}$; pressure increased to $9 \mathrm{mPa}$ during melting. A graph of current, voltage, and position during the melt is shown in Fig. 6. Several short circuits were evident during the melt and associated with the short arc length. The current was reduced to about $1800 \mathrm{~A}$ for a $40-\mathrm{s}$ hot-topping ending period to minimize the shrinkage cavity at the top of the ingot. The electrode fied rate was maintained at a relatively constant value of $4.5 \mathrm{~mm} / \mathrm{s}$.

The arc-melted ingot showed a smooth surface with no evidence of arc strikes to the mold wall, as shown in Fig. 7. The ingot was ground to remove 1.3 to $1.9 \mathrm{~mm}$ from the 


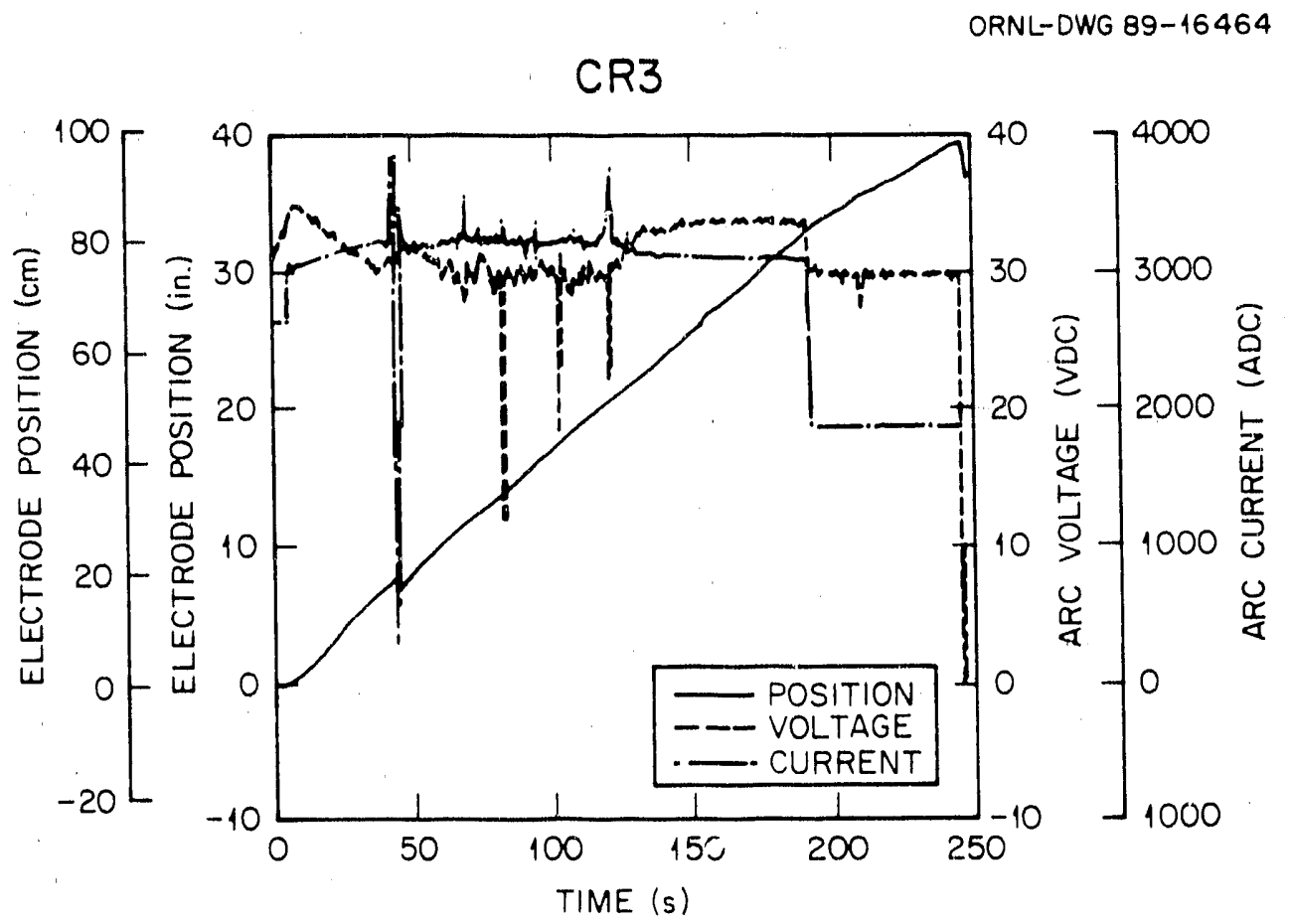

Fig. 6. Arc-melting parameters for the CR3 ingot showing uniform feed of the electrode and several short circuits indicative of a short arc length.

Y P 8150

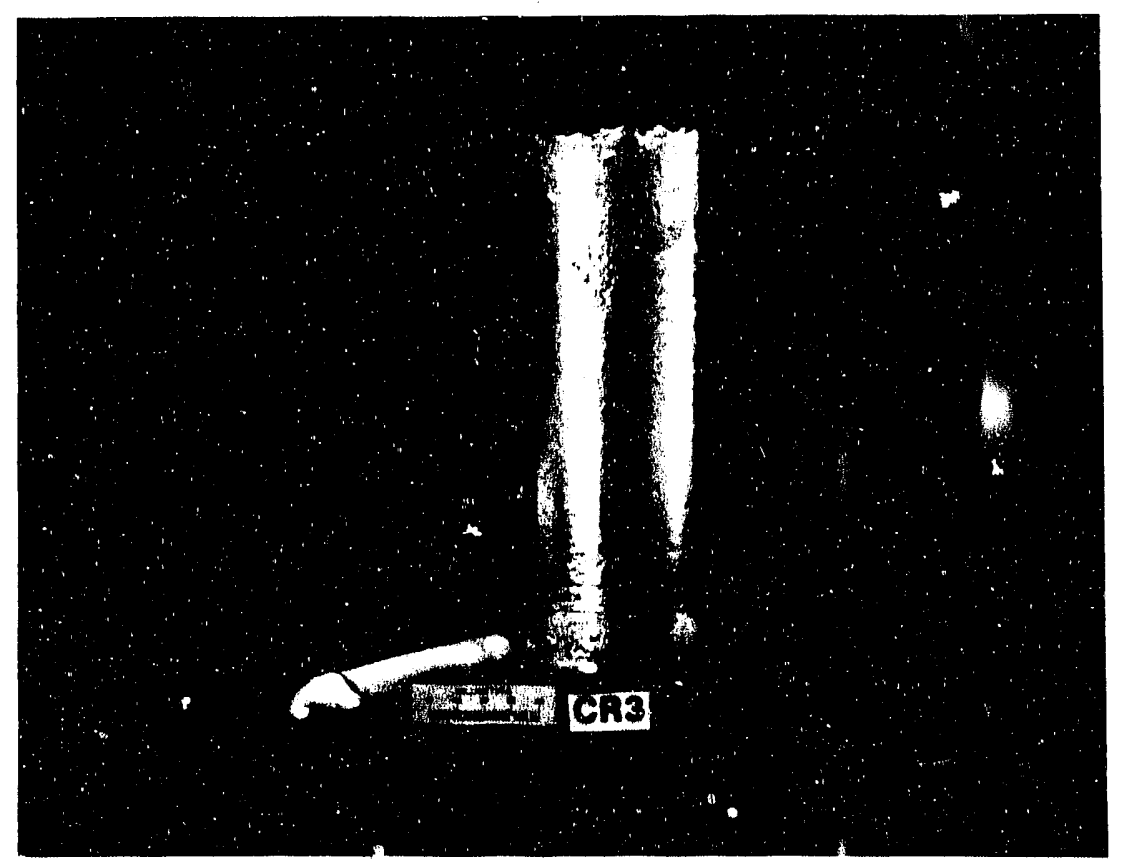

Fig. 7. The arc-melted CR3 ingot exhibiting a smooth surface with no evidence of arc strikes to the mold. 
diameter and cut to length. The ground surface showed a significant number of small pores, but these were fewer and smaller than seen on the four ground ingots examined previously. Dye-penetrant inspection of the ground ingot did produce dye indications of the pores, but, as seen in Fig. 8, there was no evidence of cracking or grain-boundary separation on the circumference.

\section{Y P8291}

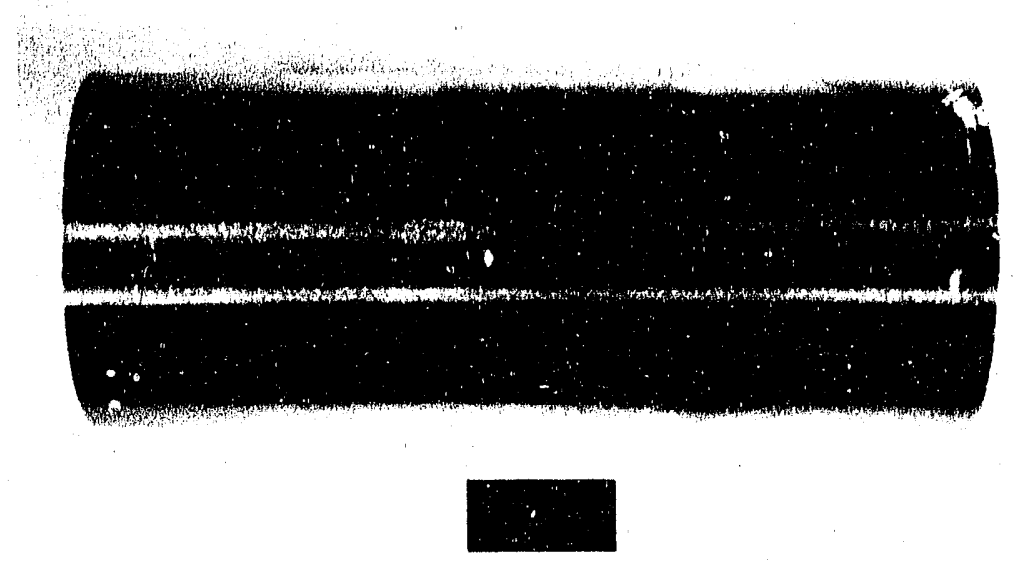

Fig. 8. The surface ground CR3 ingot showing several dye-penetrant indications associated with subsurface pores as well as linear indications corresponding to regions of lack of fusion not removed by grinding.

\subsection{ULTRASONIC INSPECTION OF GROUND INGOTS}

Ultrasonic inspection of ground ingots was first performed in FY 1988 with D1 and E1. The examinations were performed using both a normal incident beam focused at $6 \mathrm{mrn}$ below the surface and an angled-incident beam at $45^{\circ}$ to the surface tangent as the ingot rotated on a turntable. These inspections suffered from a number of important limitations. First, visible surface flaws would frequently give indications of subsurface flaws despite 
the electronic gating of the signals used to avoid this. Second, both of these techniques are limited to near-surface analysis of up to about $12-\mathrm{mm}$ depth so that most of the ingot remains uninspected. Finally, the coarse grain size of the casting creates ultrasonic indications from grain boundaries giving false positive indications. The results from the ultrasonic inspection of the D1 ingot revealed four likely flaws that show some correlation with location of blanks rejected for ultrasonic indications. There was no correlation of the number of rejected blanks from a sheet with the expected size of the flaws.

During FY 1989, a significant effort was made to obtain an ultrasonic inspection of the interior of the ingot. Monitoring of the reflection of the ultrasonic beam from the back surface of the ingot was performed on $\mathrm{CR} 2, \mathrm{CR} 3$, and $\mathrm{BF} 7$ ingots as well as arc-melted stainless steel ingots. None of the ingots were considered inspectable by this technique. It was observed that the ultrasonic beam did propagate with less scattering in the bottom portion of the CR2 ingot melted with a long arc than in the top portion melted with a much shorter arc. This is most likely the result of differences in grain structure producing differences in scattering behavior of the grain boundaries. A portion of the ultrasonic scan obtained using a 5-MHz signal is shown in Fig. 9. A sketch of the grain structure in the CR2 ingot is shown in Fig. 10. The information to produce this sketch was obtained by piecing together the sections made by crushing the ingot in a press forge at room temperature following its partial extrusion and removal from the extrusion can.

A stainless steel ingot showing similar behavior was sectioned and polished in an attempt to identify any pores or cracks in the regions which most scattered the ultrasonic beam. None could be found. On the basis of these results, the arc-melted ingots are considered to be uninspectable by this technique.

Ultrasonic examination of the CR3 ingot was performed using the normal-incident and angled-incident beams. 'These tests, described previously, showed large numbers of 
Y P 10364

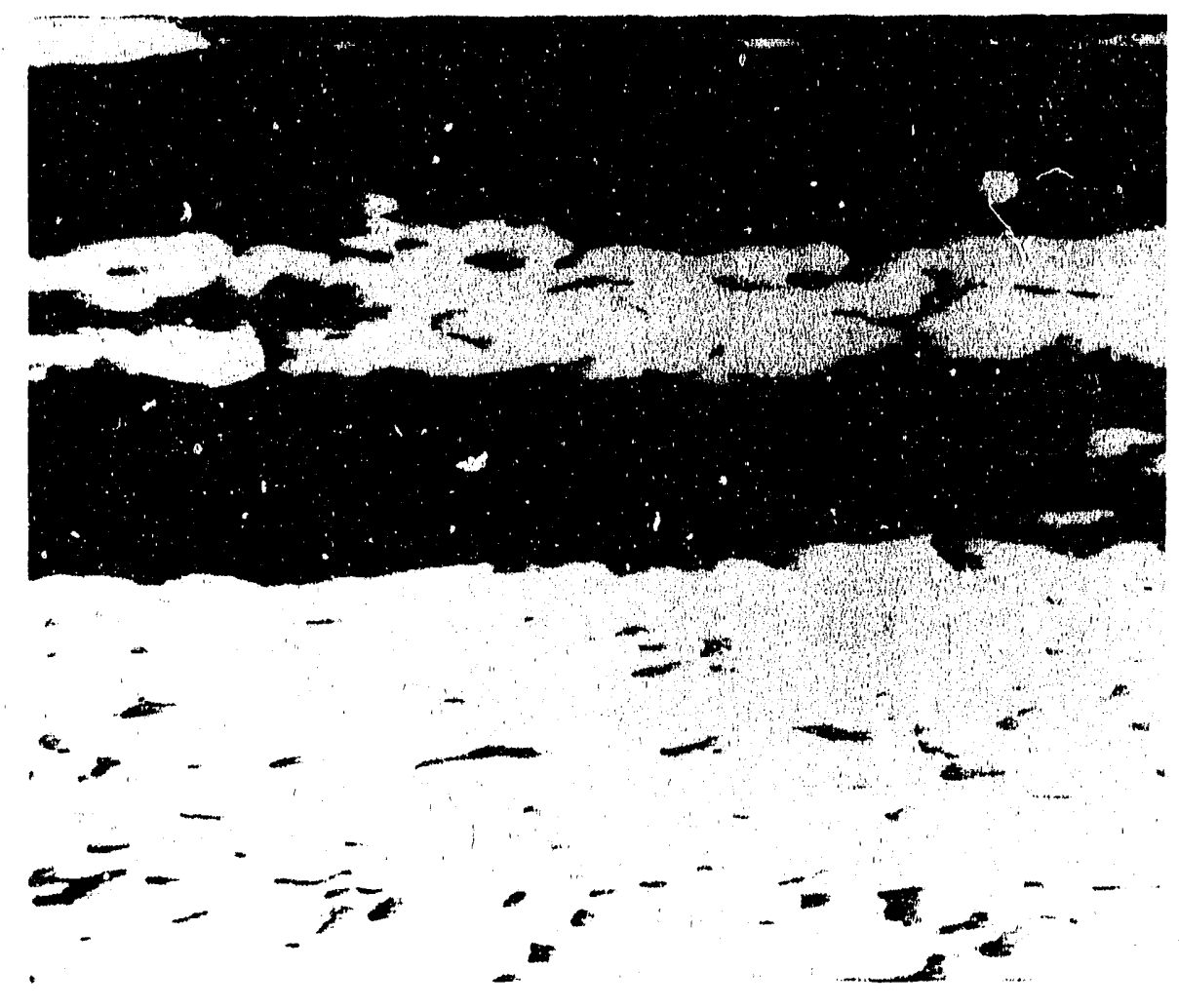

Fig. 9. Portion of the ultrasonic chart of the CR2 ingot. White areas show ingot orientations for which the ultrasonic pulse reflected from the back surface is detected.

ORNL-DWG 89-16906

Fig. 10. A sketch of the grain structure in the CR2 ingot showing a columnar structure extending from the bottom surface to nearly half the height of the ingot.

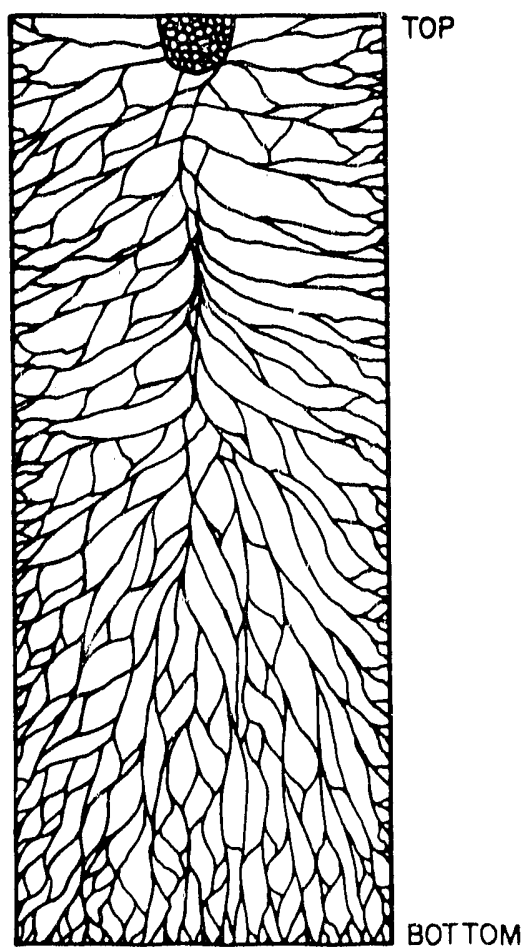


indications of defects. A significant number of these indications were comparable in size and location to a standard 1.5 -mm-diam side-drilled hole located $6.4 \mathrm{~mm}$ below the surface. The results for CR3 ingot showed many more indications than in ingots previciusly inspected although prior ingots had a large number of surface defects that interfered to some extent with the ultrasonic examinations.

\subsection{ARC MELTING EQUIPMENT}

The apparatus currently used for consumable arc melting is approximately 30 years old, manually controlled, and, because it was designed for 75- to 150-mm-diam ingots, does not have the alignment or control for reproducing the small arc gaps required for melting 50- to 63-mm-diam ingots. The smaller iridium ingots are required because of the material cost and risk of loss of the material in the event that contamination occurs. This smaller size also requires that ingots be melted in a time period of about $3 \mathrm{~min}$, allowing little time for operator adjustments to maintain steady-state operations. To solve this problem, capital funds have been approved to procure a consumable arc-melting apparatus having the alignment and computer controls and electrode-weighing capability for automated melting of the small ingot. A specification for the apparatus was completed in February 1989, and a fabricator was selected in April 1989. It is anticipated that the new consumable arc-melting apparatus will be installed and operational in June 1990 and be qualified for iridium production by September 1990 .

\section{EXTRUSION}

The extrusion of arc-melted ingots provided the primary breakdown of the cast structure under conditions that should minimize the chances of crack propagation under tensile stresses such as are developed during rolling. The ingot is placed in a close-fitting 
molybdenum can prior to extrusion in order to avoid both contaminating and rapid quenching of the ingot surface during the extrusion. The previous extrusion of the 51-mm-diam ingots was performed using cans of 75-mm diam with a wall thickness of approximately $12.5 \mathrm{~mm}$. The can was extruded through a rectangular die opening of 19 by $38 \mathrm{~mm}$ to produce an iridium-alloy bar of about 12 by $2.9 \mathrm{~mm}$. The increase in ingot diameter to $63 \mathrm{~mm}$ required an increase in the outside diameter (OD) of the can to maintain the same approximate wall thickness. The die opening was increased to 19 by $51 \mathrm{~mm}$ to maintain the nominal reduction in area of $6.6: 1$.

The first three extrusions of the larger size ingots (RS3, E1, and CR2) were performed using preheat, lubrication, and tooling similar to that used for the smaller 51-mm-diam ingots. Following less than satisfactory results with two of the three extrusions, modifications to the extrusion practice were evaluated, tested, and implemented. Three successful extrusions (RS4, CR3, and BF7) were performed with the improved practice, which includes increased preheat temperature, use of glass lubrication, improved tooling design, and electrochemical cleaning of extruded bars prior to rolling of sheet.

\subsection{EXTRUSION OF RS3, E1, AND CR2 INGOTS}

Each of the three ground ingots (RS3, E1, and CR2) were placed in a molybdenum can that had been machined to an inside diameter (ID) 0.2 to $0.4 \mathrm{~mm}$ larger than the ingot diameter and an internal cavity length $0.5 \mathrm{~mm}$ greater than the ingot length. The cans had a $45^{\circ}$ cone tapering to a $24-\mathrm{mm}$-diam flat at the nose. This $87.6-\mathrm{mm}$ OD provides sufficient clearance after heating to the extrusion temperature to be manually inserted in the $90.3-\mathrm{mm}$ ID extrusion container liner. An end cap of about $25 \mathrm{~mm}$ length mates with the can by a screw thread. The end cap was pure molybdenum for the RS3 and CR2 ingots and a 
higher strength TZM alloy (N.0-0.5\% Ti-0.07\% Zr) for the E1 extrusion. Ground iridiumalloy ingots were placed in the can with the bottom of the cast ingot at the nose of the extrusion. The extrusions were all preheated at $1325^{\circ} \mathrm{C}$ for $4 \mathrm{~h}$ using a partial argon cover to minimize oxidation of the molybdenum. A new zirconia-coated die with a rectangular 19- by 51-mm opening was used for each extrusion. The die is supported from behind by a die-backer that has an opening $6 \mathrm{~mm}$ larger than the die opening in each direction.

Lubrication was provided with Necrolene (J. F. Hall \& Company, Carnegie, Pennsylvania) on the die and liner, followed by Fiske 201 (G. Whitfield Richardson Co., Philadelphia, Pennsylvania) using the normal practice. The transfer times to the furnace were in the range oi 9 to $12 \mathrm{~s}$.

The CR2 extrusion stopped prematurely as the press reached its capacity of $8 \mathrm{MN}$ (900 tons). This was found to be the result of rotation of the die in the liner prior to the extrusion. Wear of the liner was a contributing cause of the rotation. The iridium-alloy ingot showed a large crack following removal of the molybdenum-can material, as seen in Fig. 11. The failure is tensile in nature with about $5 \%$ reduction of area at the fracture. It is postulated that differential thermal contraction produced tensile stresses sufficient to cause the fracture.

The load and $K$-factor vs time are shown in Fig. 12 for the E1 extrusion. The $K$-factor is defined as

$$
\mathrm{K}=P / A_{0} \ln \left[A_{0} / A_{f}\right]
$$

where

$$
\begin{aligned}
P & =\text { the load } \\
A_{0} & =\text { the cross-sectional area of the container liner, } \\
\mathrm{A}_{\mathrm{f}} & =\text { the cross-sectional area of the extruded bar. }
\end{aligned}
$$




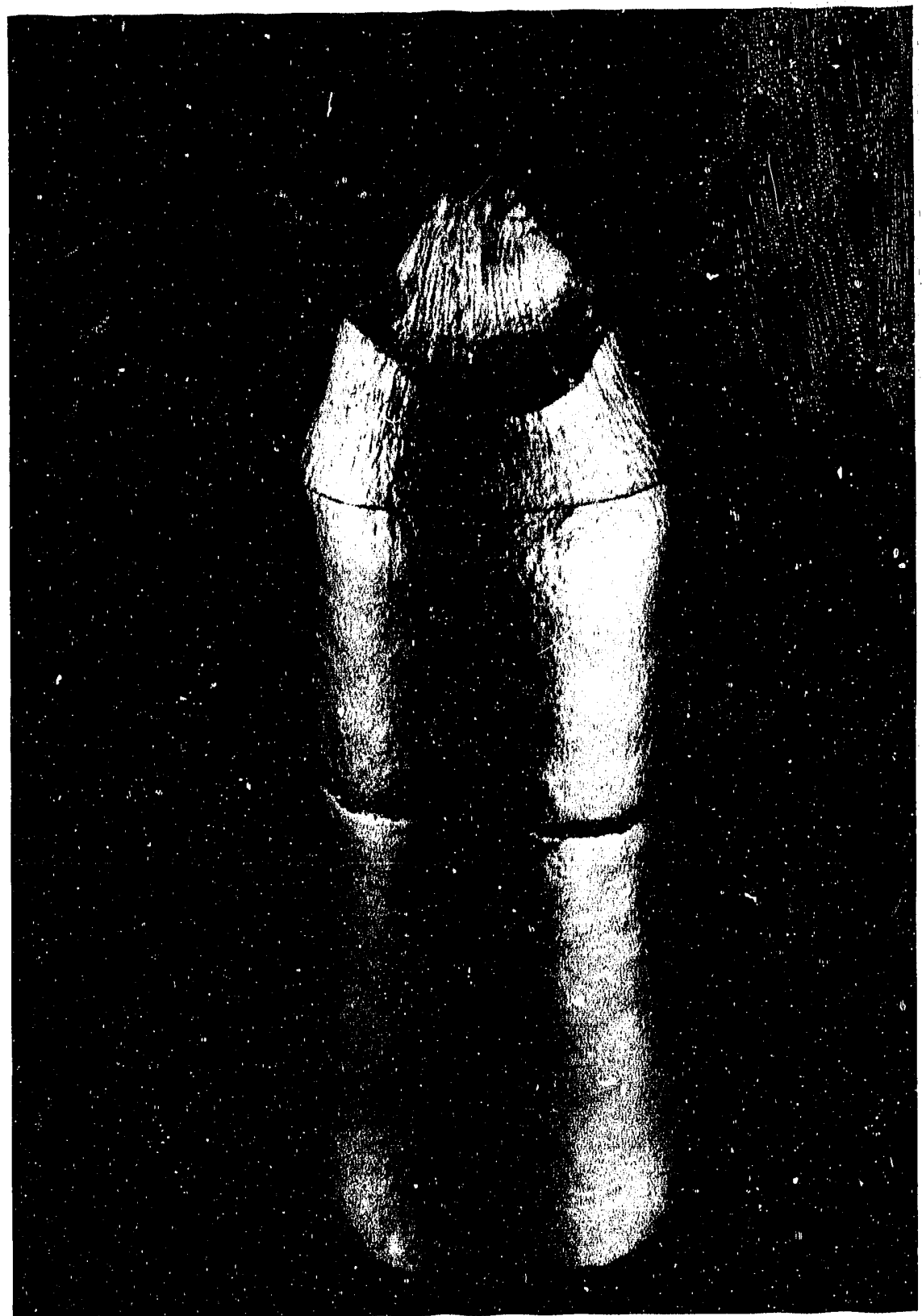

Fig. 11. Partial extrusion of CR2 ingot showing tensile-type fracture with measurable reduction of area. 


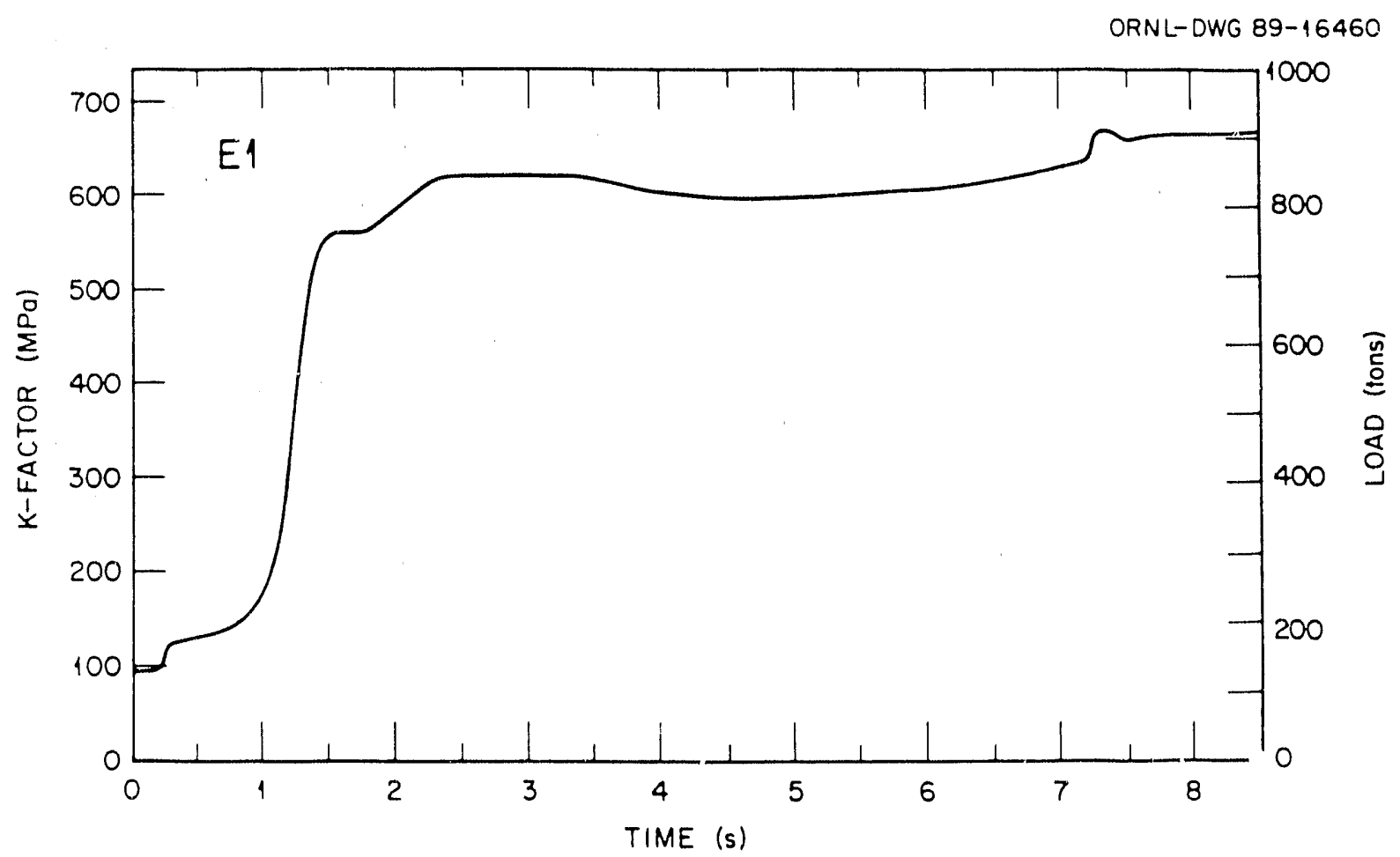

Fig. 12. Extrusion loads for E1 ingot exceeding the press capacity.

The E1 extrusion stopped at the point where the TZM alloy end cap entered the die, leaving about $1 \mathrm{~kg}$ of unexsuded iridium alloy in the die. The incomplete extrusion was caused by an insufficiently heated graphite follower block which in turn caused excessive cooling of the end cap. The use of a TZM end cap, rather than molybdenum, was a contributing cause because of the greater flow strength of TZM, although it had been successfully used for previous extrusions. The location at which the end cap entered the die can be seen on the load curve in Fig. 12 at the 7-s position.

The load curve for the successfully extruded RS3 extrusion in Fig. 13 shows that even for this case, there is little margin between the extrusion load and the press capacity. This is clearly another contributing cause of the partial extrusion of E1. 
ORNL-DWG 89-16459

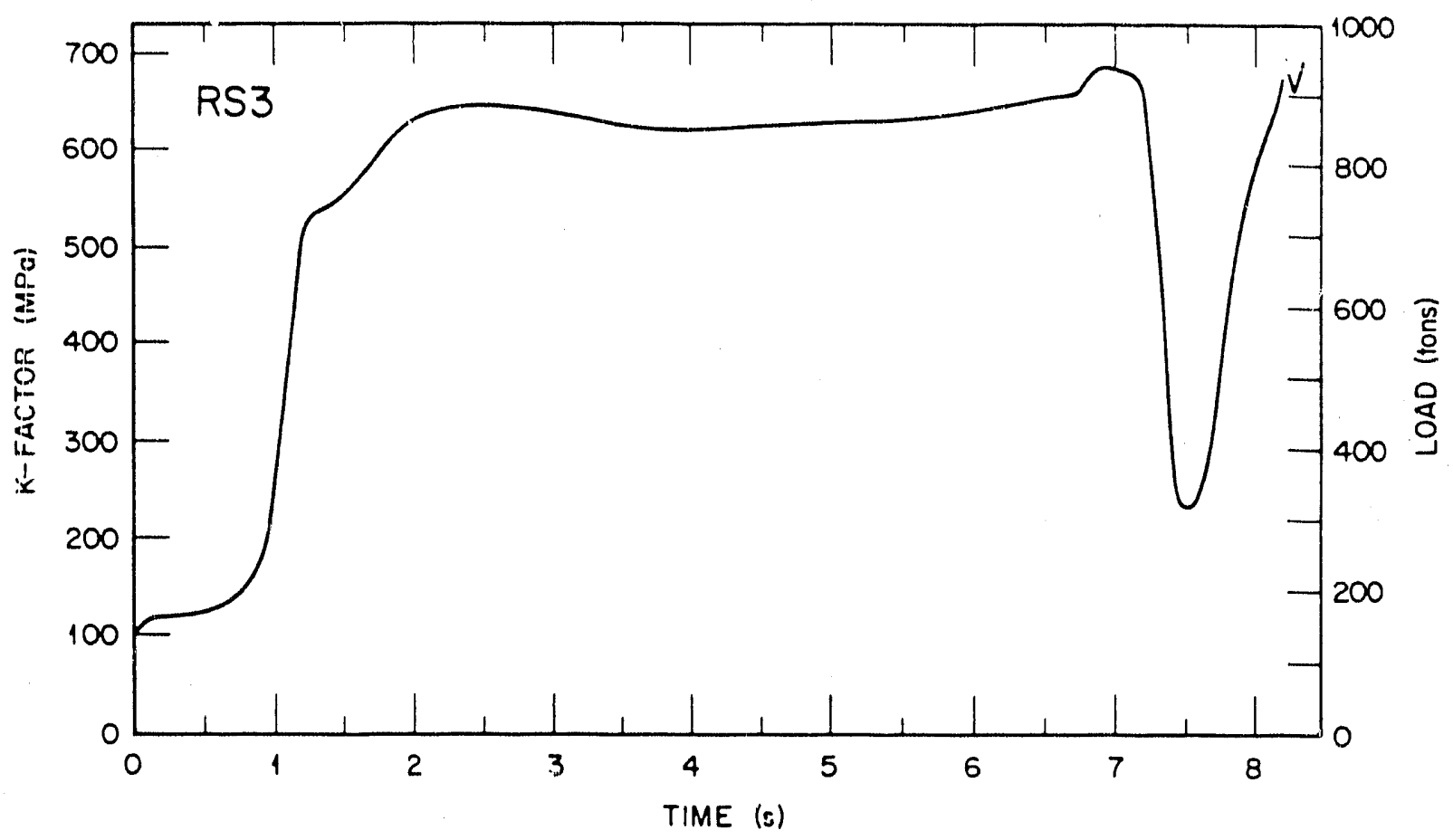

Fig. 13. Extrusion loads for RS3 ingot approaching press capacity as seen at the extreme right of the curve.

\subsection{EXTRUSION PKOCESS IMPROVEMENTS}

As a result of the incomplete extrusions of the E1 and CR2 billets and the absence of a significant margin between the required loads and the press capacity, a number of changes to the process were evaluated. Initially, three conditions were selected for evaluation: (1) an increase in preheat temperature to 1450 from $1325^{\circ} \mathrm{C}$ as a means to reduce load, (2) the use of glass iubricants for the same reason, and (3) the mechanical pinning of the die and die-backer to ensure proper alignment. The evaluation of preheat temperature included analysis of expected loads, heat-flow analysis of billet during heating and cooling, and the study of the reactions between the molybdenum can and the iridium ingot during preheat. Several chemical-cleaning procedures were also evaluated because a study of the reaction between the iridium alloy and the molybdenum can indicated that chemical cleaning of the extruded bar would be necessary. 


\subsubsection{Reactions of Molybdenum With Iridium Alloy}

Reactions between molybdenum and DOP-26 iridium alloy were evaluated over the temperature range of 1200 to $1475^{\circ} \mathrm{C}$. The $1200^{\circ} \mathrm{C}$ lower limit corresponds to the lowest preheat temperature used for extrusion. The $1475^{\circ} \mathrm{C}$ upper limit was selected to be slightly higher than the maximum planned preheat temperature. Experimental diffusion couples were made in which an iridium-alloy sheet sample was placed in contact on one side with molybdenum, which had been preoxidized in air at $500^{\circ} \mathrm{C}$ for $30 \mathrm{~min}$, and on the other side with unoxidized molybdenum. The couples were placed in the container and compressed by means of a screw. The container and screw were made of Mo-0.5 wt \% Ti alloy. Each assembly was heated under an argon cover for $4 \mathrm{~h}$ in a furnace of the same design as the preheat furnace for extrusion. The test temperatures used were $1200,1325,1375,1425$, and $1475^{\circ} \mathrm{C}$. A similar assembly, but without preoxidized molybdenum, was heated in a vacuum furnace at $1450^{\circ} \mathrm{C}$ for $4 \mathrm{~h}$. After cooling, the containers were cut to expose the samples inside. It was observed that the molybdenum and iridium alloys did not adhere to each other after heating in argon but did adhere after heating in a vacuum.

The samples examined by optical metallography were generally etched electrolytically with alternating current $(\mathrm{ac})$ at $10 \mathrm{~V}$ in a solution of 1 part $\mathrm{HCl}$ to 4 parts $\mathrm{H}_{2} \mathrm{O}$ with a small addition of $\mathrm{NaCl}$ for improved contrast. Measurements of layer thicknesses were made using as-polished samples. Microprobe analysis was performed on as-polished samples heated at 1475 and $1325^{\circ} \mathrm{C}$. Auger analysis was performed on the sample heated at $1475^{\circ} \mathrm{C}$, which was fractured in the vacuum chamber of the Auger microscope. Optical micrographs of the intermetallic layers formed at 1325 and $1475^{\circ} \mathrm{C}$ are shown in Figs. 14 and 15 , respectively. The results of optical metallographic examination of the total intermetallic layer thickness are shown in Fig. 16 as an Arrhenius plot of natural logarithm 
Y215142

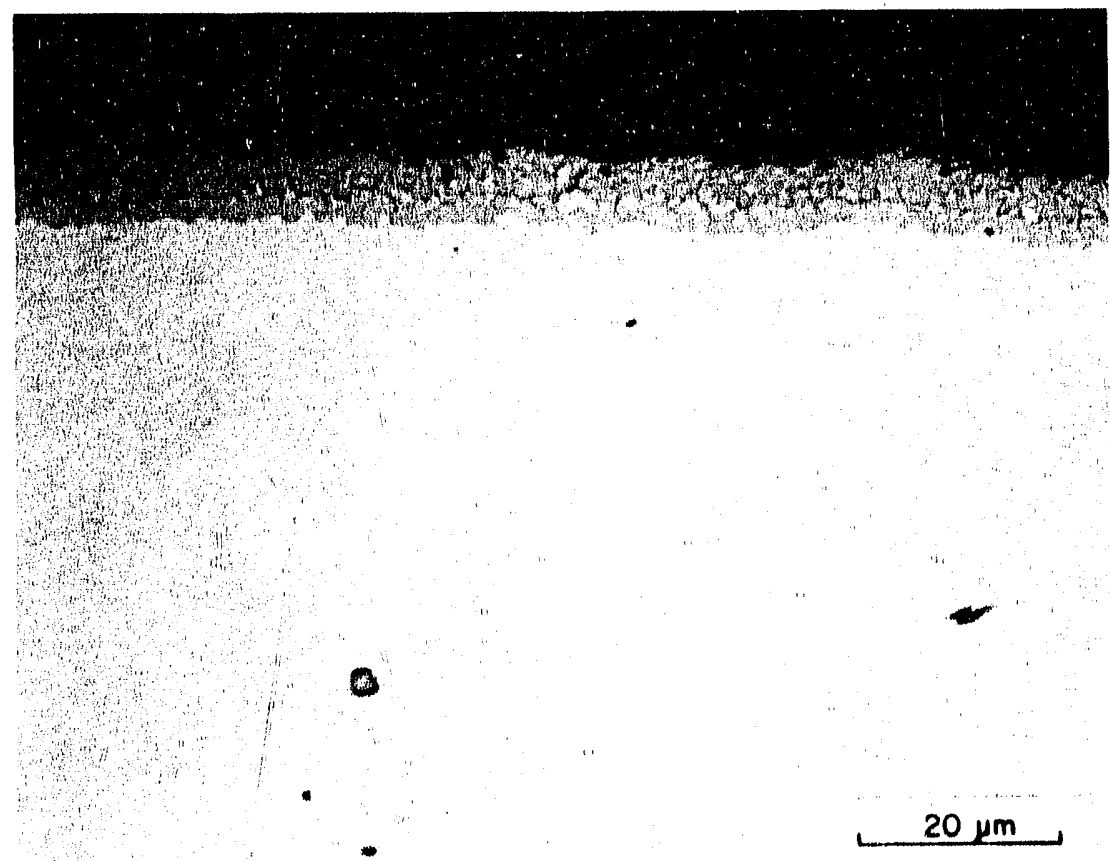

Fig. 14. Metallographic section of iridium-molybdenum diffusion couple with about $10 \mu \mathrm{m}$ of intermetallic compounds formed at $1325^{\circ} \mathrm{C}$ in $4 \mathrm{~h}$.

Y 215143

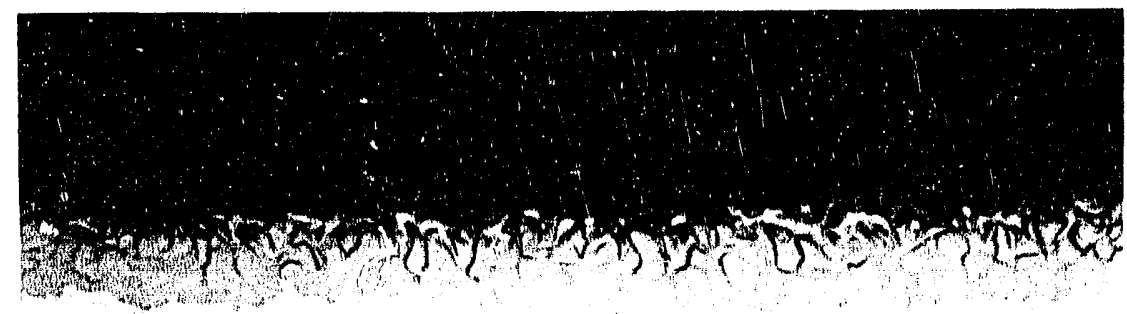

Fig. 15. Metallographic section of iridium-molybdenum diffusion couple with about $15 \mu \mathrm{m}$ of intermetallic compounds formed at $1475^{\circ} \mathrm{C}$ in $4 \mathrm{~h}$. 


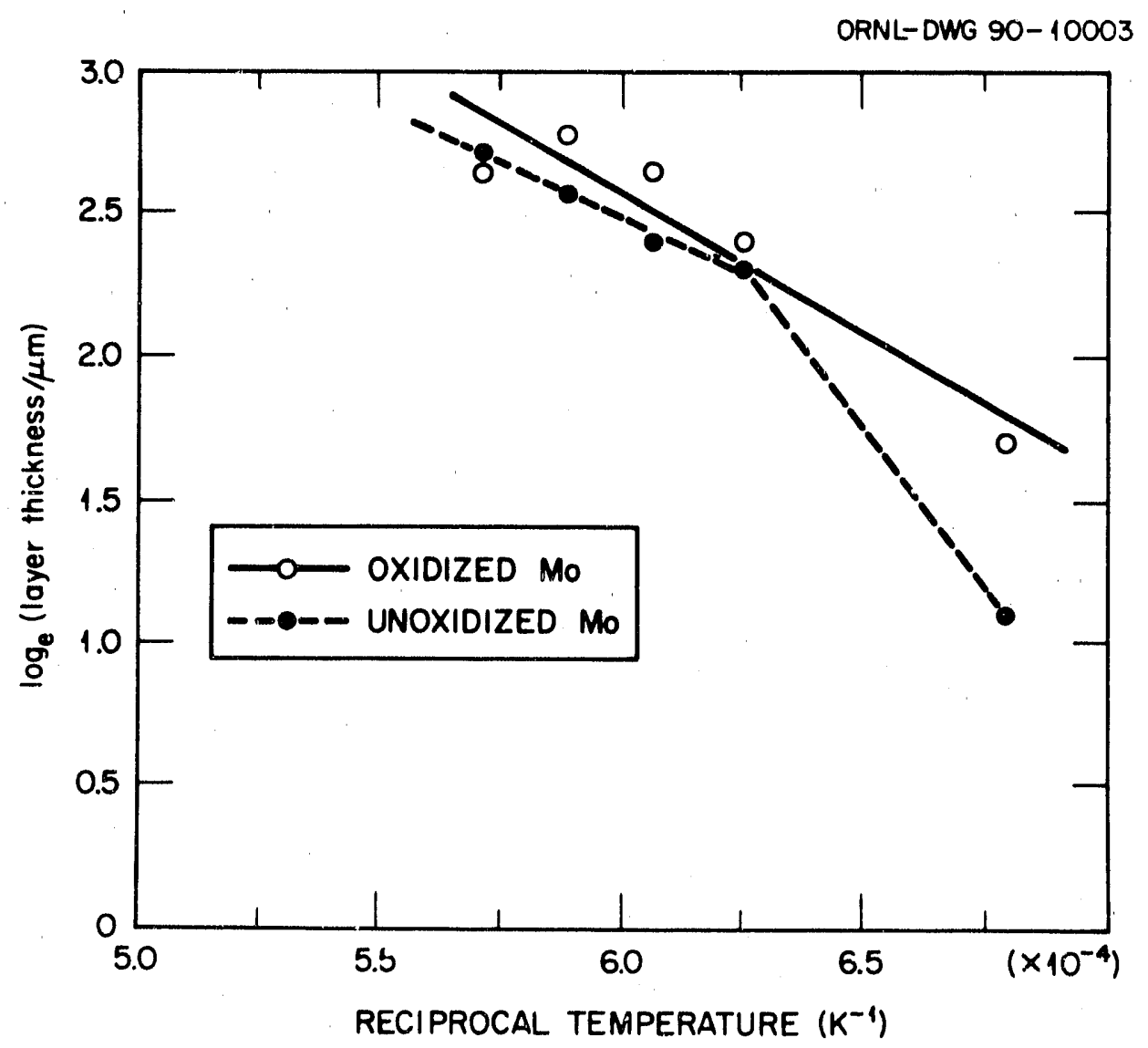

Fig. 16. The Arrhenius plot of natural log of intermetallic layer thickness formed in iridium-molybdenum diffusion couples heated for $4 \mathrm{~h}$ increases with reciprocal temperature showing no appreciable effect of preoxidation of the molybdenum at temperatures in the range 1325 to $1475^{\circ} \mathrm{C}$.

of total layer thickness vs reciprocal absolute temperature for the temperature range of 1200 to $1475^{\circ} \mathrm{C}$. The average total layer thickness is found to be similar for both the preoxidized and unoxidized molybdenum. The layers are uniform in thickness to within 1 or $2 \mu \mathrm{m}$ on each sample. The average layer thickness is 3 to $5 \mu \mathrm{m}$ at $1200^{\circ} \mathrm{C}$, about $10 \mu \mathrm{m}$ at $1325^{\circ} \mathrm{C}$, and about $15 \mu \mathrm{m}$ at $1475^{\circ} \mathrm{C}$. The sample heated in vacuum at $1450^{\circ} \mathrm{C}$ for $4 \mathrm{~h}$ exhibits a layer thickness of about $13 \mu \mathrm{m}$, although a number of areas of contact between molybdenum and iridium show no intermetallic layer. 
The microprobe analysis of the samples heated at both 1325 and $1475^{\circ} \mathrm{C}$ showed the intermetallic layer to consist of two distinct layers, one with a composition corresponding to IrMo adjacent to the molybdenum and a second layer with a composition corresponding to Ir3Mo adjacent to the iridium. The two layers are each about one-half of the total layer thickness. The backscattered electron image of the sample heated at $1475^{\circ} \mathrm{C}$ in Fig. 17 shows the two intermetallic layers. The molybdenum content of the two layers can be seen graphically in the Mo $\mathrm{L}_{\alpha} \mathrm{X}$-ray map shown in Fig. 18. Trace levels of tungsten $(0.1$ to $0.4 \mathrm{wt} \%$ ) were also found in the intermetallic layers, presumably resulting from the 0.3 wt \% tungsten content of the iridium alloy.

Scanning Auger microscope analysis of the sample heated at $1475^{\circ} \mathrm{C}$ clearly showed intermetallic layers on the surface. The composition of the layers was consistent with those found by microprobe analysis. Analysis of the grain boundaries exposed by the fracture showed no evidence of molybdenum. No molybdenum was detected even as close as $2.5 \mu \mathrm{m}$ from the surface of the intermetallic layers. Iridium and thorium are the only detected elements at any of the examined grain boundaries.

To define further the extent of the reaction layer, sections of earlier extrusions (B1, B2, BR3, D1, and E1) were also examined by optical metallography. Sections from E1 and D1 extrusions showed intermetallic particles of up to about $10 \mu \mathrm{m}$ in thickness distributed along the surface, such as those seen in Fig. 19. These extrusions had been preheated for $4 \mathrm{~h}$ at $1325^{\circ} \mathrm{C}$. Microprobe analysis of the D1 extrusion showed the particles to consist of the same intermetallic compositions as found in the diffusion couples. Optical metallography of the BR3 extrusion showed continuous intermetallic surface layers of $10 \mu \mathrm{m}$ or more. This material had been preheated at $1250^{\circ} \mathrm{C}$, upset in the container, reheated at $1250^{\circ} \mathrm{C}$ with the molybdenum can in intimate contact with the iridium alloy, and then reextruded. Sections of the $\mathrm{B} 1$ and $\mathrm{B} 2$ extrusions, preheated at 1200 and $1250^{\circ} \mathrm{C}$, 
Y P8713

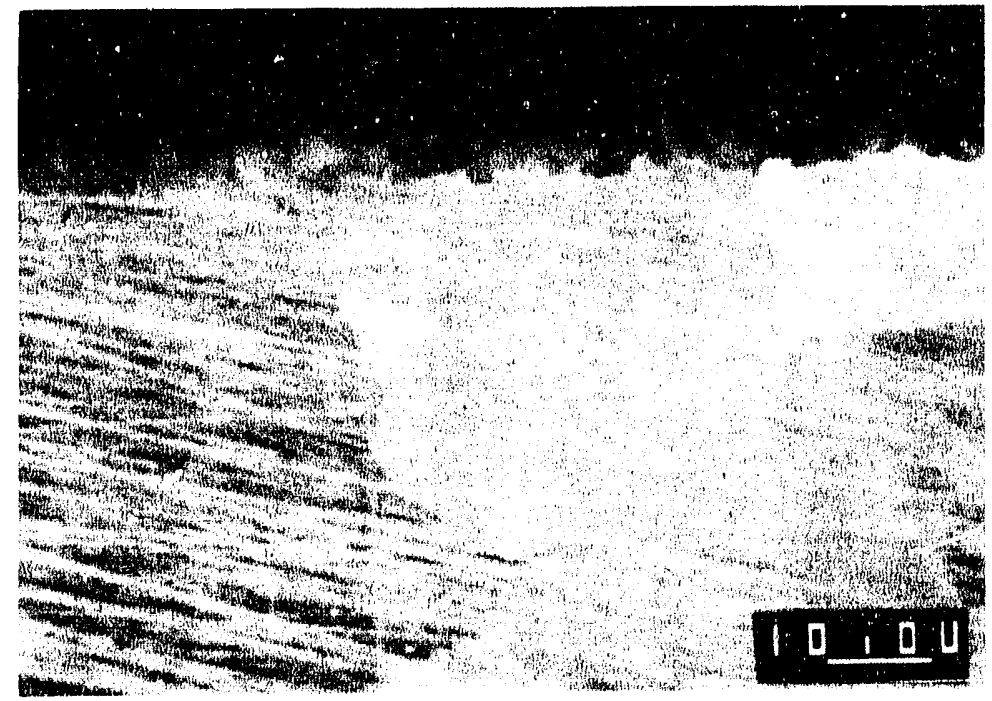

s.

Fig. 17. Electron microprobe backscattered electron image of an iridium-molybdenum diffusion couple heated $4 \mathrm{~h}$ at $1475^{\circ} \mathrm{C}$ showing intermetallic layers and grain structure of the intermetallic compound on the surface of the iridium base metal. The molybdenum couple has separated from the iridium and is not shown.

YP 11343

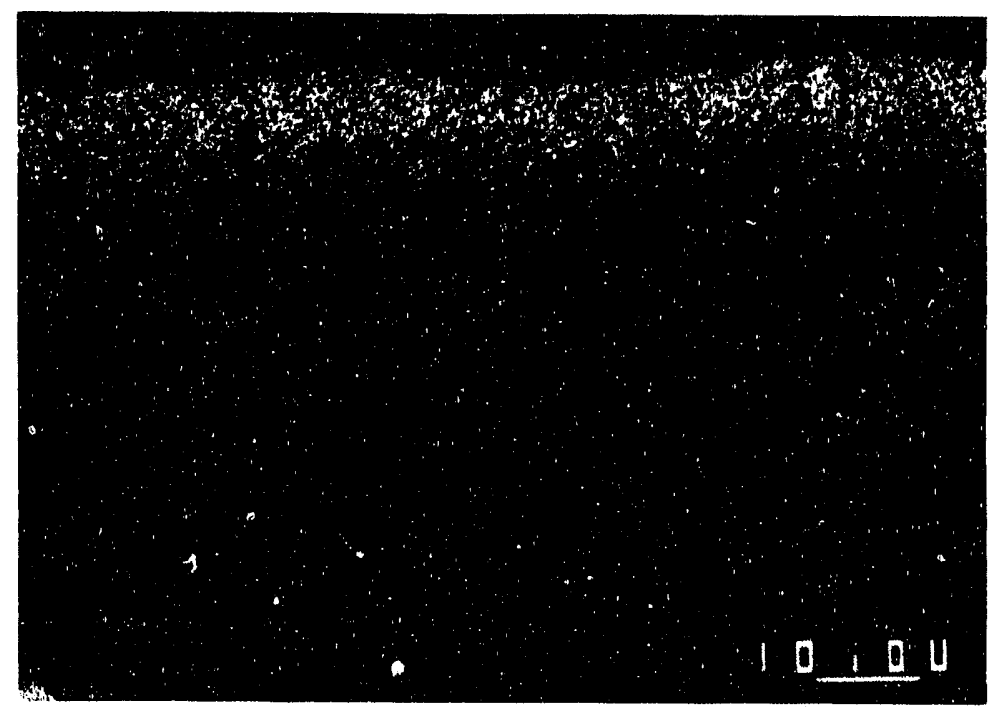

Fig. 18. Electron microprobe Mo $\mathrm{L}_{\alpha} \mathrm{X}$-ray map of an iridium-m、ybdenum diffusion couple heated $4 \mathrm{~h}$ at $1475^{\circ} \mathrm{C}$ showing two intermetallic layers, IrMo closest to the top surface and $\mathrm{Ir}_{3} \mathrm{Mo}$ underneath. 
Y 215145

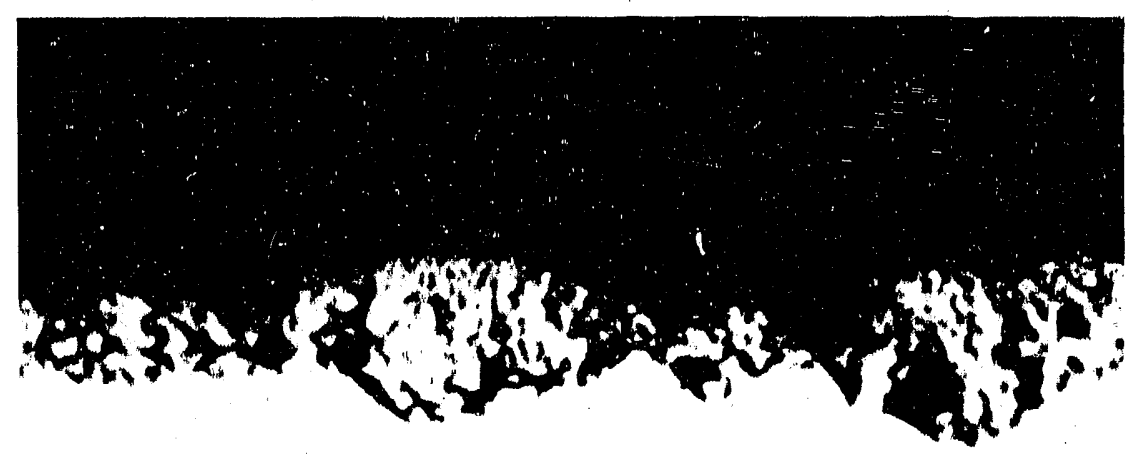

$20 \mathrm{\mu m}$

Fig. 19. Metallographic section of D1 extrusion showing intermetallic compounds of molybdenum with iridium on the surface.

respectively, were similarly exarnined and found to have no detectable intermetallic compound on the as-extruded surface.

The plot of intermetallic layer thickness vs temperature shown in Fig. 16 indicates that oxidation of the molybdenum couple increases the quantity of intermetallics formed, especially at the lowest temperature of $1200^{\circ} \mathrm{C}$. This suggests that at $1200^{\circ} \mathrm{C}$, the transport of molybdenum to the reaction layer interface may be a rate-controlling step, and the presence of sufficient oxygen may assist in the transport of molybdenum as $\mathrm{MoO}_{3}$ vapor. This may also explain the absence of intermetallic compounds on the B1 and B2 extrusions, which were preheated at 1200 and $1250^{\circ} \mathrm{C}$, respectively, in a relatively tightly sealed can and with a larger clearance between the iridium-alloy ingot and the molybdenum can. 
The results of these evaluations on diffusion couples and extruded bars indicate that significant quantities of intermetallic compound will form at all temperatures in the range of 1200 to $1475^{\circ} \mathrm{C}$ when the iridium alloy and molybdenum are in close contact. Because it is not possible to avoid the intermetallic formation, the layer formed on the extruded surface should be removed prior to the rolling of sheet.

\subsubsection{Chemical Removal of Intermetallic Compounds}

The cleaning of intermetallic layers from extruded material was evaluated by metallographic studies of iridium alloy samples following a variety of acid-cleaning operations and also following electrolytic $\mathrm{KCN}$ cleaning. The samples consisted of relatively small pieces (approximately $10 \times 20 \times 2 \mathrm{~mm}$ ) of the D1 extrusion. The acid-

cleaning treatments correspond to all those currently used to clean iridium-alloy products at various steps during fabrication. The electrolytic cleaning with ac in an aqueous $\mathrm{KCN}$ solution is the same procedure as that now used to clean blanks, foil, and scrap materials. The cleaning treatments are listed in Table 2. Metallographic examination of the acidcleaned samples showed no significant removal of the intermetallic by any of the three acid treatments. Metallographic examination of the KCN-cleaned sample (Fig. 20) shows complete removal of the intermetallic material from the iridium after $10 \mathrm{~min}$.

In order to evaluate the effectiveness of $\mathrm{KCN}$ cleaning on a larger sample, a piece from the tail of the D1 extrusion of about $10 \times 20 \times 20 \mathrm{~mm}$ was cleaned for $10 \mathrm{~min}$ in $\mathrm{KCN}$ using the same parameters as treatment 4 in Table 2. Metallographic examination showed several regions on the extruded surface that were not completely cleaned of intermetallic material. As a result of this observation, additional studies were performed on refinable iridium-alloy scrap material. The material was canned in molybdenum, preheated at $14.50^{\circ} \mathrm{C}$ for $3.5 \mathrm{~h}$, and extruded. A bar about $180 \mathrm{~mm}$ in length was cut to produce a 
Table 2. Cleaning treatments for samples from D1 extrusion

\begin{tabular}{ccccc}
\hline Treatment & $\begin{array}{c}\text { Solution } \\
\text { composition } \\
(\text { vol. \%) }\end{array}$ & $\begin{array}{c}\text { Temperature } \\
\left({ }^{\circ} \mathrm{C}\right)\end{array}$ & $\begin{array}{c}\text { Time } \\
(\mathrm{min})\end{array}$ & $\begin{array}{c}\text { Electric } \\
\text { potential } \\
\text { difference } \\
(\mathrm{V})\end{array}$ \\
\hline $1^{a}$ & $50 \mathrm{H}_{2} \mathrm{O}, 45 \mathrm{HNO}_{3}, 5 \mathrm{H}_{2} \mathrm{SO}_{4}$ & 20 & 30 & \\
2 & $20 \mathrm{H}_{2} \mathrm{O}, 60 \mathrm{HCl}, 20 \mathrm{HF}$ & 90 & 60 & \\
3 & $63 \mathrm{HCl}, 22 \mathrm{HNO}_{3}, 15 \mathrm{HF}$ & 20 & 60 & \\
4 & $\mathrm{KCN}$ (saturated, aqueous) & 20 & 10 & 10 \\
\hline
\end{tabular}

$a_{\text {This acid cleaning treatment was carried out on all samples because it is used to }}$ dissolve the molybdenum can material from all extrusions.

Y 215146

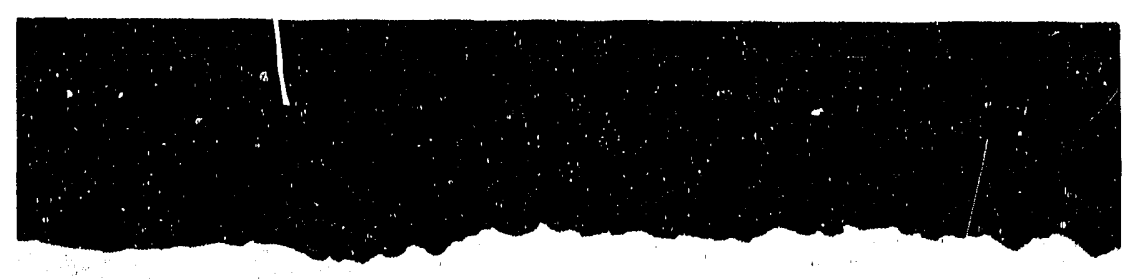

$\cdots$ 
section from the nose of $125-\mathrm{mm}$ length and a section from the tail of $25-\mathrm{mm}$ length. Each section was cleaned separately in $\mathrm{KCN}$ for 3 consecutive 10-min intervals.

The weight loss and current and calculated current density values obtained during KCN cleaning of the nose and tail sections are shown in Table 3. The values for ac are those at the end of each interval. Currents were typically $20 \%$ lower at the start, possibly hecause of an initial contact resistance. In a summary of Table 3, the current density appears to be higher for the tail section, which had about $30 \%$ of the surface area of the nose section; the specific weight loss values for each 10-min cleaning interval are all within the range of 45 to $60 \mathrm{~g} / \mathrm{m}^{2}$; and the variation range can be explained by the surface-area estimates. These results indicate section size had no effect on material removal for these

Table 3. Characterizing data for electrolytic KCN-cleaning tests on refinable iridium-alloy scrap material

\begin{tabular}{lccccc}
\hline Location & $\begin{array}{c}\text { Total } \\
\text { elapsed } \\
\text { time } \\
(\mathrm{min})\end{array}$ & $\begin{array}{c}\text { Current } \\
(\mathrm{A})\end{array}$ & $\begin{array}{c}\text { Weight loss } \\
\text { for 10-min } \\
\text { interval } \\
(\mathrm{mg})\end{array}$ & $\begin{array}{c}\text { Current } \\
\text { density } \\
\left(\mathrm{kA} / \mathrm{m}^{2}\right)^{a}\end{array}$ & $\begin{array}{c}\text { Specific } \\
\text { weight loss } \\
\text { for 10-min } \\
\text { interval } \\
\left(\mathrm{g} / \mathrm{m}^{2}\right)^{a}\end{array}$ \\
\hline $\begin{array}{l}\text { Vose } \\
\text { Tail }\end{array}$ & 10 & 110 & 623 & 17 & 60 \\
Nose & 10 & 49 & 90 & 22 & 48 \\
Tail & 20 & 82 & 301 & 13 & 51 \\
Nose & 20 & 37 & 75 & 22 & 45 \\
Tail & 30 & 94 & 307 & 15 & 53 \\
\hline
\end{tabular}

a Surface area, which was estimated to within $\pm 15 \%$ based on dimensional measurements, decreased with each successive interval due to cutting of metallographic samples. 
$\mathrm{KCN}$ cleaning treatments. In terms of thickness, the total material removed in 30 min was calculated to be $6.1 \mu \mathrm{m}$ for the small tail section and $6.9 \mu \mathrm{m}$ for the larger nose section, using a density value for the alloy of $22 \mathrm{Mg} / \mathrm{m}^{3}$. The amount of removal would be higher if a lower intermetallic density is considered,

The metallographic analysis of the sections showed substantial quantities of intermetallic covering over $50 \%$ of the extruded surface from both the nose and tail. No intermetallics could be found on metallographic samples taken from either section after 10 or 20 min of electrolytic KCN cleaning. Of the three samples taken after the $30-\mathrm{min}$ cleaning, two showed no intermetallics. The third sample showed a very small region of intermetallics (about 2 to $3 \mu \mathrm{m}$ in dimension) which appeared at the root of a very deep and narrow depression ( $\mathrm{V}$-shaped groove) near the corner of the extruded surface.

On the basis of these results, all extrusions shall be cleaned in $\mathrm{KCN}$ prior to rolling. A total cleaning time of $30 \mathrm{~min}$ was recommended as a conservative but practical cleaning time to best ensure removal of all intermetallics from the extruded bar. Any remaining particle of intermetallic would almost certainily be removed from the surface during blank grinding or subsequent electrolytic cleaning of foil. It was further recommended that all recyclable material from the extruded bar be cleaned in $\mathrm{KCN}$ in the same manner as is now done for rolled sheet. These steps, which are now incorporated into the process procedures, will permit usage of extrusion-preheating temperatures of up to $1475^{\circ} \mathrm{C}$ with no additional risk of molybdenum contamination of iridium-alloy sheet products. Intermetallic formation during rolling of iridium-alloy sheet material between molybdenum covers can occur at only a very low rate due to the maximum rolling temperature of $1200^{\circ} \mathrm{C}$. The currently used cleaning processes for blanks and foil are sufficient to remove any intermetallic material which may form during rolling. 


\subsubsection{Glass Lubrication}

In order to evaluate the effect of glass lubrication on the extrusion of molybdenumcanned iridium-alloy ingots, a series of experiments with pure molybdenum were made. The molybdenum used here is identical to that from which the cans are fabricated for iridium-alloy extrusions. Four extrusions were performed with a 3.5 -h preheat at $1450^{\circ} \mathrm{C}$ of 148 -mm-long billets with identical $45^{\circ}$ nose cones. Previously used dies of 19 - by 51-mm rectangular opening in good condition were employed. Glass lubricant was applied to three of the four extrusions by rolling the hot billet down an inclined plane covered with -200 mesh glass powders. The initial mixture consisted of 15 wt $\% 3 \mathrm{~KB}$ glass with $85 \%$ 567 glass, both manufactured by Ceramic Color and Chemical Manufacturing Company, New Brighton, Pennsylvania. Visual observation of the application of the glass to the hot billet suggested that this mixture was not sufficiently fluid for optimal lubrication, and the amount of the lower melting point $3 \mathrm{~KB}$ glass was subsequently increased to $33 \mathrm{wt} \%$. The extruding conditions and results for extrusions are summarized in Table 4.

The effect of glass lubrication on the running load, defined here as the load just prior to completion of the extrusion of the molybdenum, can be seen by comparison of extrusions 2683, 2682, and 2693 in Table 4. The running load decreases from 4.7 MN without glass to $4.5 \mathrm{MN}$ with the initial glass formulation to $4.4 \mathrm{MN}$ with the improved glass formulation. However, the lower load value for extrusion 2693 as compared to 2682 may also result in part from a shorter transfer time. On the basis of these results, the glass lubrication provides a reduction in extrusion load of about $7 \%$ despite the increased transfer time associated with additional cooling.

The fourth extrusion in the series (2694) contained a 25 -mm-diam by $44-\mathrm{mm}$-long iridium-alloy drop casting located near the center of the billet and held in place from the rear 
Table 4. Results of extrusion of molybdenum billets at $1450^{\circ} \mathrm{C}$ in $88-\mathrm{mm}$ diam under various conditions of glass lubrications

\begin{tabular}{lccccc}
\hline Extrusion & $\begin{array}{c}\text { Glass } \\
\text { lubricant } \\
(\mathrm{wt} \%)\end{array}$ & $\begin{array}{c}\text { Total } \\
\text { elapsed } \\
\text { time } \\
(\mathrm{s})\end{array}$ & $\begin{array}{c}\text { Reduction- } \\
\text { in-area } \\
\text { ratio }\end{array}$ & $\begin{array}{c}\text { Running } \\
\text { load } \\
(\mathrm{MN})\end{array}$ & $\begin{array}{c}\text { Running } \\
K \text {-factor } \\
(\mathrm{MPa})\end{array}$ \\
\hline 2682 & $\begin{array}{c}3 \mathrm{~KB}(15) \\
567(85)\end{array}$ & 53 & 5.9 & 4.5 & 395 \\
2683 & None & 32 & 5.9 & 4.7 & 410 \\
2693 & $\begin{array}{c}3 \mathrm{~KB}(33) \\
567(67)\end{array}$ & 41 & 6.1 & 4.4 & 380 \\
$2694^{a}$ & $\begin{array}{l}3 \mathrm{~KB}(33) \\
567(67)\end{array}$ & 40 & 5.8 & 4.8 & 430 \\
\hline
\end{tabular}

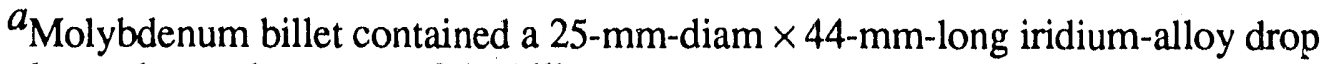
casting located near the center of the billet.

by a 38 -mm-long molybdenum screw. The extrusion conditions were otherwise identical to that for 2693 . The 2694 extrusion exhibited a substantially higher breakthrough and running load of $4.8 \mathrm{MN}$.

Following extrusion of the iridium-alloy drop casting, the molybdenum can was chemically removed to permit dimensional measurements. The extruded bar exhibited substantial bulging at each end. The central portion showed an oval cross section, $17-\mathrm{mm}$ wide and 7-mm thick, corresponding to a reduction in area ratio of about 4.5:1.

Metallographic examination of the extruded iridium alloy shows an almost completely recrystallized structure with a recrystallized grain size diameter of 20 to $50 \mu \mathrm{m}$. The results are indicative of the greater resistance of the iridium alloy to deformation, as compared to the molybdenum, and were used to estimate the loads for the full-size iridium extrusion performed subsequently at a $1425^{\circ} \mathrm{C}$ preheat temperature. 


\subsubsection{Tooling Improvements}

During extrusions of iridium-alloy ingots, the die is supported by a die-backer that has a rectangular opening slightly larger than that of the die. The die is inserted into the container and in the past has been held in place by friction. The rotation of the die during an extrusion of CR2 produced misalignment with the die-backer and a drastic decrease in the effective die opening, thereby resulting in an incomplete extrusion. In order to avoid this malfunction, it is clear that the die must be mechanically fixed to the die-backer.

The mechanical attachment of the die and die-backer is now achieved by the use of two 9.5-mm-diam pins, which are inserted into alignment holes in both the die and diebacker. The die is fixed to the die-backer and then moved into the container by means of the die slide. To date, this technique has been used for six extrusions, including four of molybdenum at $1450^{\circ} \mathrm{C}$. In all cases, positive alignment between die and die-backer was maintained. During three of the six extrusions, one of the two alignment pins fractured. This is not considered to be of great concern because one pin is sufficient to maintain the proper alignment. Furthermore, the cracking of the pins in the three extrusions is at least partly the result of dimensional variations in the used dies, which were employed for all of these extrusions.

\subsubsection{Billet Preheat Analysis}

The analysis of billet preheating included modeling of the heating of the molybdenum-canned iridium-alloy billet, modeling of its cooling during transfer, and e\%aluation of thermometry of the preheat furnace. The purpose of this work was to determine if the established preheat time of $4 \mathrm{~h}$ was excessive and if the maximum permitted transfer time of $25 \mathrm{~s}$ was reasonable. 
Numerical analysis of billet heating and cooling was performed using the model of an iridium cylinder in a molybdenum can with a 0.4 -mm air-gap space between the two. Because emissivity data for the iridium and molybdenum components were not available, extreme shape factor values of 1 and 0.2 were both analyzed. The calculated maximum and minimum temperatures in the iridium cylinder are shown in Fig. 21 for heating at $1450^{\circ} \mathrm{C}$. The results show that even under the most conservative estimates, the iridium is heated to temperature within $1 \mathrm{~h}$. On this basis the minimum preheat time for iridium-alloy billets was decreased from 4 to $3 \mathrm{~h}$. The minimum reheat time in the event of an aborted extrusion attempt was set at $1 \mathrm{~h}$. A similar analysis of the cooling of the canned billet is shown in Fig. 22. On this basis, a minimum temperature of $1300^{\circ} \mathrm{C}$ is reached in 0.4 min under the least favorable assumptions, providing some justiffcation for the 25-s maximum transfer time permitted for iridium-alloy extrusions.

This analysis of thermometry in the preheating furnace included evaluation of thermocouple degradation at $1450^{\circ} \mathrm{C}$ as well as temperature gradients within the furnace. A Type $S$ thermocouple placed in an alumina protection tube was heated at $1450^{\circ} \mathrm{C}$ for $4 \mathrm{~h}$. The drift in the calibration was determined by a "homogeneity" test to be about $\pm 5^{\circ} \mathrm{C}$. The temperature gradients in the furnace were measured at 1200 and $1325^{\circ} \mathrm{C}$. The temperature at the center of the furnace was approximately $10^{\circ} \mathrm{C}$ lower than at the control thermocouple. This was reduced to a $5^{\circ} \mathrm{C}$ difference by relocation of the control thermocouple. The results of the evaluation led to a recommendation to install a new calibrated Type $S$ thermocouple and protection tube for each extrusion in order to reliably measure temperatures to within 5 to $10^{\circ} \mathrm{C}$. This replacement was implemented for all subsequent extrusions. 
ORNL-DWG 89-16855

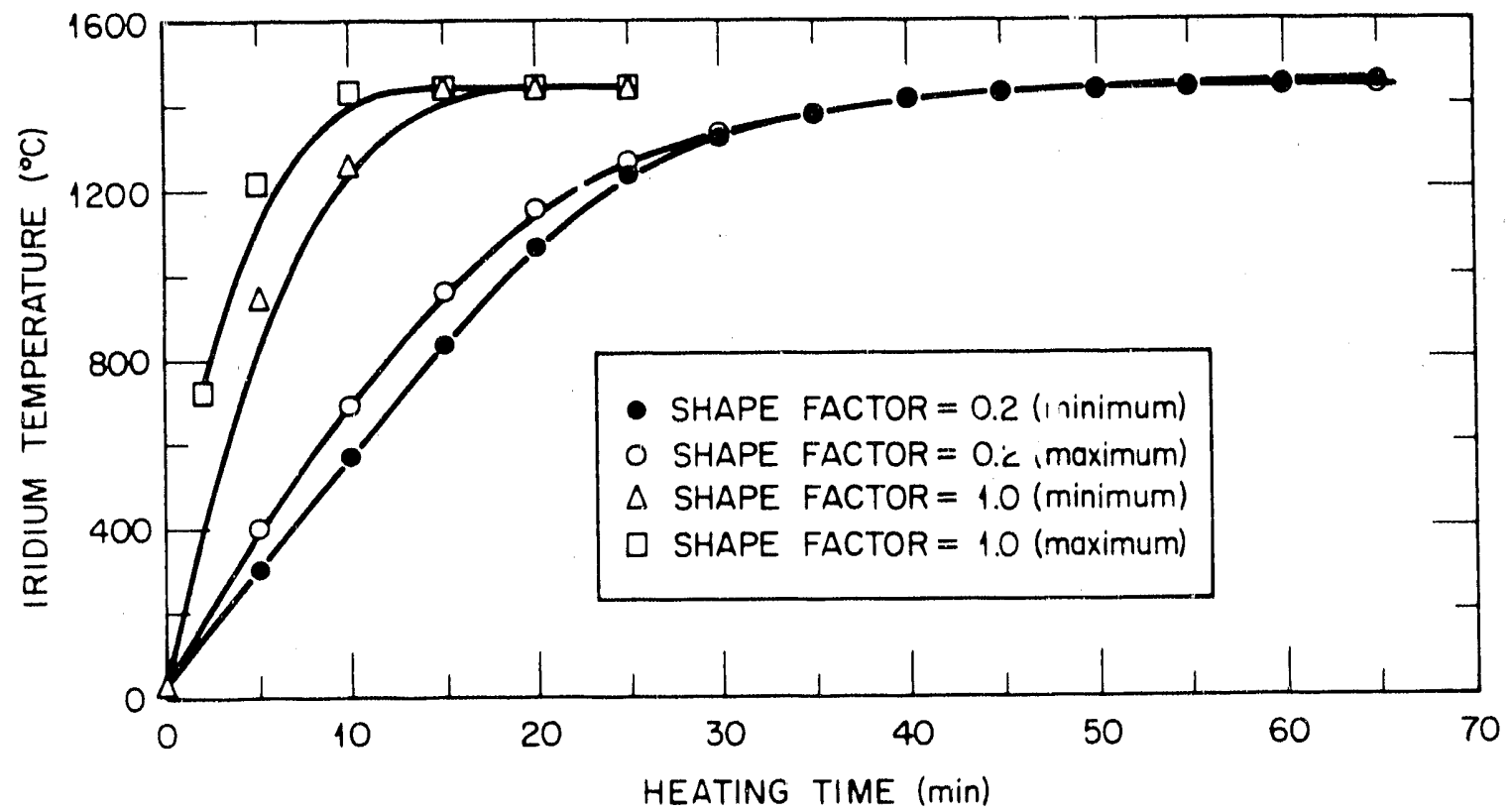

Fig. 21. The calculated heating of a molybdenum-canned iridium ingot showing the center of the ingot to be at temperature within $1 \mathrm{~h}$.

ORNL-DWG 89-16856

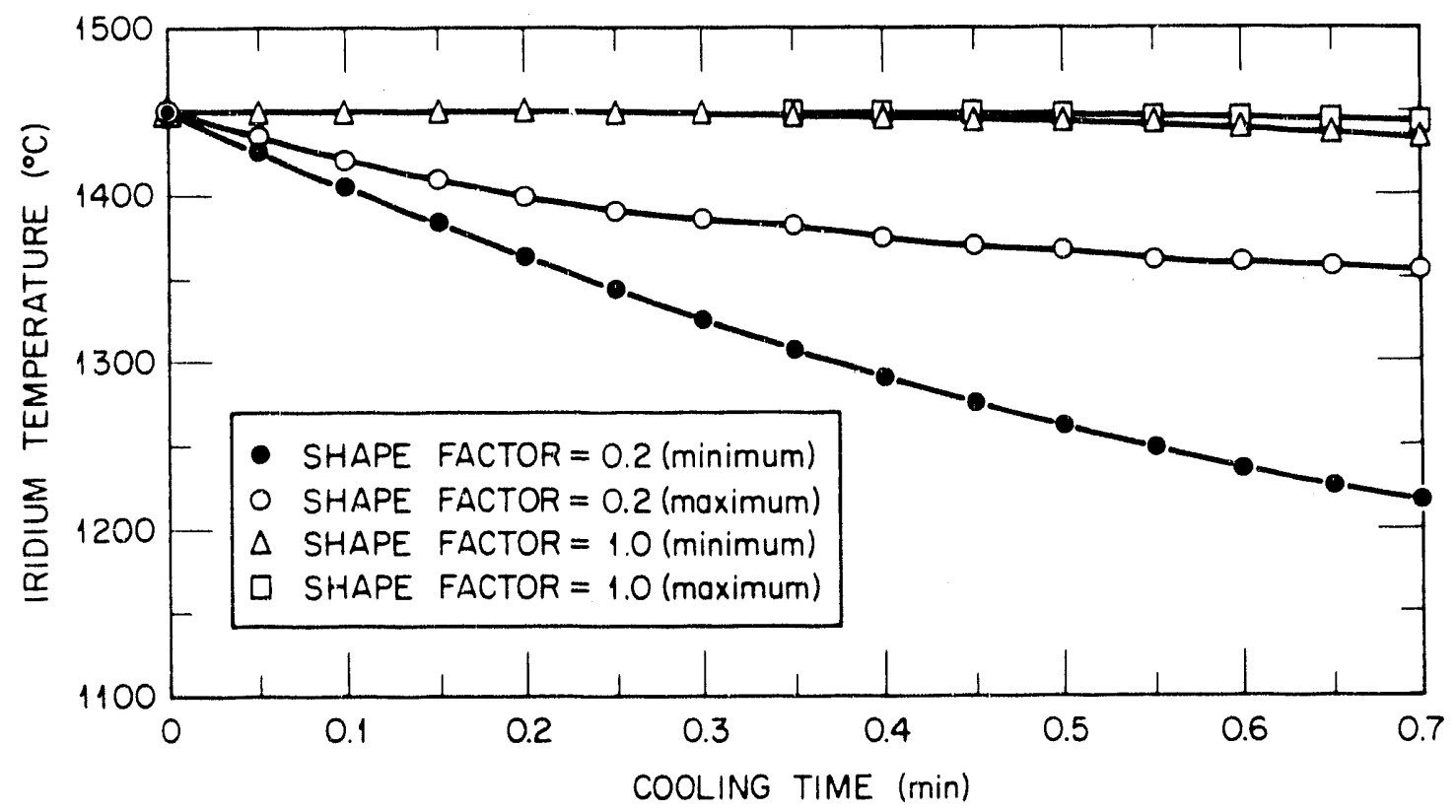

Fig. 22. The calculated cooling of a molybdenum-canned iridium ingot showing that temperatures below $1300^{\circ} \mathrm{C}$ may be at times greater than $30 \mathrm{~s}$. 


\subsubsection{Summary of Process Improvements}

The improvements that were recommended and implemented to increase the reliability of the extrusion process are as follows:

1. Increase preheat temperature from 1325 to $1425^{\circ} \mathrm{C}$.

2. Decrease preheat time from $4 \mathrm{~h}$ to $3 \mathrm{~h}$ minimum and establish a $1-\mathrm{h}$ reheat time for aborted extrusions.

3. Improve temperature measurement by the use of a new control thermocouple and protection tube for each extrusion.

4. Use a mixture of glass powders to provide additional lubrication.

5. Specify a time limit of $25 \mathrm{~s}$ for the transfer of the billet from the furnace to the beginning of the extrusion.

6. Pin the die to the die-backer to prevent misalignment.

7. Use extensive process checklist for all iridium-alloy extrusions.

8. Use calibrated pressure transducers and a new chart recorder to reliably record extrusion load histories.

These improvements have been implemented and used for three successful iridium-alloy extrusions made in the latter part of this fiscal year.

\subsection{EXTRUSIONS USING IMPROVED PROCESS}

Three iridium-alloy extrusions (RS4, CR3, and BF7) have been performed using the improved practice. All were canned in molybdenum in the same way as described previously for the E1 and CR2 except that the top end of the ingot was placed at the nose of the extrusion. They were preheated $i{ }^{\circ} 1425^{\circ} \mathrm{C}$ for $3 \mathrm{~h}$ with a partial argon cover. Each billet was removed from the furnace and rolled in a mixture of $67 \% 567$ glass powder and $33 \% 3 \mathrm{~KB}$ glass powder. Transfer times and billet length are shown in Table 5. The 
Table 5. Transfer times and billet length for three extrusions

\begin{tabular}{ccccc}
\hline & & \multicolumn{3}{c}{ Elapsed time (s) } \\
\cline { 3 - 5 } $\begin{array}{c}\text { Extrusion } \\
\text { No. }\end{array}$ & $\begin{array}{c}\text { Length } \\
(\mathrm{mm})\end{array}$ & In liner & Begin load & Complete \\
\hline RS4 & 176 & 16 & 24 & 32 \\
CR3 & 206 & 16 & 26 & 36 \\
BF7 & 178 & 12 & 23 & 30 \\
\hline
\end{tabular}

zirconia-coated dies and the lubrication of the liner and dies were identical to those described for E1 and CR2. Pinning of the die to the die-backer was done in each case.

The three extrusions were successfully made. The load curves are shown in Fig. 23. In each case, the load increases rapidly in the first $2 \mathrm{~s}$. The CR3 extrusion shows a small indication of a breakthrough load, characterized by a load drop following the transient deformation flow at the nose. The lack of breakthrough load is associated with the lower flow stress of the molybdenum nose as compared to the iridium alloy. The $K$-factor increases continuously from 500 to $570 \mathrm{MPa}$ for RS4 over the course of the extrusion of the iridium alloy but the $K$-factor is a nearly constant $510 \mathrm{MPa}$ for BF7. The CR3 extrusion, which took longer because of the greater billet length, shows an initial increase from 530 to $580 \mathrm{MPa}$ for about the first half of the extrusion, followed by a gradual decrease to $500 \mathrm{MPa}$. The load or $K$-factor during an extrusion depends on both frictional effects and the flow characteristics of the material, which are affected by cooling of the billet from conduction and radiation and by the heat input from both the deformation and friction. Although the slight differences in behavior of the three extrusions cannot be easily explained, the most important result is that the maximum load is significantly lower than the press capacity as indicated on the curves by the bottom-out condition when the stem contacts the container. The maximum load experienced was about $88 \%$ of press capacity. 


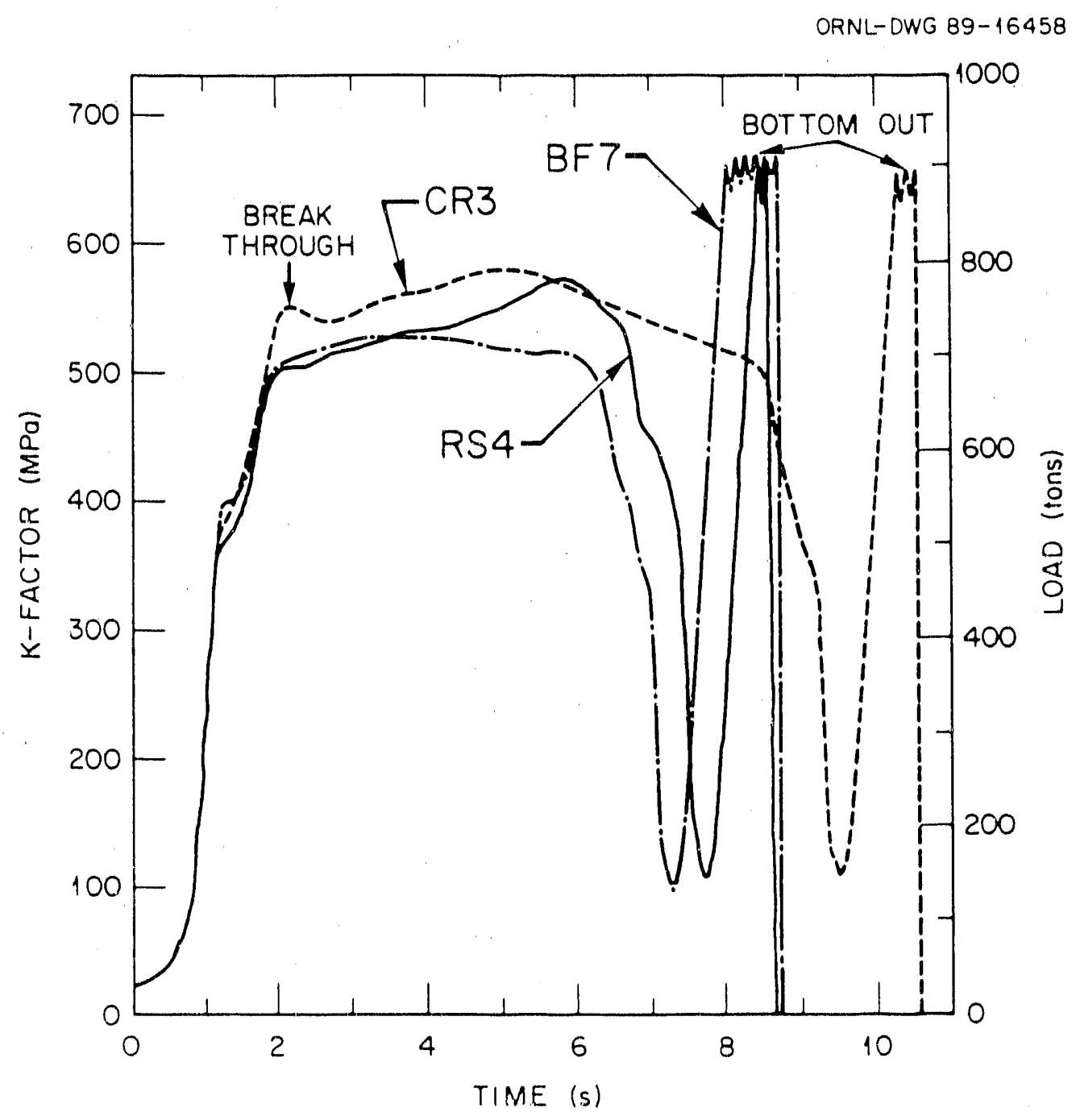

Fig. 23. The load curves for RS4, CR3, and BF7 ingots, extruded using the improved process, showing maximum load significantly below the press capacity.

Following the extrusions, the molybdenum can material was chemically removed from the iridium-alloy bar. The bars were each cut to a length of about $10 \mathrm{~cm}$, and the CR3 and BF7 material was electrolytically cleaned in the $\mathrm{KCN}$ solution before rolling. The RS4 material was similarly cleaned and remelted to produce another electrode. One extruded section was ground and ultrasonically inspected, as discussed later. Metallographic samples were taken from the nose and tail regions of each extrusion. 


\subsection{EXTRUSION MICROSTRUCTURES}

The microstructures of the three extrusions performed at $1425^{\circ} \mathrm{C}$ have been examined in order to determine the effect of increased preheat temperature. In the early stages of development of the extrusion process for iridium alloys, it was believed that a worked structure was necessary to avoid edge cracking during subsequent rolling of the extruded material. The first two extrusions, B1 and B2, were performed using preheat temperatures of 1200 and $1250^{\circ} \mathrm{C}$. The microstructure of the $\mathrm{B} 2$ extrusion showed about $50 \%$ recrystallization. The later D1 extrusion was performed with a $1325^{\circ} \mathrm{C}$ preheat temperature and showed no recrystallization. The microstructure of the E1 extrusion, also performed with $1325^{\circ} \mathrm{C}$ preheat shows substantial recrystallization both in the nose and tail regions as seen in Fig. 24.

The RS4 extrusion, preheated at $1425^{\circ} \mathrm{C}$, has a partially recrystallized structure. The sample from the nose of the extrusion [Fig. 25(a)] shows deformation of the coarse cast grains with about $10 \%$ recrystallization. The tail sample, shown in Fig. 25(b), exhibits evidence of the original cast grain boundaries with about $90 \%$ recrystallization of very fine grains of 10 to $50 \mu \mathrm{m}$ in diameter. The CR3 ingot, extruded under the same conditions, shows a similar microstructure in the nose portion [Fig. 26(a)] but no evidence of recrystallization within the tail sample [Fig. 26(b)]. The BF7 ingot, with the DOP-4 composition, is expected to have a somewhat lower recrystallization temperature. In contrast to the other two extrusions in this group, it shows complete recrystallization in the nose section [Fig. 27(a)]. The tail section [Fig. 27(b)] is approximately 50\% recrystallized.

The lack of a simple correlation between an extrusion preheat temperature and extruded microstructure, seen previously for the extrusions preheated at 1200 and $1325^{\circ} \mathrm{C}$, continues to be the case for the three extrusions preheated at $1425^{\circ} \mathrm{C}$. Factors that may 
Y 215148

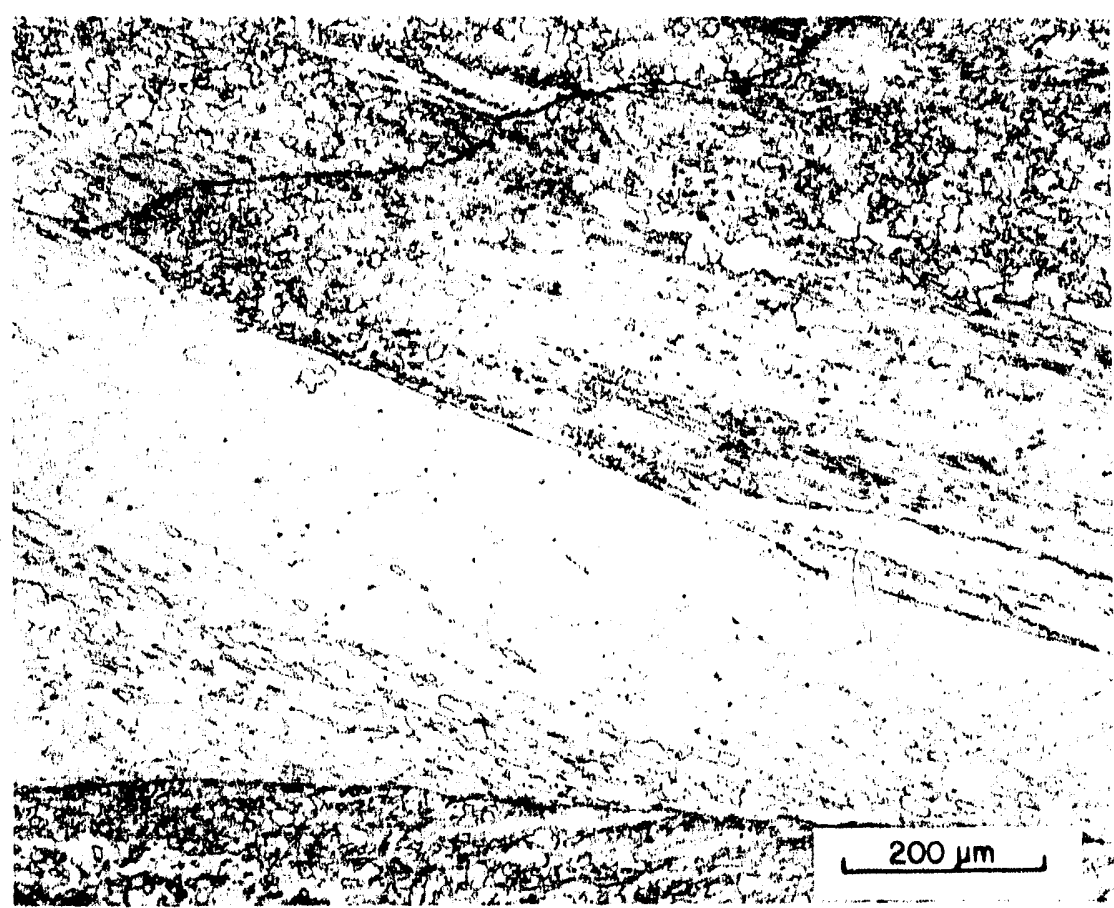

(a)

Y 215149

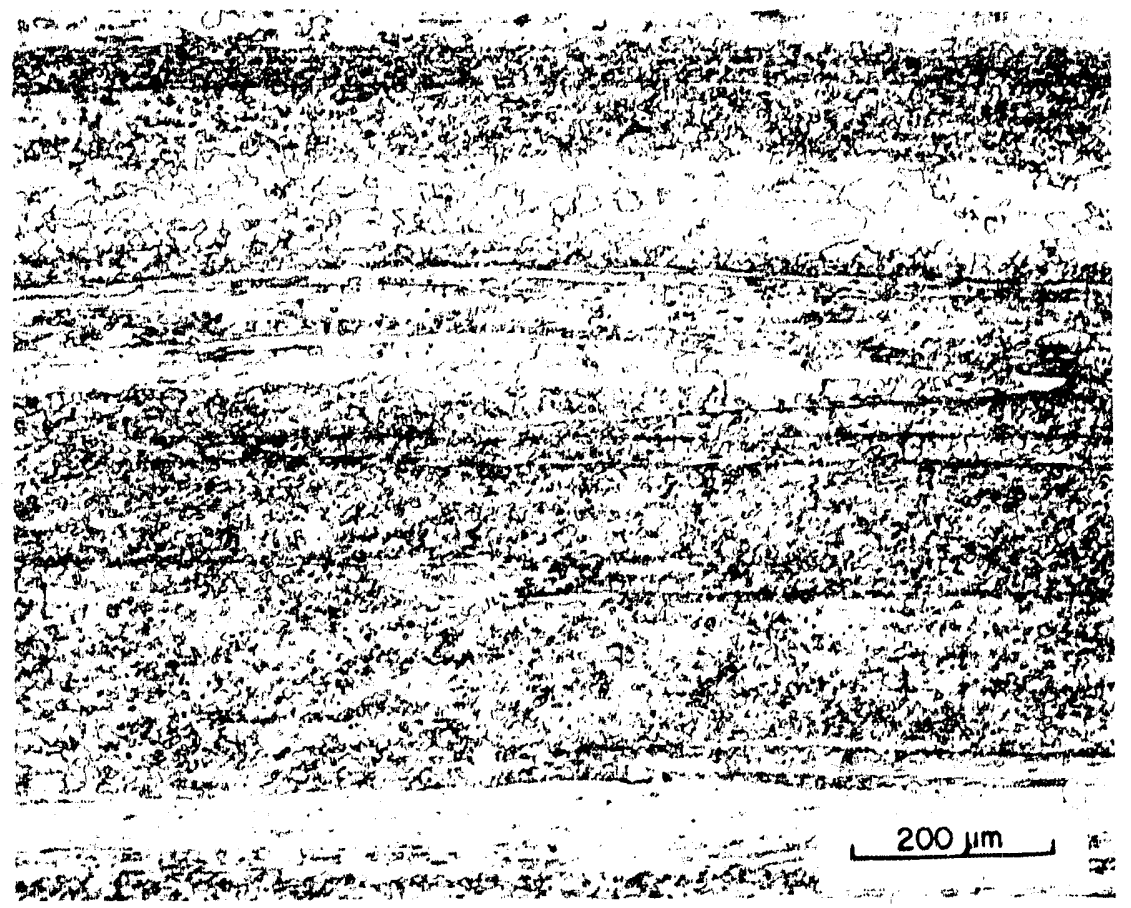

(b)

Fig. 24. Microstructure of the E1 extrusion showing partial recrystallization of both the $(a)$ nose region and $(b)$ tail region. 


\section{Y 215151}

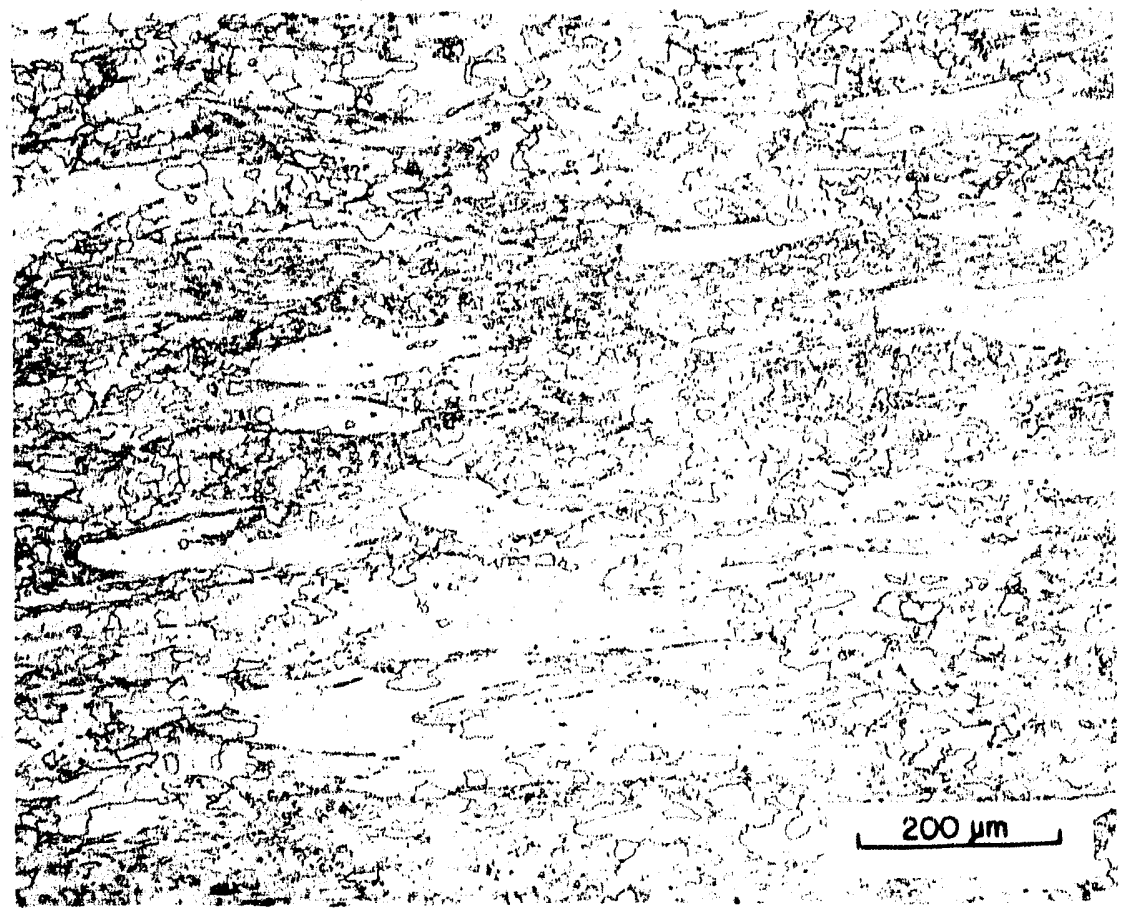

(a)

Y 215152

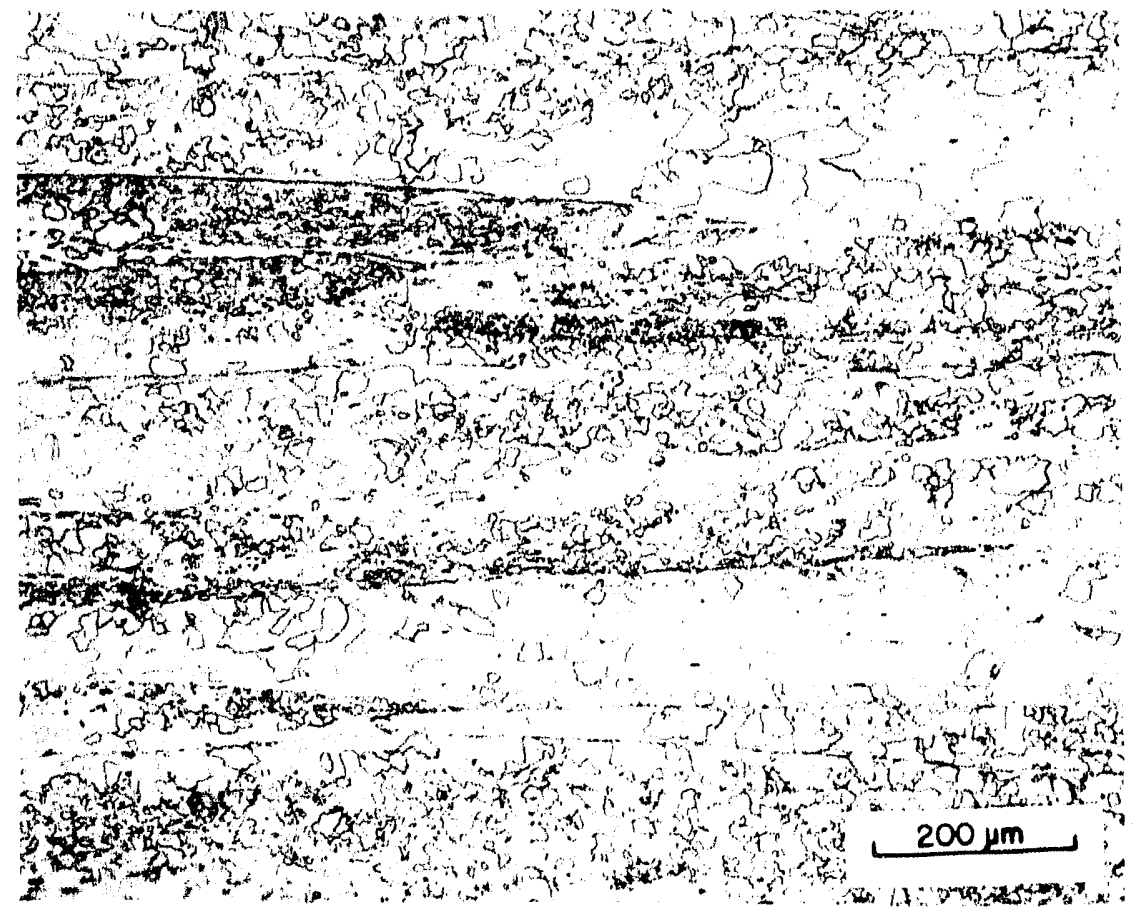

\section{(b)}

Fig. 25. Microstructure of the RS4 extrusion showing (a) about $10 \%$ recrystallization in the nose region and $(b)$ about $90 \%$ recrystallization in the tail region. 
Y 215153

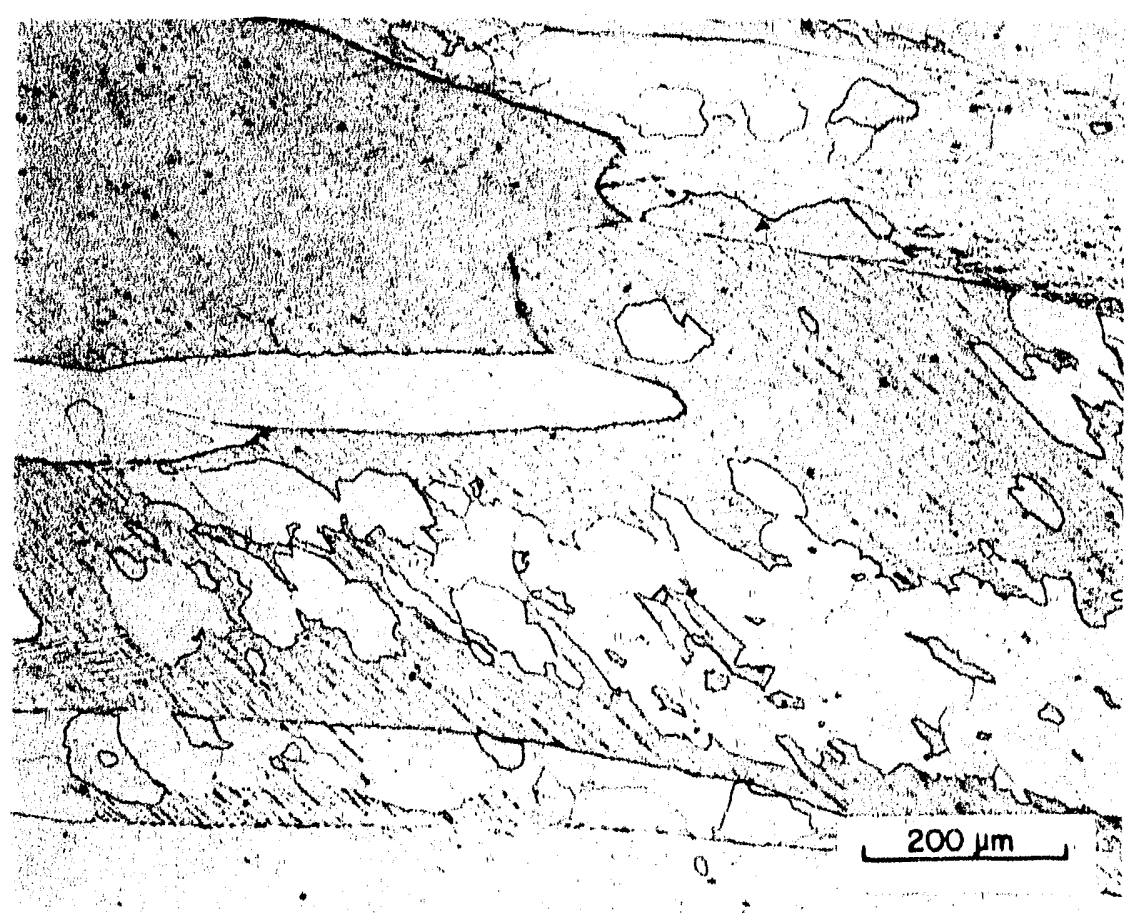

(a)

Y 215154

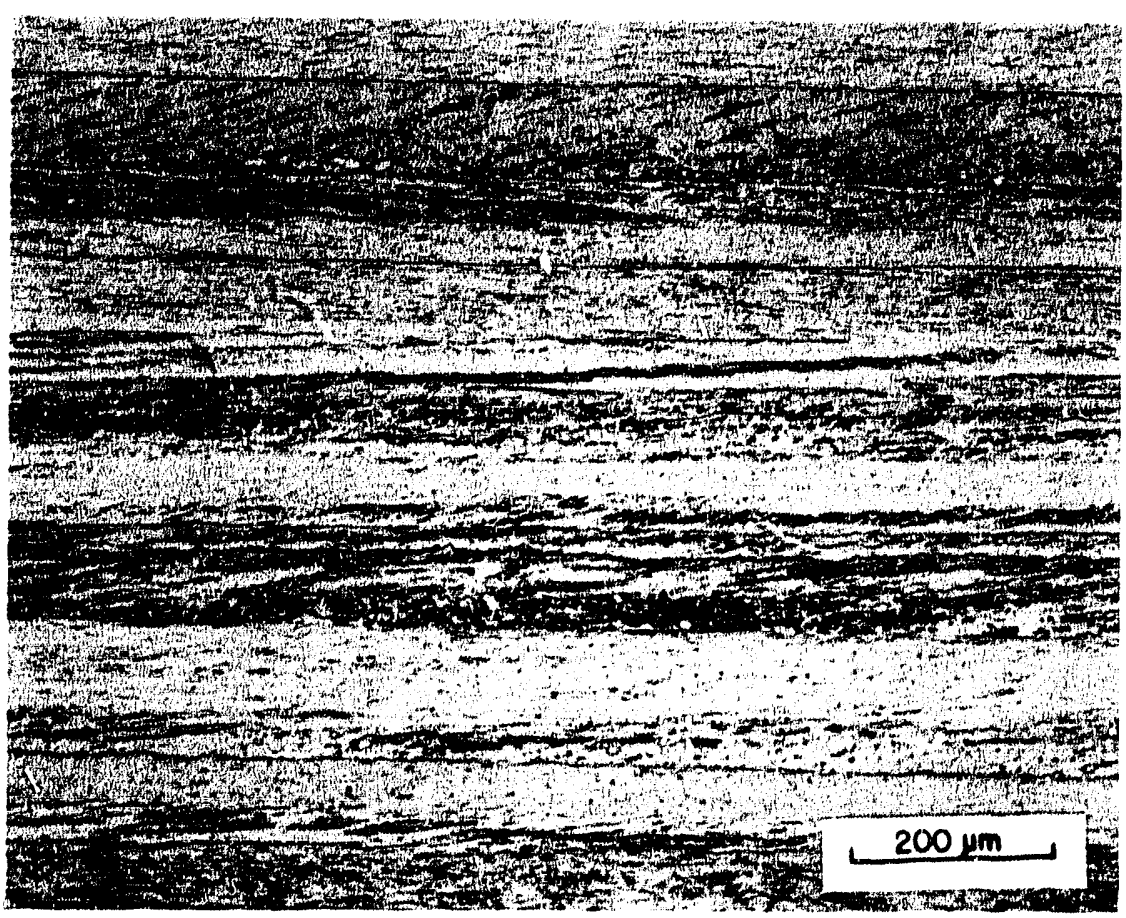

(b)

Fig. 26. Microstructure of the CR3 extrusion showing (a) the nose region with approximately $50 \%$ recrystallization and $(b)$ the tail region with essentially no recrystallization. 
Y 215155

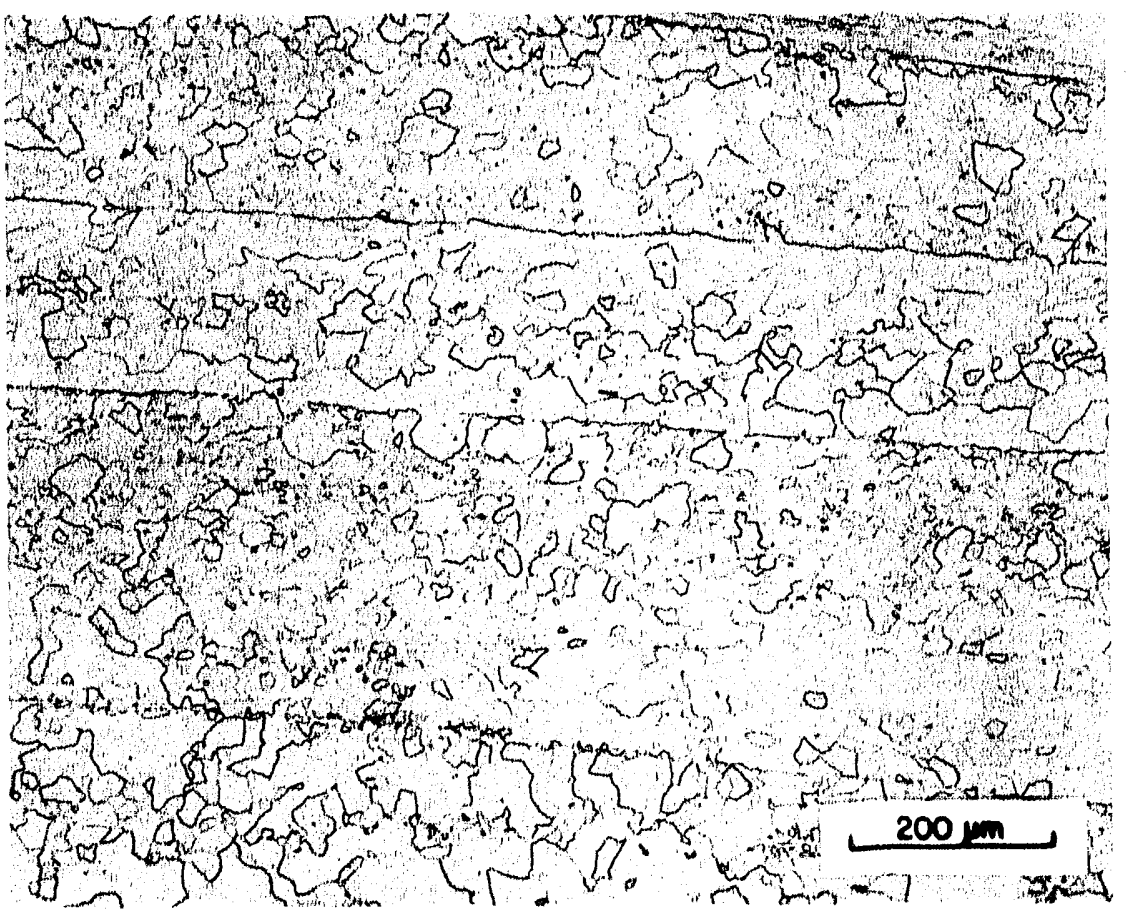

(a)

Y 215156

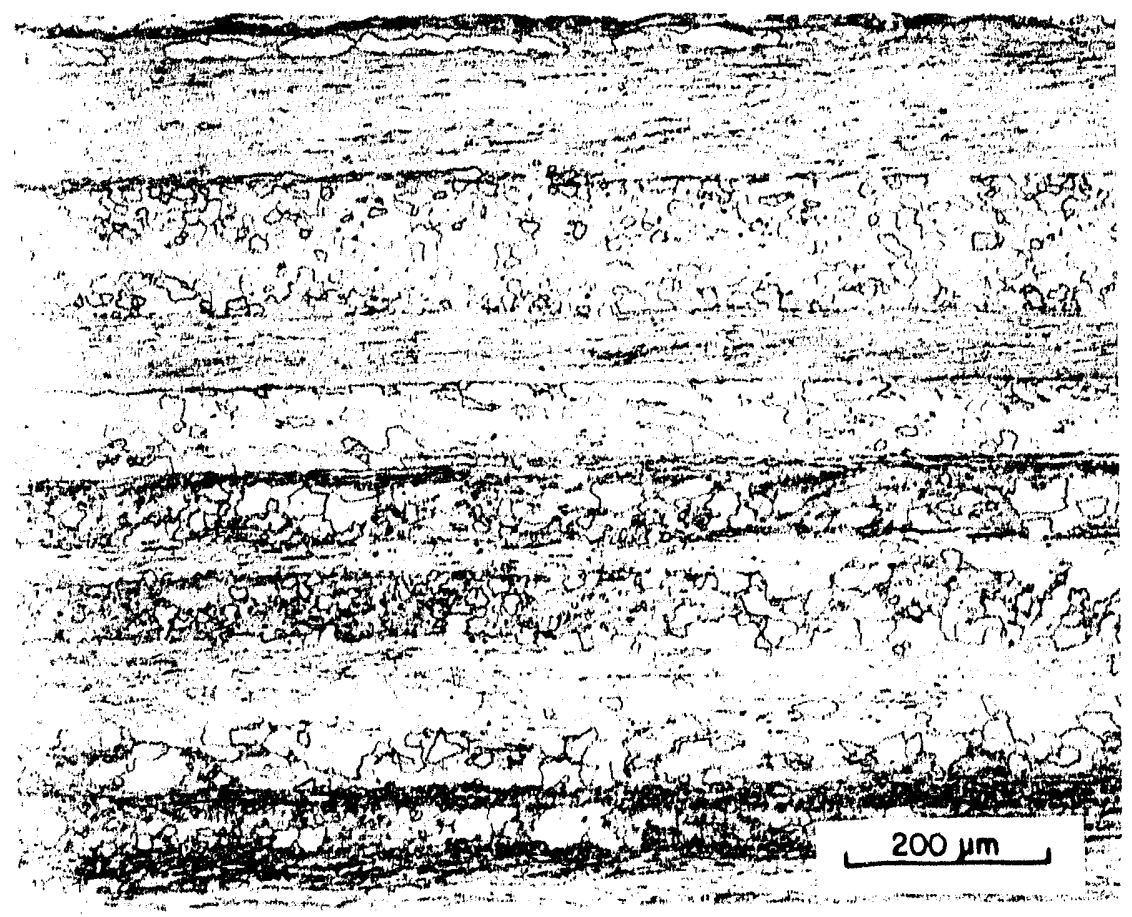

(b)

Fig. 27. Microstructure of the BF7 extrusion showing (a) complete recrystallization in the nose region and (b) $50 \%$ recrystallization in the tail region. 
contribute to this are local variations in orientation of cast grains that may cause differences in recrystallization behavior and minor changes in the temperatures in the vicinity of the die that may have large effects on the appearance of the extruded microstructure. These variations in as-extruded microstructure have no effect on the microstructure of the finish rolled blaiks and foil because of the extensive cold working and in-process recrystallization steps following the extrusion.

\subsection{ULTRASONIC EXAMINATION OF AN EXTRUSION}

In order to determine the feasibility of ultrasonic examination of extruded sections, a section cut from the nose of the RS4 extrusion was ground flat. An ultrasonic examination that was performed in a transmission mode showed a black area representing good transmission through the specimen. The ultrasonic map of the specimen (Fig. 28) outlines the rectangular specimen. The map clearly shows a $1.5-\mathrm{mm}$-diam flat bottom hole (the small white area of poor transmission of sound) as well as a lamination or pore in the extrusion (white area at extreme left), which is probably a result of a pore just below the top surface of the original ingot. Rounding of the edges of the extrusion appears as nonuniformity in the width of the image. The ultrasonic map shown in Fig. 29 is of the same material, but at a reduced decibel level. It shows that the extruded structure contains the deformed grains of the original casting. These grains are contorted in the vicinity of the nose of the extrusion and aligned and elongated in the extrusion direction at other locations. This is consistent with the metallographic results for the extrusions discussed previously. The ultrasonic results indicate that extrusions may be inspectable by this technique, but the loss of material associated with grinding of the surfaces (15\% in this case) is too large to justify routine usage. 
YP8575
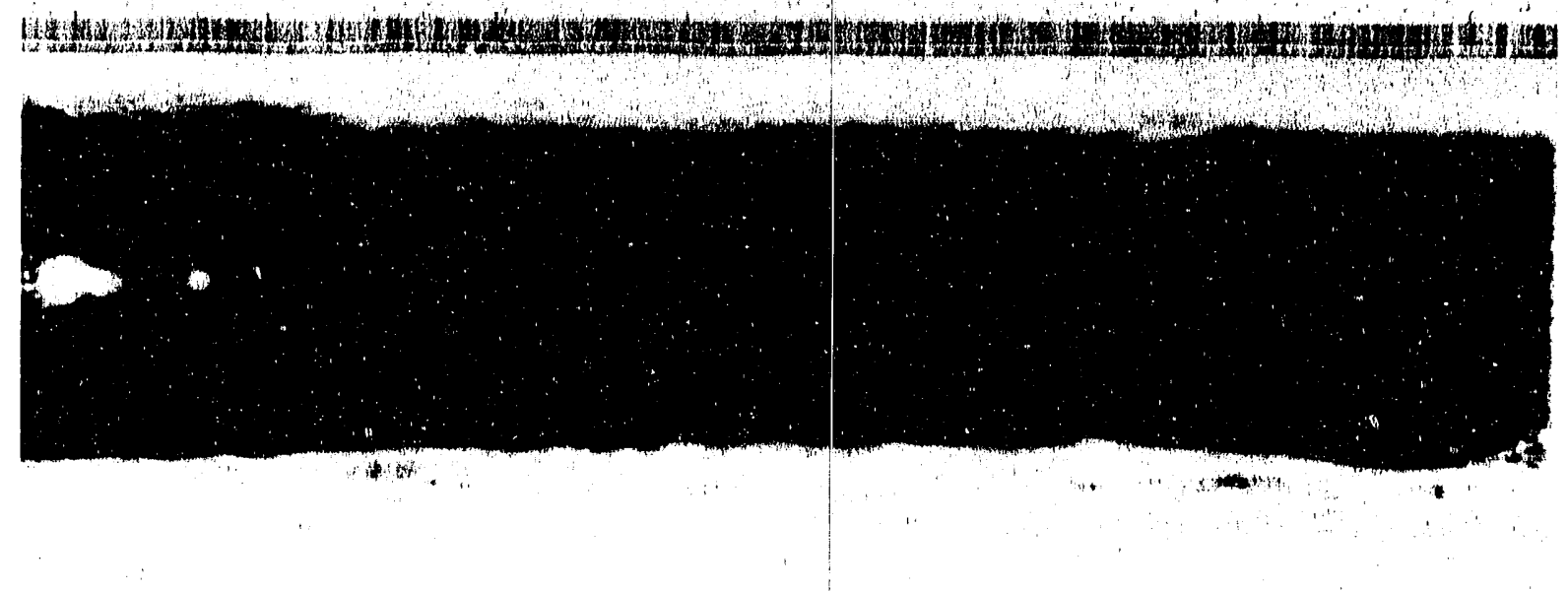

Fig. 28. Ultrasonic map of the nose from the RS4 extrusion showing a 1.5-mm-diam reference hole (the small circular white area) and a residual pore from just below the top surface of the original ingot (the white area at the extreme left).

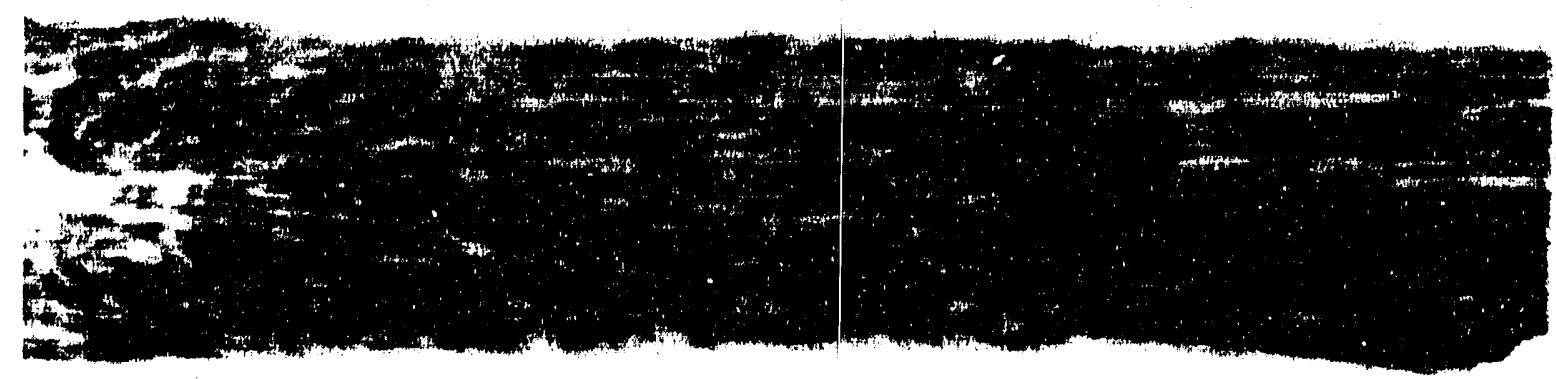

Fig. 29. Ultrasonic map of the nose from the RS4 extrusion showing the extruded structure.

\section{ROLLING OF SHEET PRODUCTS}

The materials rolled to sheet during the course of the year include E1, CR3, and BF7 extrusions and a total of five small drop-cast ingots for experimental studies. Metallographic examination of the test pieces taken from three sheets of the $\mathrm{E} 1$ ingot showed greater than the permitted $5 \%$ recrystallization following stress-relieving at $970^{\circ} \mathrm{C}$. Further investigation indicated that the recrystallization occurred during rolling and was 
present before stress-relieving. The rolling schedule was modified to minimize the likelihood of recrystallization. Preliminary results from the CR3 sheets rolled according to the new schedule show acceptable microstructures.

\subsection{ROLLING OF E1 SHEET}

A total of nine billets from the E1 extrusion were rolled to sheet initially using the rolling schedule from procedure MET-MatP-SOP-101, Rev. 0, as described in Table 6 for the 63-mm-diam extrusion. The procedural instructions are identical to those used for previous 51-mm-diam ingots, although the reductions at each step vary because of different initial dimensions of the rolling billet.

Table 6. Iridium-alloy sheet-rolling schedules for blank production

\begin{tabular}{|c|c|c|c|c|}
\hline & \multirow{2}{*}{ 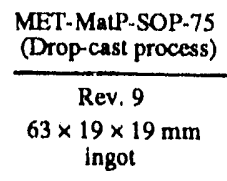 } & \multicolumn{3}{|c|}{$\begin{array}{l}\text { MET-MatP-SOP-101 } \\
\text { (Consumable arc-melt and extrusion process) }\end{array}$} \\
\hline & & $\begin{array}{c}\text { Rev. } 0 \\
\text { 51-mm-diam } \\
\text { ingot }\end{array}$ & $\begin{array}{c}\text { Rev. } 0 \\
\text { 63-mm-diam } \\
\text { ingol }\end{array}$ & $\begin{array}{c}\text { Rev. } 1 \\
\text { 63-mm-diam } \\
\text { ingod }\end{array}$ \\
\hline $\begin{array}{l}\text { Rolling billet dimensions } \\
\mathrm{mm}(1 \times w \times t)\end{array}$ & $63 \times 19 \times 19$ & $80 \times 28 \times 12$ & $50 \times 42 \times 12$ & $50 \times 42 \times 12$ \\
\hline Homogenization & $4 \mathrm{~h}$ at $1500^{\circ} \mathrm{C}$ & $\mathrm{N} / \mathrm{A}^{a}$ & N/A & N/A \\
\hline $\begin{array}{l}\text { Breakdown rolling with } \\
\text { with } 1200^{\circ} \mathrm{C} \text { preheat }\end{array}$ & $\begin{array}{l}\text { Long and cross roll, } \\
\text { two passes each }\end{array}$ & $\begin{array}{l}\text { Cross roll to } \\
70 \cdot \mathrm{mm} \mathrm{w}\end{array}$ & $\begin{array}{l}\text { Cross roll to } \\
70-\mathrm{mm} \mathrm{w}\end{array}$ & $\begin{array}{l}\text { Cross roll to } \\
70-\mathrm{mm} w_{1} \\
\text { then lcng } \\
\text { roll to } \\
-4.5 \mathrm{~mm} \mathrm{t}\end{array}$ \\
\hline $\begin{array}{l}\text { Reduction in thickness } \\
\text { at } 1200^{\circ} \mathrm{C}\end{array}$ & $\sim 70 \%$ & $\sim 60 \%$ & $\sim 40 \%$ & $-60 \%$ \\
\hline Recrystallization & $1 \mathrm{~h}$ at $1400^{\circ} \mathrm{C}$ & I h at $1300^{\circ} \mathrm{C}$ & $1 \mathrm{~h}$ at $1300^{\circ} \mathrm{C}$ & $1 \mathrm{~h}$ at $1300^{\circ} \mathrm{C}$ \\
\hline \multirow[t]{2}{*}{ Thickness, mm } & $\sim 5.6$ & $\sim 4.5$ & $\sim 7.5$ & $\sim 4.5$ \\
\hline & \multicolumn{3}{|c|}{ Further reduction in thickness } & \\
\hline $\begin{array}{l}\text { Cross roll with } 1150^{\circ} \mathrm{C} \\
\text { preheal }\end{array}$ & $\sim 45 \%$ & $N / A$ & N/A & N/A \\
\hline $\begin{array}{l}\text { Long roll with } 1100^{\circ} \mathrm{C} \\
\text { preheat }\end{array}$ & $\sim 45 \%$ & $\sim 78 \%$ & $\sim 87 \%$ & $\sim 60 \%$ \\
\hline $\begin{array}{l}\text { Long roll with } 1000^{\circ} \mathrm{C} \\
\text { preheat }\end{array}$ & $\begin{array}{l}-35 \% \\
(101.0 \mathrm{~mm})\end{array}$ & $\mathrm{N} / \mathrm{A}$ & N/A & $\begin{array}{l}-45 \% \\
(101.0 \mathrm{~mm})\end{array}$ \\
\hline $\begin{array}{l}\text { Bare roll with } 900^{\circ} \mathrm{C} \\
\text { preheal to } 0.80 \cdot \mathrm{mm} \\
\text { thickness }\end{array}$ & $01020 \%$ & 0 to $20 \%$ & 0 to $20 \%$ & $01020 \%$ \\
\hline
\end{tabular}

$a_{N} / \mathrm{A}=$ nor applicable. 
Metallographic analysis of samples of the E1 sheets stress-relieved at $970^{\circ} \mathrm{C}$ for $1 \mathrm{~h}$ was performed using standard procedures to determine microstructure and hardness. The metallographic analysis for samples from three sheets (E1-5, E1-6, and E1-10) showed recrystallization in excess of the permitted 5\%. An example is shown in Fig. 30. Samples from two other sheets (E1-4 and E1-9) show some indication of recrystallization, but within acceptable limits (see Fig. 31). The samples from E1-2, E1-3, and E1-7 sheets show no evidence of recrystallization. The E1-8 sheet split during bare rolling and was not processed to blanks. Metallographic examination of this material showed a substantial number of recrystallized grains but fewer than the maximum allowable level. Sheet E1-1 was rolled using an experimental procedure, which included both cross rolling and long rolling of the starting billet to achieve a sheet thickness at recrystallization similar to that obtained with the 51-mm-diam billets. This sheet, following bare rolling, also showed excessive recrystallization on a sample from the nose end and substantial, but not exctssive, recrystallization of a sample from the center of the sheet. The results strongly suggest that the excessive recrystallization of the three production sheets occurred before the stress-relief treatment at $970^{\circ} \mathrm{C}$. This was further supported by metallographic analysis of E1-1 materials stress-relieved for $1 \mathrm{~h}$ at 935,1000 , and $1030^{\circ} \mathrm{C}$, all of which show similar microstructure to the materials not stress-relieved.

\subsection{REVISION OF ROLLING PROCEDURE}

A revised rolling schedule was implemented following the metallographic analysis of the E1 sheets. The schedule, which is shown as procedure MET-MatP-SOP-101, Rev. 1, in Table 6, is designed to minimize the likelihood of recrystallization in the microstructure of the finished sheet and to use processing parameters at each step that are based on either the earlier revision of the procedure or procedure MET-MatP-SOP-75, Rev. 9, used 
Y 213031

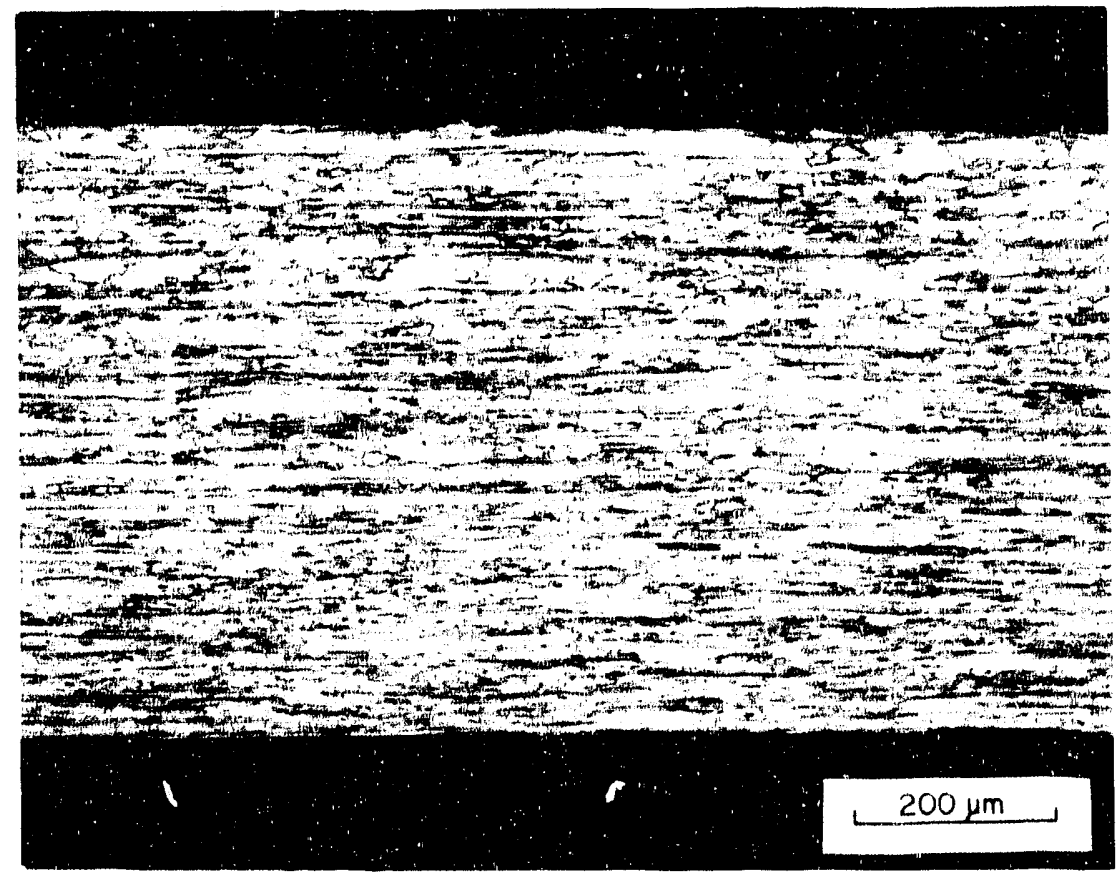

Fig. 30. Microstructure of sheet E1-6 showing recrystallization in excess of $5 \%$.

Y 213032

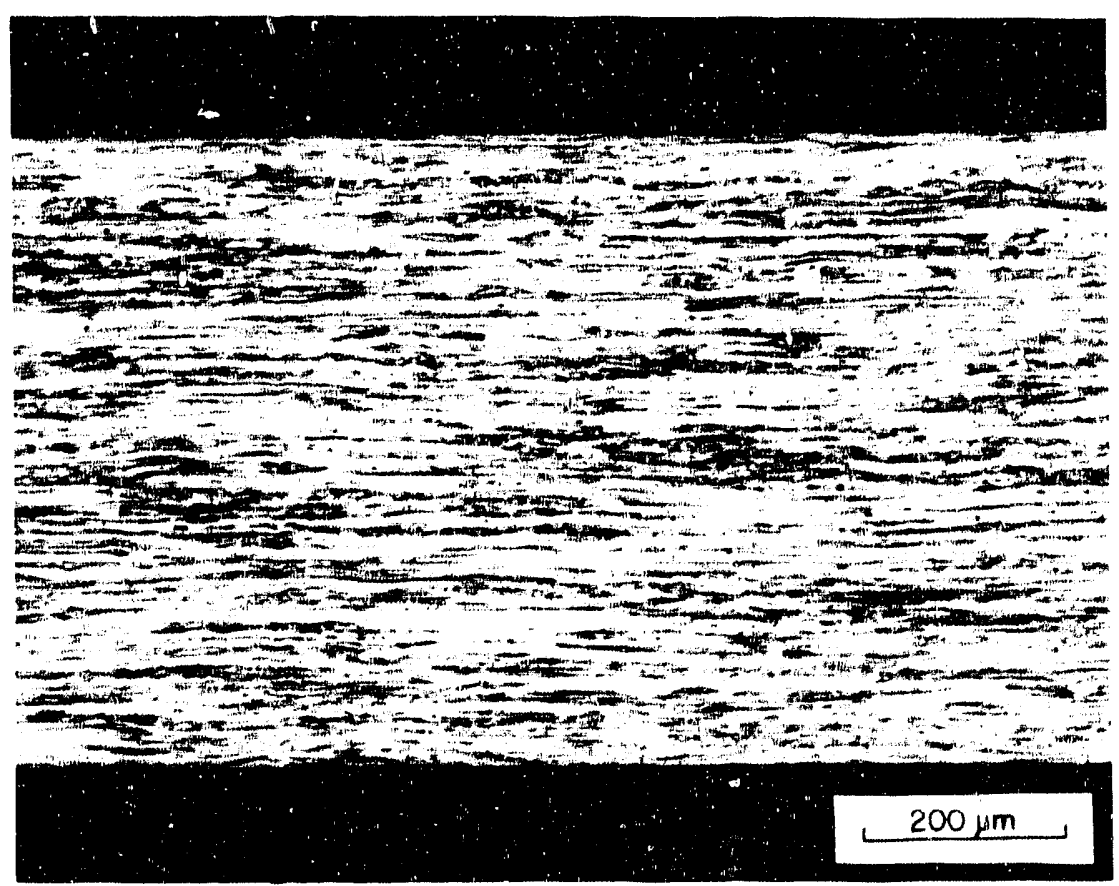

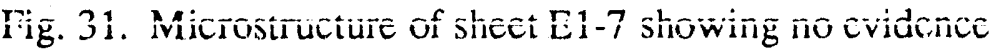
of recrystallization. 
previously for small drop-cast ingots. The breakdown rolling with $1200^{\circ} \mathrm{C}$ preheat includes both cross rolling and long rolling with a total reduction in thickness of $60 \%$. The total reduction following recrystallization is the same as that previously obtained for 51 -mm-diam ingots. The rolling at $1000^{\circ} \mathrm{C}$, which was previously performed using procedure ME'T-MatP-SOP-75, Rev. 9, is included in the revised procedure to use with 63-mm-diam ingots. In addition, the stress-relief temperature is reduced to $900^{\circ} \mathrm{C}$ as was specified in procedure MET-MatP-SOP-75, Rev. 9.

\subsection{ROLLING OF CR3 SHEET}

A total of 17 sheets were rolled from the CR3 extrusion in according to procedure MET-MatP-SOP-101, Rev. 1. The microstructure following breakdown rolling with $1200^{\circ} \mathrm{C}$ preheat shows substantial recrystallization, as seen in Fig. 32. The microstructure following recrystallization shown in Fig. 33 does show evidence of the grain boundaries in the original casting in the form of several lengths of horizontally aligned boundaries. Metallographic evaluation of the first six sheets following bare rolling and stress-relieving showed recrystallization to be well within acceptable limits. A total of 31 blanks were produced from these sheets. This was less than the expected seven blanks per sheet because of rolling to greater than optimal width that decreased length and contributed to some splitting during bare roll. The remaining eight sheets have been rolled and laid out to produce 52 blanks. A few potential blanks were lost because of greater than normal edge cracking. This is the result of an average gage thickness of $1.1 \mathrm{~mm}$ following covered rolling rather than $1.0 \mathrm{~mm}$, the aim thickness. A greater reduction during bare rolling to the finish thickness created more opportunity for edge cracking. The specification of about $1.0 \mathrm{~mm}$ may need to be made more specific. However, there are practical difficulties in recovering sheets at this point in the rolling schedule which need additional evaluation. 
Y 215157

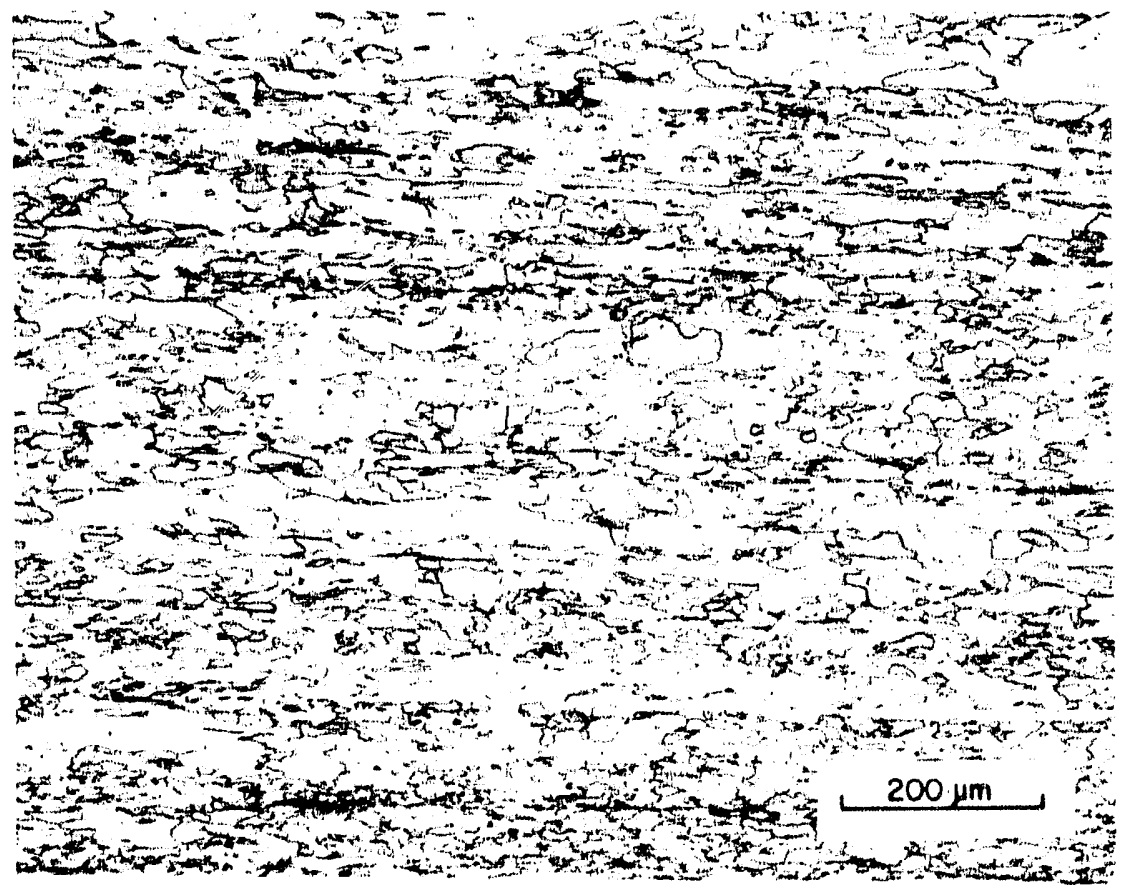

Fig. 32. Microstructure of CR3 sheet following breakdown rolling with $1200^{\circ} \mathrm{C}$ preheat temperature showing substantial recrystallization structure.

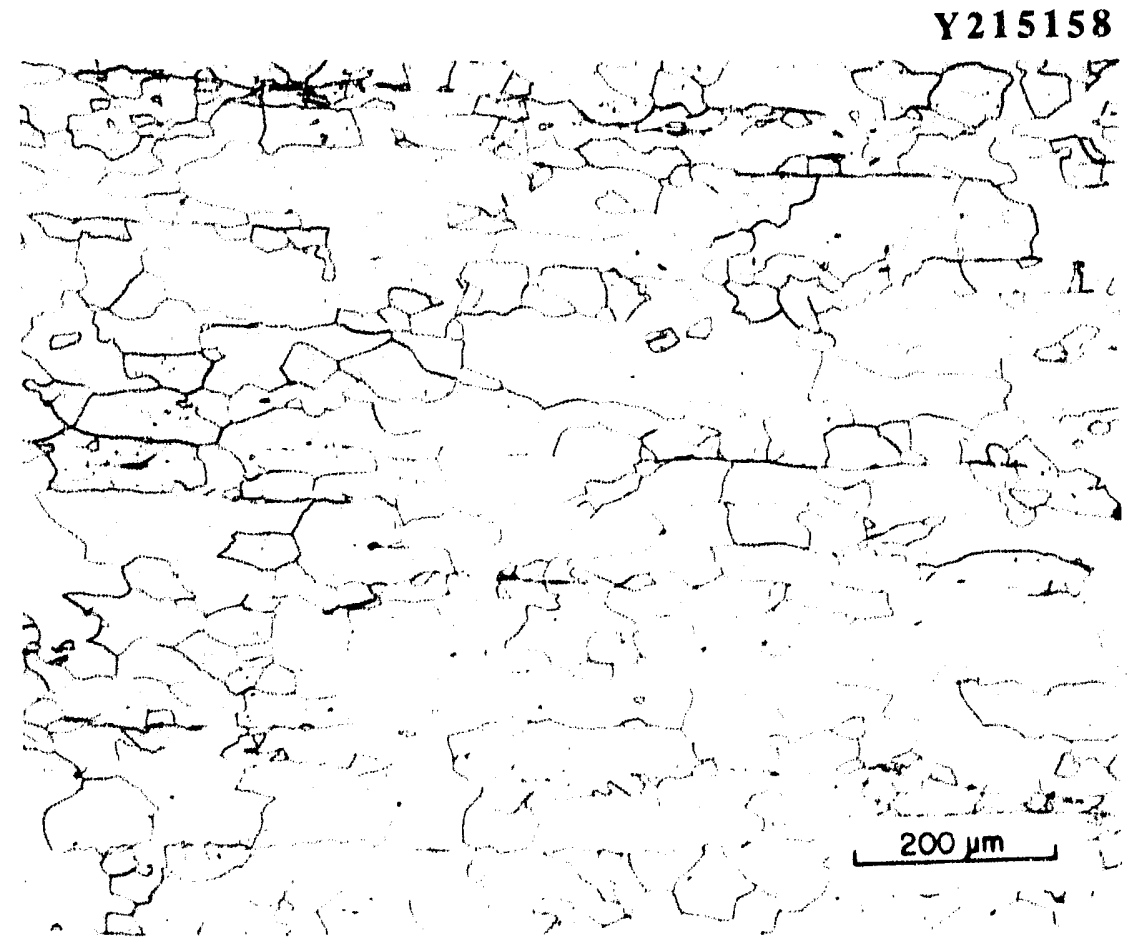

Fig. 33. Microstructure of CR3 sheet following recrystallization at $1300^{\circ} \mathrm{C}$ showing evidence of original grain boundaries in the arc-melted ingot. 


\subsection{ROLLING OF FOIL}

Foil rolling activities included the production of $0.05 \mathrm{~m}^{2}$ of foil from the EF-802 drop-cast ingot for use at the Y-12 Plant and the initial processing of two rolling billets (BF7-1 and BF7-2) to produce up to $0.3 \mathrm{~m}^{2}$ of foil. The foil from EF-802 met all dimensional, compositional, and nondestructive testing requirements and was shipped during January 1989. The BF7 material has been rolled to $0.75-\mathrm{mm}(0.03-$ in.) thickness. In order to improve the foil surface finish, it is planned to diamond grind the carbide rolls immediately before their use for foil rolling.

\section{INSPECTIONS AND QUALIFICATION}

Inspection of blanks from the $\mathrm{E} 1$ ingot includes nondestructive testing and chemical analysis as well as the metallographic analysis previously discussed. The procedures used for nondestructive testing consists of an ultrasonic inspection, using a 0.750 -mm-diam flat bottom hole standard, a dye-penetrant inspection with fluorescent die and a visual inspection at a magnification of $30 \times$. The D-batch powder consisting of $20.1 \mathrm{~kg}$ of powder was qualified for production by tensile impact testing of tensile specimens from the D1 blanks. The E-batch powder consisting of $90.4 \mathrm{~kg}$ of powder was qualified for production by tensile impact testing of specimens from the E1 blanks.

\subsection{NONDESTRUCTIVE TESTING OF E1 BLANKS}

The results of the ultrasonic inspection of the blanks is shown in Table 7. A total of 17 blanks passed the ultrasonic inspection. All the passed blanks came from the nose half of the extrusion, which also corresponds to the bottom half of the arc-melted ingot. 
Table 7. Results from ultrasonic inspection of E1 blanks

\begin{tabular}{|c|c|c|c|}
\hline \multirow{2}{*}{ Sheet } & \multicolumn{2}{|c|}{ No. of blanks } & \multirow{2}{*}{$\begin{array}{c}\text { Identity of } \\
\text { blanks } \\
\text { passing inspection }\end{array}$} \\
\hline & Produced & Passing inspection & \\
\hline $\begin{array}{l}\text { E1-2 } \\
\text { E1-3 } \\
\text { E1-4 } \\
\text { E1-5 } \\
\text { E1-6 } \\
\text { E1-7 } \\
\text { E1-9 } \\
\text { E1-10 }\end{array}$ & $\begin{array}{l}5 \\
5 \\
7 \\
7 \\
7 \\
5 \\
7 \\
7\end{array}$ & $\begin{array}{l}4 \\
1 \\
7 \\
4 \\
1 \\
0 \\
0 \\
0\end{array}$ & $\begin{array}{l}1,2,3,4 \\
4 \\
1,2,3,4.5,6,7 \\
1,2,3,4 \\
7\end{array}$ \\
\hline Total & $\overline{50}$ & $\overline{17}$ & \\
\hline
\end{tabular}

Dye-penetrant inspection showed indications on two blanks (E1-4-1 and E1-4-2) that are heing reworked by sanding. No indications were found from visual inspection.

The ultrasonic inspection of the ingot performed before extrusion shows no correlation with the results at blank inspections. One method of inspection, using a normal beam focused at $6 \mathrm{~mm}$ below the surface, showed only one indication not associated with surface-appearing porosity and this would correlate approximately to the edge region of a portion of E1-5 sheet. A second method of inspection, an angle beam test, showed two indications that were not associated with surface pores. One of these corresponds to the approximate location of the last few blanks of E1-3 and the first few blanks of E1-4. The second corresponds approximately with the first portion of E1-8 sheet. Furthermore, the results of the inspections are similar qualitatively to those obtained for the D1 ingot, which yielded a much higher acceptance of blanks.

In addition to the ultrasonic inspections, the meling record for the $\mathrm{E} 1$ ingot has been examined to determine if any correlation exists with the location of rejected blanks. The 
main feature of the $\mathrm{E} 1$ record is that the arc gap between the electrode and molten pool was larger than normal during the first half of the melt. Although no direct measurement of arc gap can be obtained, the record of arc voltage and electrode position, together with the operator's visual observations, indicates a relatively long (perhaps as much as $10 \mathrm{~cm}$ ) arc with a continuously increasing arc length for the part of the ingot corresponding to E1-2 through E1-6 sheets followed by a rapid decrease in arc length and a relatively short arc length corresponding to E1-9 and E1-10 sheets. These results by themselves suggest a benefit of a long arc gap. However, this conclusion would conflict with both the results obtained for D1, melted with a relatively uniform and short arc length, and with the conventional wisdom of consumable-electrode arc melting.

There is considerable evidence that the partial extrusion of the E1 ingot contributed significantly to the high number of blanks rejected for ultrasonic indications of flaws. The differential cooling of the partial extrusion results in tensile stress on the portion of the extruded bar near the die exit that causes cracks which may propagate toward the nose of the extrusion. The two sections (E1-11 and E1-12) near the die exit region showed visible cracks on their cut ends and were not processed to blanks. Two other sections (E1-7 and E1-8) exhibited visible flaws early in the rolling process and were trimmed to remove obvious cracks.

Thus, there is a strong possibility that smaller cracks and delaminations could have been introduced into the extrusion that resulted in ultrasonic indications of defects in the blanks. There is also experience with a previous partial extrusion that tends to support this hypothesis. The B5 extrusion was performed in January 1987. The tail portion, which did not extrude, was later reheated and extruded to sheet. For the three sheets from the nose end, 10 of 18 blanks were rejected for ultrasonic defects, and the equivalent of 7 additional blanks rejected during ultrasonic inspection of the sheets. In contrast, for the three sheets from the tail portion (at least two of which and probably all three of which were in the 
reheated extrusion) only one blank was rejected for ultrasonic indications. On the basis of these results, a provision for use of partial extrusions has been deleted from the procedures, and all such material must be treated as recycle and remelted.

\subsection{CHEMICAL ANALYSES OF E1 SHEETS}

Results from bulk chemical analyses of the E1 sheets are shown in Table 8. All these analyses are well within the specification. The material contains lower overall impurity levels than sheets produced from B-, C-, or D-batch powders. The single exception is ruthenium, which at 20 to $30 \mathrm{ppm}$ is higher than other new process materials but is similar to some sheets made earlier with standard processing. There is no indication that the omission of the powder-washing step during the processing of E1 has had any effect on the impurity content of the fabricated sheets. Historically, the washing of powder was introduced in order to remove soluble contaminants at a time when the starting material was less pure than that now used. Carbon and oxygen contents and surface impurities by SSMS were within specified limits.

\subsection{NONDESTRUCTIVE TESTING OF CR3 BLANKS}

The results of ultrasonic testing of blanks from six sheets from the CR3 ingot are shown in Table 9. These sheets consist of the two from each end and the two from the center of the extrusion. The remaining eight sheets are now being blanked. The blanks rejected for ultrasonic indications constitute $16 \%$ of the blanks inspected. Although dyepenetrant and visual inspections remain to be performed, it is anticipated that the yield from these blanks will be very close to the $85 \%$ goal. The significant increase in yield over other recently produced material is believed to be the result of improvements in the arc-melting 


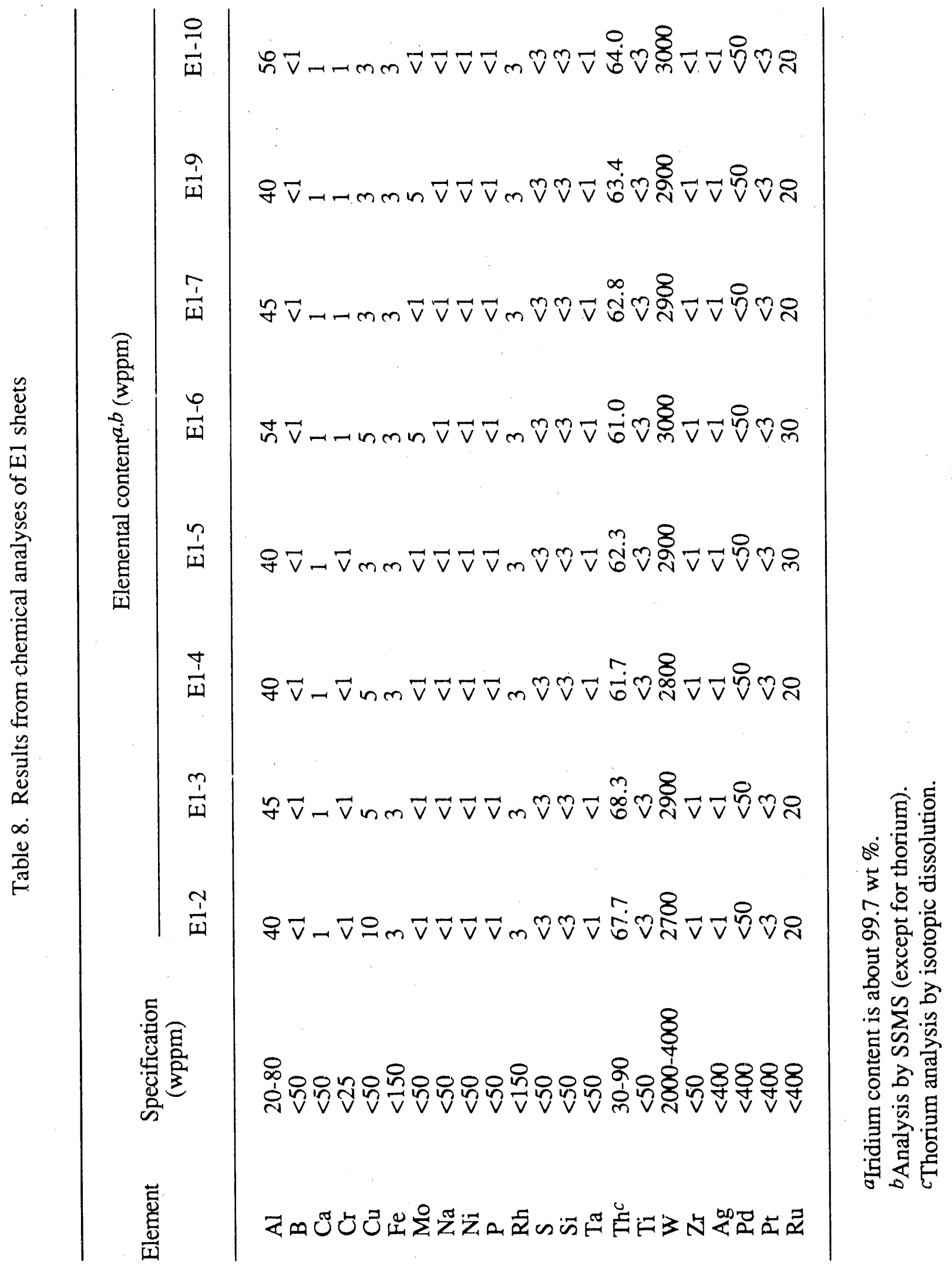


Table 9. Results from ultrasonic inspection of CR3 blanks

(6 of 14 sheets only)

\begin{tabular}{|c|c|c|c|}
\hline \multirow{2}{*}{ Sheet } & \multicolumn{2}{|c|}{ No. of blanks } & \multirow{2}{*}{$\begin{array}{c}\text { Identity of } \\
\text { blanks } \\
\text { passing inspectior }\end{array}$} \\
\hline & Produced & Passing inspection & \\
\hline CR3-1 & 3 & 2 & 2,3 \\
\hline CR3-2 & 4 & 4 & $1,2,3,4$ \\
\hline CR3-7 & 6 & 6 & $1,2,3,4,5,6$ \\
\hline CR3-8 & 6 & 6 & $1,2,3,4,5,6$ \\
\hline CR3-13 & 6 & 3 & $3,4,6$ \\
\hline CR3-14 & 6 & 5 & $2,3,4,5,6$ \\
\hline Total & 31 & 26 & \\
\hline
\end{tabular}

practice, including the use of the 63-mm-diam ingot and the improvement in the extrusion process including increased preheat temperature.

Analysis of the location of ultrasonic indications shows one in the first blank from the nose of the extrusion, a region of elongated indications in the first and second blanks from sheet No. 13, and a few small indications extending from the last blank of sheet No. 13 to the first blank of sheet No. 14. In contrast, the results of the ultrasonic inspection of the ground ingot showed numerous subsurface reflections from regions that ultimately produced sound blanks. Thus, the continuation of ultrasonic inspection of ingots does not appear to be warranted.

\subsection{TENSILE-IMPACT TESTING OF D1 SHEETS}

The results of tensile-impact testing of specimens obtained frorn blanks processed from the D1 extrusion are shown in Table 10. The impact ductilities of the four specimens 
Table 10. Tensile impact test results of samples cast from D1 blanks

\begin{tabular}{lc}
\hline Sample & $\begin{array}{c}\text { Tensile elongation } \\
(\%)\end{array}$ \\
\hline D1-1-4 & 21.6 \\
D $1-1-6$ & 14.3 \\
D1-7-7 & 14.7 \\
D1-8-4 & 20.7 \\
\hline
\end{tabular}

annealed at $1500^{\circ} \mathrm{C}$ for $19 \mathrm{~h}$ and tested at $980^{\circ} \mathrm{C}$ at a projectile velocity of $60 \mathrm{~m} / \mathrm{s}$ all exceeded the $13.5 \%$ requirement for powder-batch qualification. The D-batch material, consisting of $20 \mathrm{~kg}$ of powder, has been qualified for production.

\subsection{TENSILE-IMPACT TESTING OF E1 SHEETS}

Tensile-impact tests were performed using specimens taken from E1-3, E1-6, and E1-10 sheets. The specimens were heated at $1500^{\circ} \mathrm{C}$ for $19 \mathrm{~h}$ before testing and impacted at $61 \mathrm{~m} / \mathrm{s}$ at $980^{\circ} \mathrm{C}$. The results are shown in Table 11 . The results met the minimum requirement of $13.5 \%$ elongation. The E-batch powder, consisting of $90 \mathrm{~kg}$, is qualified for production.

Table 11. Results from tensile impact tests of E1-sheet specimens

\begin{tabular}{lc}
\hline Sample & Elongation (\%) \\
\hline E1-3-1A & 23.3 \\
E1-6-6A & 15.7 \\
E1-10-3A & 16.8 \\
\hline
\end{tabular}




\section{CONCLUSIONS}

The following conclusions can be drawn from the experience in processing of iridium-alloy sheet products.

1. The increase in ingot diameter from 51 to $63 \mathrm{~mm}$ has all but eliminated the problem of arc strikes to the mold wall and greatly improved the ingot surface condition.

2. Preliminary results of blank inspections for the CR3 ingot, showing $84 \%$ acceptance at ultrasonic inspection, indicate that the increase in ingot diameter has resulted in improved ingot internal quality.

3. Ultrasonic inspection of consumable-electrode arc-melted ingots for internal flaws has proven unsuccessful. This is most likely because of interference by the coarse cast grain boundaries.

4. Ultrasonic inspection of the CR3 ingot for subsurface flaws showed no correlation with the subsequent results from ultrasonic inspection of blanks. The continued ultrasonic inspection of ingots does not appear to be warranted.

5. Incomplete extrusions are likely to produce internal cracks in both the extruded and unextruded portions of the ingot. In the event of a partial extrusion, the material should generally be treated as recycle and remelted.

6. The improvements in the extrusion practice, including increase in preheat temperature from 1325 to $1425^{\circ} \mathrm{C}$ and use of glass lubrication, has improved the reliability of the process.

7. Heating of molybdenum in contact with the DOP-26 iridium alloy at temperatures of 1200 to $1475^{\circ} \mathrm{C}$ produces intermetallic layers of 5 to $: 5 \mu \mathrm{m}$ total thickness in $4 \mathrm{~h}$. The intermetallics, IrMo and $\operatorname{Ir}_{3}$ Mo, are present on extruded iridium alloy bars following chemical removal of the molybdenum can by acid cleaning. There is no penetration of molybdenum along the iridium alloy grain boundaries. 
8. The intermetallic layers can be removed by electrolytic cleaning of extruded sections in a saturated KCN solution. Electrolytic cleaning of extrusions has been implemented. Intermetallic layers would also be removed during grinding of blanks and electrolytic cleaning of foil.

9. The improved extrusion and cleaning procedures have been implemented using approved Special Instructions Deviation requests. The permanent changes will be incorporated into procedures early in FY 1990.

\section{ACKNOWLEDGMENTS}

The author thanks W. J. Barnett (Department of Energy, Office of Special Applications), R. L. Heestand, V. K. Sikka, and M. M. Martin for useful discussions of this work; K. V. Cook and R. A. Cunningham, Jr. for performing the nondestructive testing; G. E. Angel, C. E. Dunn, K. S. Blakely, C. R. Howell, and J. D. Vought for performing the fabrication work; G. C. Marsh for performing the metallography; and M. L. Atchley and G. R. Carter for preparing the manuscript.

\section{REFERENCES}

1. C. T. Liu, H. Inouye, and A. C. Schaffhauser, Metallurgical and Mechanical Properties of Thorium-Doped Ir-0.3\% W Alloys, ORNL-5616 (1980).

2. R. L. Heestand, G. L. Copeland, and M. M. Martin, A Consumable Arc-Melting, Extruding, and Rolling Process for Iridium Sheet, ORNL-6270 (1986).

3. R. L. Heestand, E. K. Ohriner, and T. K. Roche, Advances in Iridium Alloy Processing in 1987, ORNL/TM-10852 (1988).

4. E. K. Ohriner and R. L. Heestand, Advances in Iridium Alloy Processing in 1988, ORNL/TM-11392 (1989). 

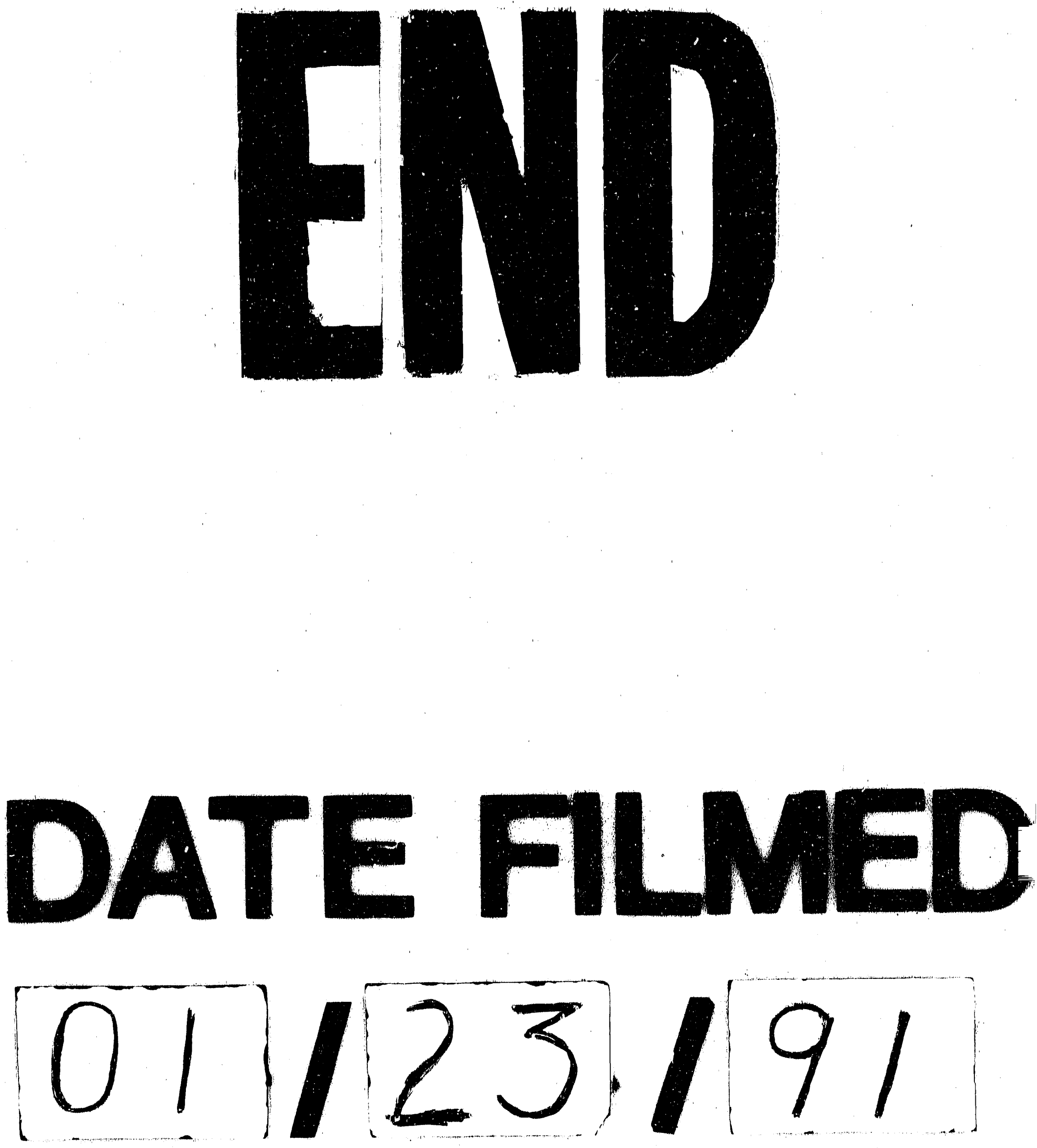